\title{
A guide to good practice in Mediterranean surface survey projects
}

\author{
Peter Attema, ${ }^{1}$ John Bintliff, ${ }^{2}$ Martijn van Leusen, ${ }^{1}$ Philip Bes, ${ }^{3}$ \\ Tymon de Haas, ${ }^{2}$ Damjan Donev ${ }^{2}$ Wim Jongman, ${ }^{1}$ Eva Kaptijn, ${ }^{4}$ \\ Victorino Mayoral, ${ }^{5}$ Simonetta Menchelli, ${ }^{6}$ Marinella Pasquinucci, ${ }^{6}$ \\ Steve Rosen, ${ }^{7}$ Jesus García Sánchez, ${ }^{5}$ Luis Gutierrez Soler, ${ }^{8}$ \\ David Stone, ${ }^{9}$ Gijs Tol, ${ }^{10}$ Frank Vermeulen, ${ }^{11}$ Athanasios Vionis ${ }^{12}$
}

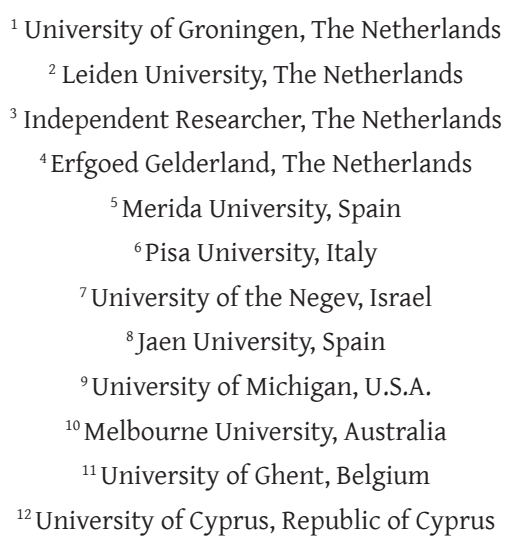

Available author ORCIDs: Attema 0000-0003-1360-5757, Van Leusen 0000-0002-4778-9534, De Haas 0000-0002-3138-7012, Menchelli 0000-0002-4167-4648, Tol 0000-0003-0743-5173, Vermeulen 0000-0001-7963-0336, Vionis 0000-0002-1658-4034.

Author contribution: the idea for this article emerged from extensive discussions at the twiceyearly International Mediterranean Survey Workshops. Bintliff and Attema took the lead in collecting the literature and drafting the text, using input from all other authors. Attema and Van Leusen drafted the recommendations. ${ }^{1}$

\section{Introduction}

This article deals with a relatively new form of archaeological research in the Mediterranean region - intensive surface survey, coverage of the landscape by teams walking in close order, recording patterns of human activity visible on the landsurface as scatters of pottery and lithics, or building remains. Since 2000, archaeologists from Dutch and Belgian universities working on Mediterranean survey projects have gathered annually to discuss methodological issues in workshops that gradually attracted landscape archaeologists from other European countries and Turkey. On the basis of these discussions, this paper, written by regular workshop contributors and other invited authors with wider Mediterranean experience, aims to evaluate the potential of various approaches to the archaeological surface record in the Mediterranean and provide guidelines for standards of good practice in Mediterranean survey.

This article begins by justifying the need for recommended best practices, then moves to address the issues we find most critical: sampling; approaches to sites at multiple scales; the integration of survey with ancillary methods; and laboratory analyses, before turning to our concluding remarks.

${ }^{1}$ Drafts of this paper received invaluable comments from Edward Banning, Nicola Terrenato and Rob Witcher. Remco Bronkhorst provided invaluable help with the editing process. 
We have summarised our main recommendations from this detailed article under 17 headings in section 6.

At the outset, we want to make clear that our definition of what constitutes Mediterranean survey refers to practices in the circum-Mediterranean countries, broadly speaking. We recognise that there are many variations in the techniques used here, and also different intensities with which survey is practised, with much greater emphasis on survey archaeology in Italy, Greece, and Turkey, and less in Albania, Algeria, Morocco, and Croatia, for example. We do not discuss the evolution of field survey, nor take a country-by-country approach; rather, we focus on examples that we feel illustrate or illuminate good practices; though we are certain that we have omitted many salient examples, it is not our intention to catalogue all of these.

Although we have limited our discussion by including just a few non-Mediterranean references, it appears to us likely that these good practices could be usefully applied in other parts of the world, with appropriate adaptations to local environmental and cultural differences. ${ }^{2}$

Let us first remind ourselves why we do intensive fieldwalking surveys at all: we want to know more, and in better spatial, functional and chronological detail, about the archaeological record for a given region than is obtainable through excavation or traditional topographical and extensive survey. Surveys provide information at spatial and temporal scales that excavation cannot: on settlement patterns and hierarchies, off-site intensity of land use, and the longue durée of regional developments. Survey is very cost-effective at this, we can reconstruct regional settlement patterns by expending only a fraction of the resources necessary with other archaeological methods. And finally, surveys record a fast-disappearing resource, and are thus vital for heritage management. Most of the archaeological record will only ever be recorded in a survey (if that). Current policy in Europe and increasingly elsewhere in the Mediterranean lands, is to focus excavation on sites under threat of immediate destruction or of outstanding historical importance. Other archaeological sites are either protected monuments, unavailable for invasive research, or are left to erosion and removal: the fate of most rural sites in Mediterranean countries owing to their immense numbers and slight surface manifestation.

Defining good practice is needed because:

- It serves comparability between survey projects concerning issues of scale and representativeness. ${ }^{3}$ Economic, demographic, social developments and Braudelian ${ }^{4}$ long-term trends cannot be studied unless survey data are collected and made available in a comparable manner. It is currently impossible to meaningfully compare results from different survey projects and different regions, in all but a very few cases.

- $\quad$ Sharing survey data through open access publications requires that in-field collection and finds' processing methods, and file metadata have been sufficiently documented to common standards, which currently do not exist. The MAGIS (Mediterranean Archaeology GIS) online inventory of regional survey projects in the greater Mediterranean from 2002 aimed to share computerised data. The objective was to study regional or Mediterranean-wide patterns and draw historical conclusions beyond the uploaded study areas. Lately, Fasti Online has gathered this obsolete database and offers a viewer for Mediterranean survey projects. ${ }^{5}$

\footnotetext{
${ }^{2}$ For an earlier introduction to field survey see Banning 2002; for Europe see Bintliff et al. 2000; for the Mediterranean the Populus project conference volumes, general editors Barker and Mattingly 1999-2000.

3 Bintliff 1997; Alcock and Cherry 2004; Attema, Burgers et al. 2010.

${ }^{4}$ Braudel 1972.

5 www.fastionline.org/survey/
} 
- $\quad$ Survey data by themselves make little sense if their landscape context is missing; it is therefore good practice to document relevant geoarchaeological information and post-depositional processes as well.

- Surveys are the main supplier of archaeological data to regional heritage managers, to answer questions such as: What is the current quality of the remains? How rare are they? What are the threats? These must be addressed explicitly in reports, and therefore need to conform to high-quality standards of collecting and documenting.

\section{Lessons from current practice in sampling landscapes and artefact-based survey}

How easy life would be for the survey archaeologist if only we could cover $100 \%$ of the landscape, and detect $100 \%$ of the archaeological material present at the surface! But of course it is not, so much of our time and energy goes into the design of surveys that attempt to achieve lesser goals: detecting all visible sites above a certain minimum diameter, collecting diagnostic artefacts of all periods present, detecting off-site 'carpets'... it is not our goal here to investigate the choices researchers make, and have made in the past; rather we look at how these choices are implemented and at their consequences in terms of the analytical potential of the collected finds and observations. With limited resources how do we weigh the spatial extent of the survey against its intensity? How do we use sampling methods to answer our questions in the most efficient way possible? How do we then deal with the practical obstacles preventing us from carrying out our research design obstacles to accessing, and then to investigating the earth's surface, imposed by land use and land cover? How do we deal with 'marginal' parts of the landscape, where we expect very low densities of archaeological material, and how do we avoid being overwhelmed by the large and/or highdensity sites, especially from the classical periods, that abound in the Mediterranean landscape? These questions are explored below.

\subsection{Scale and Intensity of Regional Survey}

Let us begin with the spatial scale or extent of surveys. A survey covering $2000 \mathrm{~km}^{2}$ in a few years could not possibly yield a representative image of the complexity of Mediterranean settlement and land use patterns. ${ }^{6}$ Clearly, therefore, the landscape has to be investigated with a minimum amount of intensity, or effort per surface area. John Cherry long ago showed the necessity of intensive survey as opposed to extensive survey, using survey results to show that the more intensive the survey, the more sites were recovered, and the more diverse the range of sites. ${ }^{7}$ This observation has been repeatedly corroborated. ${ }^{8}$ Mediterranean survey archaeologists do carry out large regional projects, but these require considerable time investment: the South Etruria Survey ${ }^{9}$ is now 60 years old; the Boeotia Project ${ }^{10}$ over 40; the Metapontino survey ${ }^{11}$ started in 1981 while the Regional Pathways to Complexity Project ${ }^{12}$ accumulated data over some 30 years in Italy, building on three regional projects. Good projects can be reborn and rechecked: the South Etruria Survey of the 1950s-1970s has stimulated the Tiber Valley and related projects from the 1990s to present, as improved pottery typochronologies from excavations enable more subtle analyses of the original survey ceramics. ${ }^{13}$ Similarly, the seminal 1930s Oriental Institute Amuq Valley Survey in southeast Turkey was continued by Wilkinson and Yener in the 1990s. ${ }^{14}$ Likewise, a map sheet of the Forma Italiae national survey project in Italy has recently been restudied for a better understanding of

\footnotetext{
6 Contra Blanton 2001.

7 Cherry 1983.

8 Van Leusen 2002: chap. 4.

9 Potter 1979; Patterson 2004; Patterson et al. 2020.

10 Cf. Bintliff et al. 2007.

11 Carter and Prieto 2011.

12 Cf. Attema, Burgers et al. 2010.

13 Patterson 2004: Patterson et al. 2020.

14 Braidwood 1937; Yener et al. 2000; Casana and Wilkinson 2005.
} 
Republican settlement around the colony of Venusia (Basilicata, Italy) by the Landscapes of Early Roman Colonization project. ${ }^{15}$

We consider the careful study of the longue durée of integral landscapes as the only way to achieve meaningful time-depth. Here the concept of Siedlungskammer is fundamental, the search for the spatial migration of settlements around small landscapes. ${ }^{16}$ It seems to us to be unethical to plan a survey which intentionally neglects certain periods present in the surface evidence. The recent Antikythera survey for example did not study sites of the historic periods: ${ }^{17}$ who will come back to resurvey the same areas in order to take the missing periods seriously? Moreover, comparison of settlement and activity in the same region over diverse periods gives an essential understanding of the variety or similarity of human responses to a specific landscape.

In Mediterranean survey practice regional landscape projects typically comprise (parts of) river valleys ${ }^{18}$ or (parts of) coastal plains ${ }^{19}$ both of these often including hills and uplands in their hinterland. Less common are surveys of really mountainous areas, although these increasingly receive attention. ${ }^{20}$ Surveys in the arid zones of the Mediterranean, the Levant and North Africa, ${ }^{21}$ offer an important complement to those within the more temperate Mediterranean zone proper. For site scale, research ranges from small rural sites to large, complex sites, with the latter being pioneered by Perkins and Walker at Etruscan Doganella, ${ }^{22}$ and by Bintliff and Snodgrass in Greece. ${ }^{23}$ First in line are complex Classical to Roman urban sites, but in section 2.6 we will also introduce complex protohistoric or proto-urban settlements. ${ }^{24}$

Reviewing the goals set by rural and urban surveys shows that there are no essential differences: it is only the relative differences in density and complexity that lead researchers to make adaptations to otherwise comparable methods. For example, both are gridded although the size of the grids will differ; both attempt full-coverage of a contiguous area in order to detect spatial patterns; both grapple with sampling issues to minimise the effort needed to obtain the desired information. The definition and characterisation of 'sites' (and therefore of site haloes, non-sites and off-site scatters as well) plays a central role in modern surveys, and in both the smallest and largest artefact clusters.

As it is impossible to document regional landscapes in their entirety using intensive survey methods, researchers have experimented with sampling. ${ }^{25}$ Even where fieldwalkers are at a desirable $5 \mathrm{~m}$ to $20 \mathrm{~m}$ apart, while effective high-resolution visibility is $1 \mathrm{~m}$ to $2 \mathrm{~m}$ width, we only physically see $5 \%$ to $40 \%$ of the landsurface. ${ }^{26}$ These small walker intervals have been adopted to suit the kinds of surface traces surveyors have learnt to encounter in everyday practice. In actuality, almost all surveys have also selected parts of their target landscape for surveying, such as blocks, strips, or merely windows of high surface visibility.

However, different landscapes have varying degrees of opacity with respect to features and artefact scatters; unsurprisingly desert landscapes, with little vegetation and little land disturbance offer a greater level of visibility. Furthermore, extending our perspective into the deeper past, microliths

\footnotetext{
15 Marchi and Sabbatini 1996; Stek et al. 2016.

16 Lehmann 1939 is a pioneer example from Crete illustrating this approach; for another application see Bintliff 1996.

17 Bevan and Connelly 2013.

18 Barker 1995; Vermeulen et al. 2017.

19 Attema, Burgers et al. 2010.

20 Efstratiou et al. 2006; Van Leusen et al. 2010, 2011, forthcoming; Vandam 2019 and Vandam et al. 2019; Attema et al. 2019 and 2020.

21 E.g Barker et al. 1996; Rosen 2017.

22 Perkins and Walker 1990.

23 Bintliff and Snodgrass 1988 b.

24 Attema 1993; Attema and De Haas 2012.

25 Orton 2000.

${ }^{26}$ For a full discussion of the effectiveness of survey tract cover see Banning et al. 2006, 2011, 2017.
} 
are less evident than flake industries as a function of size of artefact. Time of day also affects visibility; the oblique light of early morning or late afternoon renders glossy lithics more visible. ${ }^{27}$

Below we discuss sampling under the subsequent headings of methodological concerns regarding landscape sampling; marginal landscapes; and hidden landscapes. We conclude with guidelines to good practice in the sampling of landscapes.

\subsubsection{Methodological concerns}

Early experiments with landscape sampling (e.g. the Melos Survey ${ }^{28}$ ) have revealed that extrapolation can be dangerous; ${ }^{29}$ in a regional survey the study of small patches of a landscape is only useful as a follow-up to fuller survey, to test patterns elsewhere. Yet minority sampling continues without discussion of the risks. ${ }^{30}$ Although here the intentions were survey on a limited timescale, hence focussed on a series of thin strips and well-cultivated field blocks from varied landscape types, respectively, the limited and patchy cover raises unresolved issues of recovering original settlement patterns adequately, even where walker-intervals are acceptably close within the blocks surveyed. A distribution of regularly-spaced sites can be reconstructed from such a procedure, although the modern distribution of intensive farming acts as a bias; but certainly irregular site patterns elude such surveys completely. How then can we deal with this problem? should we turn to gridding the entire surface of regional landscapes or can we opt for different methods using modern recording systems?

Whole regions cannot feasibly be covered totally. Even the Archaeological Survey of Israel, where the entire state is divided into survey blocks of $10 \mathrm{~km}$ by $10 \mathrm{~km}$, each assigned to a particular researcher, does not operate on $100 \%$ close-order fieldwalking. ${ }^{31}$ Therefore the sampled areas to be intensively walked should be chosen because of their representative value for their different geomorphological contexts and/or historical aspects.

Definitive answers to such questions are not easy. A recent intensive survey project in the Xeros Valley of Cyprus proved that sampling landscapes may lead to missing sites of transitional eras whose material culture is not easily recognised. The Xeros Valley, some 2500 ha in size, is being surveyed by a combination of methods, i.e. sampling landscapes (strips of $150 \mathrm{~m}$ wide at $150 \mathrm{~m}$ intervals) and field-by-field intensive survey (Figure 1). The sampling landscapes' methodology alone, would have missed one of the few sites dated to the island's 'gap period' (9thto 11thcenturies AD) of some 0.7 ha. To further place a priority on survey intensity, such sites are also represented by a thin carpet of handmade low-fired pottery, which is usually ignored by fieldwalkers or mistakenly dated as prehistoric (see infra). ${ }^{32}$

Another methodological concern of sampling landscapes is the uneven visibility between landscape units within a survey landscape. In the next section, we will first focus on the visibility of archaeological remains in areas presently and/or formerly marginal for habitation and land use and ways to mitigate this in fieldwork strategies. In section 2.1.3 we will discuss the concept of "hidden landscapes" as used in recent survey literature to indicate either settlement phases only ephemerally present in landscapes dominated by classical remains, or settlement phases physically buried by sedimentation.

\footnotetext{
27 Schon 2002.

28 Renfrew and Wagstaff 1982.

29 Discussed by Flannery 1976; Cherry et al. 1978.

30 E.g. the Sydney Cyprus survey: Given and Knapp 2003; and the Simeto Valley project, with less than $1 \%$ coverage: Leone et al. 2007

31 www.antiquities.org.il/survey/new/default_en.aspx

32 Papantoniou and Vionis 2017; Vionis 2017a.
} 


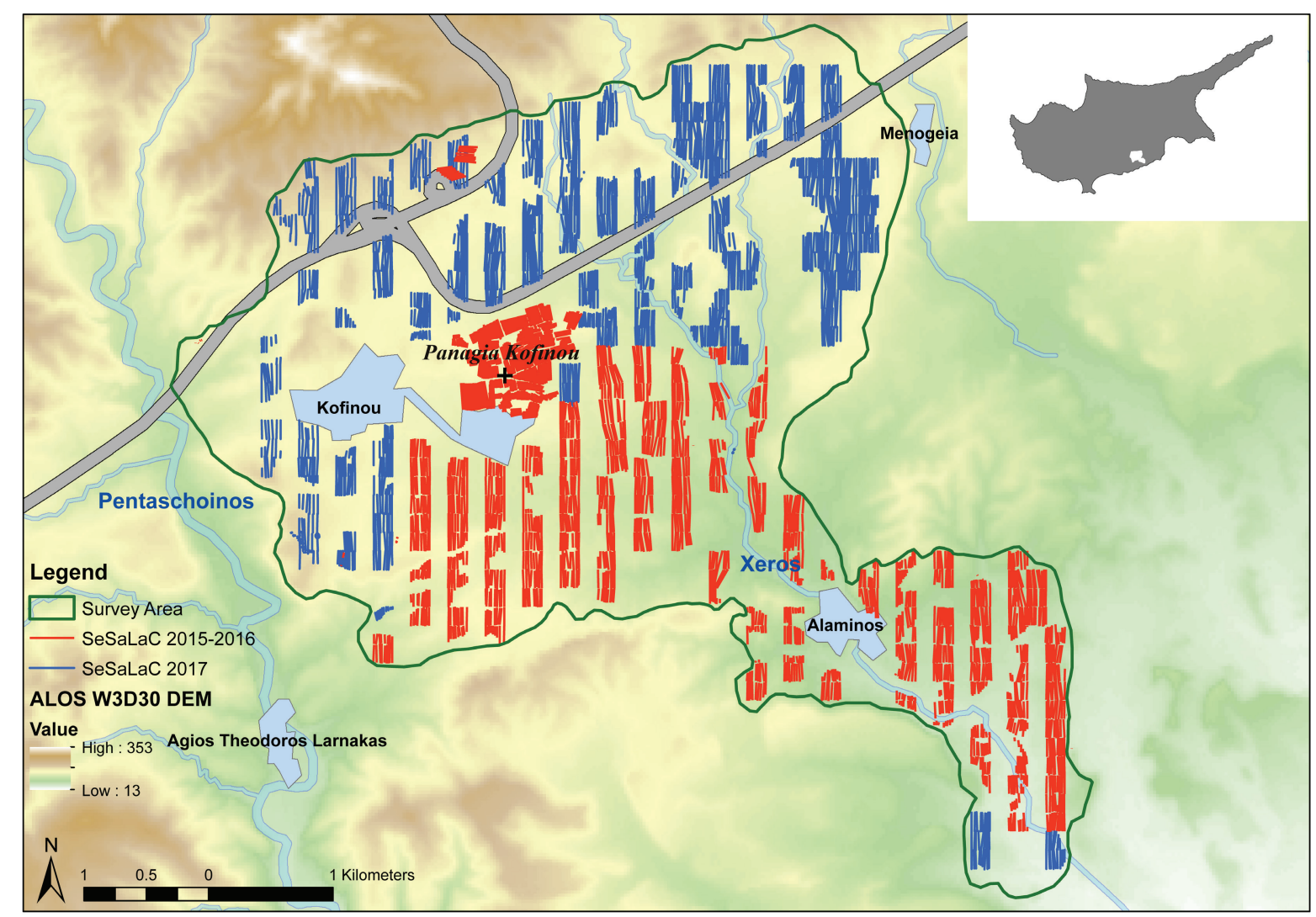

Figure 1. Surveyed transects in the Xeros Valley (2015-2016 and 2017). Digital data courtesy of the Geological Survey Department, Republic of Cyprus. GIS mapping by H. Paraskeva (Settled and Sacred Landscapes of Cyprus Archaeological Project).

\subsubsection{Marginal landscapes}

Presently marginal areas preferentially preserve standing monuments otherwise damaged or destroyed in core farming and settled districts: barrows, fortification structures and field boundaries. In the outer countryside of Attica, the province of Athens, a district neglected by land use and settlement since the Late Classical era preserved an entire system of farms, checkdams, estate boundary walls and tomb platforms from this period as standing stone remains. ${ }^{33}$ In southwestern Turkey the exhaustive study of the city and territory of the minor ancient town of Kyaneai likewise recorded standing urban and rural house-walls and burial monuments in a rocky landscape with current populations far below those of Antiquity. ${ }^{34}$ However, agricultural marginality in both cases meant that artefact quantities on the surface were disappointingly low, preventing the complex spatial analysis desirable for a detailed cultural biography of the sites studied.

Nonetheless, uncultivated landscapes may only appear unsurveyable. The ancient city of Koroneia for example, owing to the recent trend for upland Mediterranean landscapes to revert to scrub and woodland, is not being widely cultivated and even in summer is covered with high grass. Nonetheless training the students to be hyperattentive to the surface, and using careful slow study, enabled total area survey of $c .60$ ha in six summer seasons, with adequate densities of ceramics recovered from the majority of the city hill's surface..$^{35}$ Close attention to disturbances such as burrow spoils, and test-pitting (often disallowed by national heritage bodies in Mediterranean lands however),

\footnotetext{
33 Lohmann 1993.

${ }^{34}$ Kolb 2008.

35 Bintliff et al. 2009.
} 
can additionally mitigate such issues. ${ }^{36}$ Some point sampling approaches, pioneered by the Riu Mannu Survey, ${ }^{37}$ also clean the surface as one solution to investigate low-visibility areas.

Survey outside current farming zones has long posed methodological problems. Dense natural vegetation, rock scree, erosion and deposition are typical aspects of mountain landscapes, whilst uplands are commonly used for pastoralism, hence covered in rough grazing scrub or grassland. Past surveys in the Mediterranean either avoided such areas, focussed on patches of farmland amidst them (e.g. the Aetolia Project ${ }^{38}$ ), or targeted visible monuments such as stone-walled prehistoric and historic forts and tumuli. However recently, specific projects have explored the potential of such areas, deploying surveys adapted to these problems and with more limited aims. ${ }^{39}$ An Apennine valley north of Genoa (Valpolcevera) provided particular experience in researching mountain districts with poor visibility. ${ }^{40}$ Here archaeological evidence is scanty due to the nature of ancient settlement (perishable mountain dwellings) and archaeological visibility (urbanisation, vegetation cover, steep slopes, erosion). Pre-Roman and Roman small sites and a few boundary stones were identified by survey and excavations. Collected data and the study of a $117 \mathrm{BC}$ inscription (sententia Minuciorum, CIL V 7749) provide a clear picture of the private and public land exploited by a Ligurian tribe: the former, with the best agricultural soils, being in the valley heart, the latter at the periphery, higher above sea level, more suitable for grazing and wood exploitation. In a second Italian example, scattered finds in the inner mountainous district in the Tenna and Aso upper valleys (which were not intensively settled), studied by the South Picenum Survey, represent seasonal activities (hunting, gathering, animal-breeding, wood and wicker harvesting) utilising ephemeral huts and basic tools and equipment (e.g. pens for transhumant sheep and cattle). ${ }^{41}$ Ethno-archaeological studies have also used survey and excavation to characterise the kinds of material traces that pastoralists leave in the landscape..$^{42} \mathrm{~A}$ final example, again from Italy, is the survey of forested Samnite hillforts in Central Italy (Molise). LiDAR mapping and an adaptable survey methodology based on point sampling within $50 \mathrm{~m}$-side blocks and navigation using handheld GPS, have effectively documented previously ignored areas, hitherto limited to surviving polygonal masonry fortifications. ${ }^{43}$

Another problematic environment targeted for survey adaptations is reclaimed coast and marshland. Intensive survey in the former marsh-lagoonal environment of the Pontine region revealed a complex settlement history, only comprehensible in the context of its wetland ecology and ways to manage this. ${ }^{44}$ While surface surveys detected small Roman Republican pottery scatters pointing to reclamation of the marsh, ${ }^{45}$ geoarchaeological approaches were essential to investigate the buried pre- and protohistoric evidence for the use of this landscape. ${ }^{46}$ Another problematic environment are sand dunes. Return visits 10-20 years after initial surveys indicate that the dune heads shift, covering previously known sites, and reveal previously invisible sites. ${ }^{47}$ Surface artefact survey has even proven useful in steppe grasslands around the Black Sea where GPS recording of individual sherds and surface stones, followed by the application of large-scale geophysical research, revealed a densely settled indigenous landscape. ${ }^{48}$

\footnotetext{
36 E.g. Düring and Glatz 2016; Sapir and Faust 2016.

37 Van de Velde 2001.

38 Bommeljé 2009.

39 Van Leusen et al. 2011; Mocci et al. 2005; https://icac.academia.edu/JPalet.

40 Pasquinucci 2004; Pasquinucci and Launaro 2009; cf. Crawford 2016.

${ }_{41}$ Menchelli 2016.

${ }_{42}$ Chang 1993; Rosen 1993a; Palmer et al. 2007; Galaty et al. 2013.

43 García Sánchez and Termeer forthcoming.

44 Walsh et al. 2014.

45 Tol et al. 2014.

${ }^{46}$ Feiken et al. 2012; Feiken 2014; Van Gorp et al. 2020.

47 Bar-Yosef and Goren 1980; Ammerman et al. 2013.

48 Guldager Bilde et al. 2012; Attema 2018.
} 
Based to a great extent on ethnographic surveys undertaken in Greece, Chang and Koster also noted anthropogenic features - trails, wells, enclosures - which may not have associated artefacts allowing reasonable dating. ${ }^{49}$ These may be datable by reference to larger contexts. Advances in remote sensing followed by 'groundtruthing', checking the details within the landscape itself, have introduced major advances for the history of pastoralism. ${ }^{50}$

\subsubsection{Hidden Landscapes}

The concept of a 'hidden landscape' arose however in a different kind of problematic context than discussed above, one in which finds of particular periods were proving hard or even impossible to recognise during intensive fieldwalking. ${ }^{51}$ In survey we may indeed deal with archaeological phases that are only thinly present on the surface and that can be detected only by hyperintensive survey. As we will argue below, such periods will be even harder to detect when 'hidden' in denser artefact distributions of artefact rich periods. Ancient landscapes may also be completely hidden from the eye by being buried under sediment load, typically in river valleys and deltas, and at times far beyond the reach of the plough. Research of this kind of hidden landscape requires invasive research (manual or mechanical augering).

\section{Settlement phases only ephemerally present in surface scatters of dominant periods}

Hyperintensive survey has taught us that particular periods prove hard or even impossible to recognise even during intensive fieldwalking. The inspiration for interpreting such phenomena can be credited to pioneering studies by survey teams in the Czech Republic where excavation could clarify the underlying depositional source of the surface finds. ${ }^{52}$ With time, ceramics on the surface and in the ploughsoil degrade. Ceramics from a village abandoned in the 19th century AD will be larger and better preserved than those of the Bronze Age several thousand years older, not to mention those of the Neolithic up to 9000 years older. Technological advances have generally increased the quality of ceramics over time, low-fired handmade wares and coarsewares becoming more infrequent. Although large, long-occupied settlements of prehistoric or protohistoric times still provide rich pickings for sample collection, they are far below the density of a Greco-Roman city centre, where up to a third of a million potsherds per hectare can be reached. Especially at risk from relative survey 'invisibility' in such high-density artefact contexts are the majority of prehistoric hamlet or farm sites, or scatters representing temporary 'taskscape' activities across the landscape. Although the artefacts from such sites may be present in plough zones, their integrity is usually destroyed and they may often be identified as proper sites only with difficulty.

On smaller rural prehistoric sites-activity foci, we expect finds lower in density and poorer in condition than more easily spotted historic era potsherds. Notably when an historic farm overlies such sites, we often observe in the site catalogues that a Roman villa, or similar well-defined and well-represented surface site, has included in its finds a small number of earlier pieces that are rarely recognised as a vestigial preceding occupation. Even where prehistoric sites lie alone in the landscape, the aforementioned properties may cause survey difficulties. On the other hand, prehistoric periods with well-made ceramics in a landscape not littered with historic sites or offsite finds may respond well to modern survey: Minoan Bronze Age rural sites on the Greek island of Kythera for example. ${ }^{53}$ In contrast, in Central Greece the predominance of Classical, Medieval and Post-Medieval rural occupation foci, coupled with widespread ancient and later manuring carpets, make the search for prehistoric settlement seem like looking for a needle in a haystack. In this landscape it has been shown that a handful of artefacts, often discovered as an incidental find

\footnotetext{
49 Chang and Koster 1986.

50 Ansart et al. 2016.

${ }^{51}$ One of the first to raise awareness of this issue was ceramologist Jeremy Rutter in his 1983 paper; see Bintliff et al. 1999 ; for a debate on the concept see Barker et al. 2000.

52 Reviewed in Kuna 2000.

53 Bevan 2002.
} 
amidst large numbers of historic sherds, are likely to represent a subsurface deposit: a vestigial settlement site or a significant if temporary activity focus. ${ }^{54}$ A close parallel occurs in later prehistoric and protohistoric Italy where the handmade Final Bronze Age through Iron Age ware known as Impasto, a ceramic with poor survival and recognition qualities, has created a similar challenge to intensive survey. ${ }^{55}$

In contrast, campsites, essentially short term residential sites, may be well evident in deserts (Figure 2). ${ }^{56}$ In surveys in the Negev, tiny ceramic scatters -3 sherds in a $10 \mathrm{~m}^{2}$ area, perhaps with stones - might indeed register as a 'site'. ${ }^{57}$

The detection of lithics deserves special attention, since it is recognised that contemporary surveys are failing to identify the levels of stone artefacts expected from landscapes occupied since the Middle Pleistocene..$^{58}$ Exceptions from this critique are again surveys in the desert and semi-desert landscapes of North Africa and the Levant, where palaeolandscapes are often well-preserved, soil depth slight, and thus lithic scatters can easily appear in standard fieldwalking, whilst original site patterning can often be recorded through gridding. ${ }^{59}$ Sites may achieve densities of hundreds of lithics per $\mathrm{m}^{2}$, and can be exhaustively collected (and sieved) in quarter-meter grids in a few days (cf. the Petra survey, ${ }^{60}$ the Wadi Faynan survey, ${ }^{61}$ and the Libyan Valleys Survey ${ }^{62}$ ).

Since survey in the Mediterranean agropastoral zones is confronted by almost immeasurable quantities of broken pottery, training field teams to distinguish potsherds from soil and stones whilst walking at a steady pace, creates a visual filter discriminating against stones which are actually tools. Some lithics still stand out; obsidian or other kinds of stone clearly distinct from local rocks stand far more chance, but sherd-focus mostly misses these too. Neglect becomes apparent when one rare student has 'an eye' for lithics and locates them ten times more frequently than the rest (similarly with surface coins and Roman glass). ${ }^{63}$

Bringing a lithic specialist onto the team increases lithic recovery, but emphasises the disparity between general recording and the swathes seen by that specialist. Deploying this person during gridding is more effective, as they can cover the whole site with only an eye to their own artefact types. A more drastic strategy has been adopted by surveyors whose primary aim is indeed to find pre-Neolithic lithic sites in agropastoral landscapes. Runnels has impressively demonstrated the value of predictive-modelling in the Argolid (Greece) ${ }^{64}$ and with Strasser on Crete: ${ }^{65}$ microenvironments closely associated with hunter-gatherer activities are targeted for intensive survey. An unimagined density of sites and taskscape foci emerged.

Macrolithics, large items like bread grinders, olive and wine presses, are easier to record. As querns or millstones have wide chronological ranges, their plotting across a large site may be matched to ceramics to identify changes in the site extent over time ${ }^{66}$ while concentrations of industrial presses suggest artisanal quarters.

\footnotetext{
54 Bintliff et al. 1999.

55 Attema et al. 2000; De Neef et al. 2017.

56 E.g. Yekutieli 2007.

57 Rosen 1994.

58 Cf. Davis et al. 2003: 68 and note 58.

59 Bar-Yosef and Phillips 1977; Goring-Morris 1987; Rosen 2000.

60 Knodell et al. 2017.

61 Barker et al. 2007.

62 Barker et al. 1996: 83-109.

63 A situation for which anecdotal evidence and our personal experience can attest; however we are not aware of published studies.

64 Runnels et al. 2005; Runnels 2009.

65 Strasser et al. 2011.

66 Boswinkel 2015.
} 

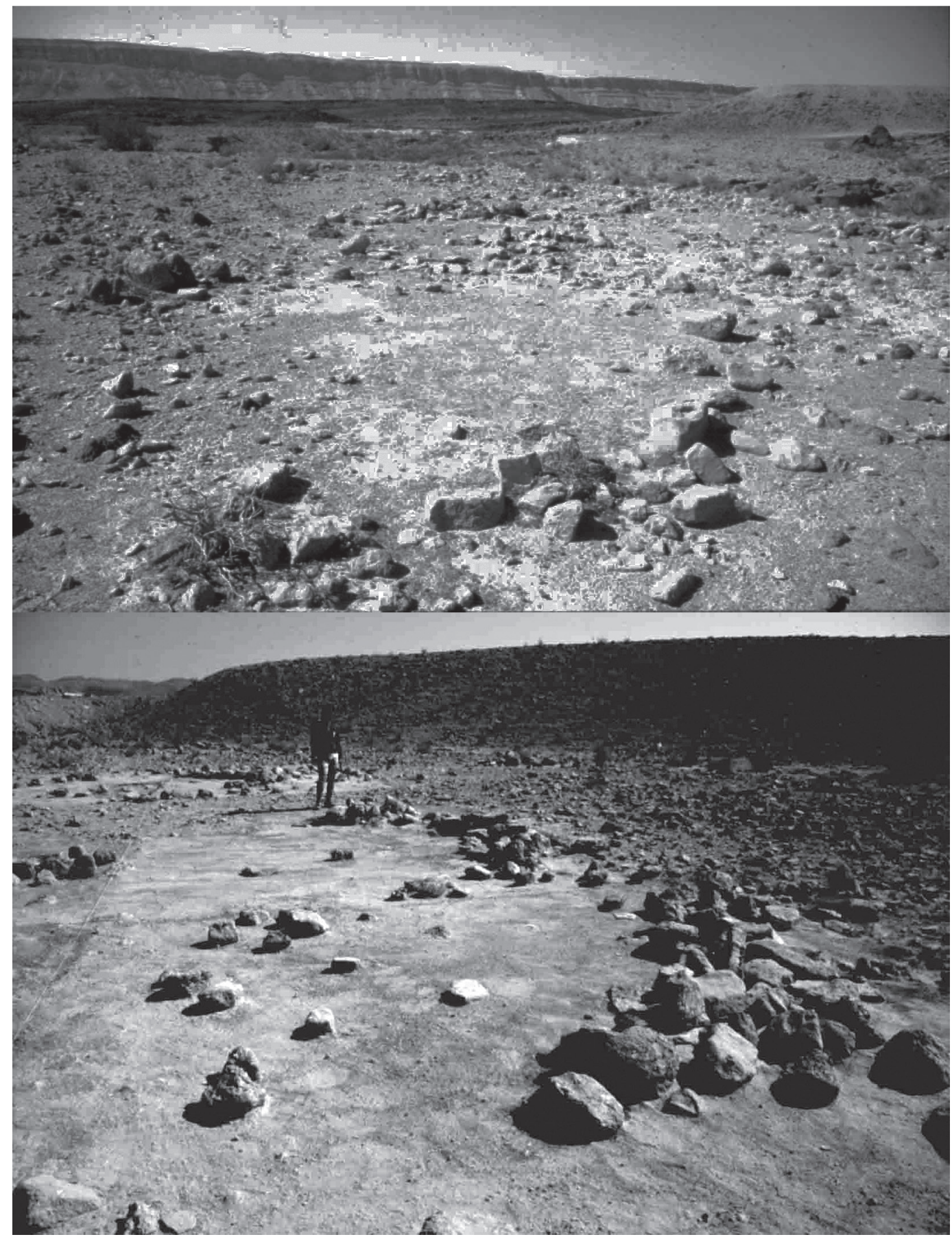

Figure 2. The site of Givot Reved, in the Central Negev, dating to Roman and recent times (Rosen 1993b). Upper: Recent (19th- to early 20th-century AD) tent remains associated with Bedouin encampment based on association with Gaza Ware, an 18th- to 20th-century ceramic type.

Lower: Roman period (2nd century AD) tent remains associated with Nabatean ceramics.

Note the 'excavation' consisted of surface scraping. The original landsurface is evident around the edges of the unscraped areas. The architecture was readily evident on the surface without scraping, which served primarily to facilitate collection (all sediments were sieved) and the clearer delineation of the architecture.

Hidden landscapes, however, also exist in historic eras, when the ceramic assemblage is poorly known or ceramics were in minimal use; both hinder recognising Early Medieval sites in many regions of the Mediterranean. ${ }^{67}$ In the low and middle valleys of the South Picenum project, settlement patterns are documented by abundant ceramics coming from Mediterranean trade,

${ }^{67}$ Francovich and Hodges 2003; Vionis et al. 2009. 
showing that rural sites were active to the late 6th century $\mathrm{AD}$, when the Lombards conquered the region. In contrast, in the upper mountain valleys, Late Roman ceramics are absent, but other sources reveal a landscape with some occupation even during the Lombard occupation: toponomy reveals Germanic alongside preceding Latin place-names, and churches dedicated to saints venerated by the Lombards became widespread. ${ }^{68}$ In Central Spain (Salamanca and La Rioja) during the Late Roman-Visigothic period (5th to 8th centuries AD), friable pottery and its absence in surface collections conceals the nature of rural settlement between the collapse of the Western Empire and the 9th to 10 th centuries AD.$^{69}$ In the most rural and remote regions of Greece, ceramics may have become largely replaced by organic utensils in post-medieval times. ${ }^{70}$

Sample size in surface collections represents a vital factor in the accurate representation of a period in a regional survey. Pettegrew has argued that the easier recognition of Late Roman versus Early to Middle Roman ceramics in the Mediterranean exaggerates finds of the former era, ${ }^{71}$ yet even for that ubiquitous assemblage, the size of collections might affect its apparent presence negatively. Thus the Petra Survey ${ }^{72}$ found only 13 Late Roman sherds, but the Petra papyri suggest the presence of extensively cultivated landscapes in the Late Roman period. The team counted 215,281 sherds for the entire survey region but collected 19,913 diagnostic sherds - only $9 \%$. For comparison, the Wadi Faynan survey collected $25 \%$ of sherds seen, documenting considerable Late Roman evidence. ${ }^{73}$

\section{Settlement phases buried by sedimentation}

Geoarchaeological research into sedimentation of river valleys and coastal plains in the Mediterranean has, ever since the seminal work by Vita-Finzi, alerted landscape archaeologists to the fact that entire occupation phases, even relatively recent ones, may now be buried (far) below plough depth. ${ }^{74}$ This bias in our knowledge of past settlement and land use operates at various spatio-temporal scales depending on the palaeogeographical development of the landscape. Whereas erosion takes place mainly in the upper reaches of watershed basins, deposition through alluviation mainly takes place in the lower reaches - both in the coastal plains and in smaller basins and valleys. In the case of the coastal plain of Sybaris, on the Ionian coast of South Italy, prehistoric to Roman landscapes for the most part lie buried below several meters of accumulated sediment, and in the adjacent Metapontino plain to the north, with fewer large streams to add sediment, the early Archaic farms that were preferentially located near the river courses are now deeply buried by alluvium, whereas the classical landscape that extended further from the rivers is still ploughed up. ${ }^{75}$ The combination of lateral extent from the rivers, and depth of burial, makes for subtle and locally varying biases in the recorded surface archaeology.

Similar conditions obtain in geomorphological basins, no matter where they are located and what their size. In the case of the subcoastal wetland of the Pontine plain in Central Italy, Bronze Age occupation is deeply buried but Roman archaeology appears in the plough zone, whereas ongoing sedimentation in the small karst basins on the pre-Apennine chain has obscured even remains of the Roman period. ${ }^{76}$ Such examples can be found all over the Mediterranean and make us aware of the important role of landscape bias in the evaluation of the archaeological surface record. No regional field survey project is therefore complete without an accompanying palaeogeographical reconstruction study and, for the erosive parts of the landscape, an assessment of the relevant

\footnotetext{
68 Menchelli 2016

${ }^{69}$ Ariño 2006.

70 Vroom 1998.

71 Pettegrew 2007, 2010.

72 Knodell et al. 2017.

73 Barker et al. 2007: 166.

74 Vita-Finzi 1969.

75 Attema, Burgers et al. 2010: 21-24; Attema 2016; Attema and Sevink in press.

76 Van Leusen 2010.
} 
slope processes.$^{77}$ In steeply sloping and geologically variable terrain, mass movements generated during the wet season can easily change the local topography and hydrology, such that little or no indication of the presence of settlements remains. ${ }^{78}$

\section{Crew training and apprenticeship}

Specific training of fieldwalkers to spot material of problem periods, especially if low-density, is needed, even though standard survey will still miss much of this landscape, requiring intensive walking of sub-areas to reveal the missed components. It has proved useful to revisit locations with rare occurrences of problem period finds, ideally bringing along specialists in such periods, to test whether isolated finds are just the fortunately-spotted part of a larger area of such finds - in effect applying Orton's cluster sampling approach. ${ }^{79}$ In fertile districts well-made historic pottery frequently attracts fieldwalkers' attention away from the far less visible sherds of other eras when ceramics were less well-made. The related issue of prehistoric, protohistoric and early historic lithic use is of importance here. Relatively diagnostic chipped stone tools were used at least until the end of the 2nd millennium BC in the entire Mediterranean region, but they often go unrecognised. Lithic production waste may be common, if not diagnostic, offering clues to human presence when ceramics are missing or scarce.

Typically a survey project is institutionally-funded and comprises staff, doctoral and postdoctoral team-leaders to direct the fieldwork, which is carried out with undergraduate walkers and finds' processors. So what about apprenticeship and the skills required for archaeological survey? How long does it take a student to develop an eye to pick out anomalies in the landscape, whether they be minor ceramic scatters, lithic concentrations (how many students have training in the recognition of artefactual lithics?) or stones/rocks which are out of place and represent human activities? $?^{80}$

The requirements of adequate training do not exclude contributions to landscape history by smallerscale projects. We adduce three examples of well-defined surveys carried out by a few or even a single prospector. One of the earliest Mediterranean surveys - and due to political circumstances still the only one completed and published in Algeria - was Leveau's remarkable one-man study of the surroundings of Iol Caesarea.$^{81}$ His conclusion that the immediate hinterland of the city was exploited from the urban centre by its residents, while the more distant hinterland was largely disconnected from the city, has continued to shape our understanding of the ancient economy. In the Vardar Valley Survey, in Macedonia, complete fieldwalking of a few village territories was achieved by a self-funded doctoral student with unpaid friends, supported by likewise unpaid finds' dating assistance by specialists. ${ }^{82}$ More remarkable is the one-person survey of the historic settlement patterns of the Greek island of Skyros by Karambinis. ${ }^{83}$ A series of small landscapes was selected in diverse natural regions of the island for intensive survey, followed by gridding of representative type-sites for the Late Roman to Early Modern eras. Control strips of off-site landscape were walked to provide data on local background values to allow a 'residual analysis' of finds onsite (see infra). The value of micro-surveys of a single village territory for insights into wider historical and prehistorical processes has been shown by the exemplary long-term study of the English parish of Shapwick, where members of the public were also widely-involved. ${ }^{84}$

\footnotetext{
77 Sevink et al. 2016

78 Van Leusen and De Neef 2018; Sevink et al. 2020.

79 See Orton 2000 and Section 2.4 infra.

80 Cf. Banning 2002.

81 Leveau 1984.

82 Donev 2015.

83 Karambinis 2015.

${ }^{84}$ Gerrard and Aston 2007.
} 


\subsubsection{Good practice in sampling landscapes}

The design of a sample follows from the goals that we set ourselves. If our intention is to measure parameters such as finds' density or site density per type and period, then theory tells us that we should stratify our sample to account for appreciable landscape variation, and to decide on the size of the sample (area to be surveyed) on the basis of the confidence level that we want to achieve. ${ }^{85}$ However, few if any survey projects have ever taken this approach. Instead, we design our surveys in 'blocks' or 'transects' so that we can retrieve the spatial, cultural, and chronological patterns in one or more landscape units within our study area. Experience has taught us that these survey blocks should have a minimum size of several square kilometres to ensure the possibility to discover a representative range of periods and site types for each particular landscape unit. Transects, too, should have a minimum width to ensure that sites of the target populations, if present, will be found. Within either blocks or transects, the temptation to survey only the currently accessible and cultivated fields must be resisted: rougher terrain or abandoned land where settlement and land use may previously have occurred, or where complementary pastoral, industrial, burial, military or hunting activities left their trace, must be included. Two projects offer excellent examples of this. The Sydney Cyprus project selected a region between the fertile lowlands and mountainous spine of Cyprus, to study the effects of farming, pastoralism and specifically mining on settlement history in diverse local landscape types. ${ }^{86}$ The Antikythera Survey surveyed an entire small island regardless of terrain variation and varied uses of the landscape in time and space..$^{87}$

Landscape-scale sampling designs should take into account the palaeogeographical development, and especially the post-depositional history, of the landscape. Parts of the landscape that, for some archaeological periods, are inaccessible due to excessive erosion or sedimentation must be excluded from the design unless that design includes alternative research approaches (see section 3); in such cases, absence of evidence cannot be interpreted as evidence of absence. For these reasons, a geoarchaeological study of the study area should always precede and guide the survey itself. A desktop assessment, based on available cartography, should suffice to segment the study area into landscape units that are internally homogeneous, but have distinct affordances for past settlement and land use, and distinct overall post-depositional histories, but for a more specific assessment of these aspects a physical geographer should be involved in the survey itself.

\subsection{Artefact distribution: sites, haloes and off-site sherd carpets}

The goals and methods of field survey have shifted over time. In a tradition going back to the 19thcentury travellers and topographers, surface sites till the 1970s were discovered through extensive navigation, usually around large areas of countryside. Sites where finds had previously been recorded, notably places mentioned in ancient sources, or where finds might be expected such as prominent defensible hilltops, or where local villagers suggested 'antiquities' were believed to lie, conditioned movement. Pendlebury ${ }^{88}$ walked the length of Crete more than once in the preWWII era, producing maps of Bronze Age findspots of unparalleled density for that age. Once such locations were reached, they were usually studied by mapping standing remains and the collection of some bags of artefacts, most commonly randomly gathered. Reference can be made here to large-scale topographical 'survey' programs such as the Forma Italiae series by Italian landscape archaeologists. ${ }^{89}$ Occasionally collections were based on larger subdivisions of sites, but only by the 1960s and early 1970s, under the quantitative influence of the New Archaeology, were regular experiments made with gridded sampling..$^{90}$ In this section we discuss the shift to artefact-based

\footnotetext{
85 Orton 2000.

86 Given and Knapp 2003.

87 Bevan and Connelly 2013.

88 Pendlebury 1939.

89 See Cambi and Terrenato 1994 on the development of Italian landscape archaeology.

90 Redman and Watson 1970.
} 
survey that led to the discovery of the settled and cultivated landscape beyond the obtrusive site. We start with a discussion of the relevance of artefact survey in contiguous blocks, to move on to the recognition of a phenomenon that in the literature are referred to as site haloes, i.e. the spread of sherds around site cores, as well as off-site sherd 'carpets' relating to land use most plausibly interpreted as resulting from outfield manuring. We also draw attention to the fact that the lastnamed may hide lesser sites of the same chronological and/or other periods.

\subsubsection{Artefact-based survey beyond the site}

Following methodological advances in the USA,${ }^{91}$ the mapping of all surface finds, ideally on a field-by-field coverage of contiguous blocks of the landscape, inaugurated a shift from site-based to artefact-based survey. ${ }^{92}$ In many Mediterranean lands it became clear that artefactual remains were common outside of those concentrations considered as potential sites, and that in particular areas and periods, large parts of the landscape between sites might even be covered with carpets of pottery. It has been observed that if a project does not proceed by 'siteless' methods, there is a clear tendency to claim that artefacts either do not exist outside of recognisable finds' concentrations or sites, or are so rare as to be insignificant. The Argolid Survey operated on this principle, ${ }^{93}$ although Bintliff found ubiquitous off-site ceramics in the same landscape. ${ }^{94}$ Again, despite the claim of almost absent off-site on Sicily by Bergemann, ${ }^{95}$ artefact-based surveys at Agrigento city and its near-hinterland map important spreads around and between sites. ${ }^{96}$

The work of Mayoral and colleagues in Spain explores moving from transect or grid collection to GPS recording of individual sherds across the landscape (Figure 3)..$^{97}$ From 2007 Mayoral developed an approach in which the first stage was detailed cartography of finds utilising GPS receivers, geolocating materials with a spacing of $10 \mathrm{~m}$ between fieldwalkers. A 2-3m error of single-frequency GPS hand-held devices was assumed. The result was a point cloud. Qualitative data were added regarding types of materials found, terrain conditions and visibility factors. Sherds with high 'diagnostic' value were picked up at this stage (assigned to point coordinates). Further density analysis of point distribution identified areas worth detailed grid collection for qualitative data. Point mapping, as used also in the Venosa survey in Italy, can be amalgamated to contour maps using kernel-density statistics (Figure 4). ${ }^{98}$ Often advances in survey lead to greater time-investment, but there may be downsides: in both the Spanish and Italian case-studies, the limited collection to broad classes of likely diagnostics in the field may reduce chronological and functional resolution of the data recorded.

Even artefact-based surveys almost always define 'sites' in the field, on the basis of increased finds' densities ('POSIS' = places of special interest, 'ADABS' - artefact densities above standard), automatically producing an 'off-site' distribution as well. Revisiting and grid-collecting is normally undertaken to clarify the status of apparent finds' concentrations. Surprisingly, interpreting offsite distributions initially caused controversy. Partly this arose through a misunderstanding of the different phenomena being observed. Large-scale mapping of sherd patterns on, out of and well beyond activity foci (or 'sites') shows frequently one feature and importantly infrequently a second feature: the 'halo' and the 'off-site carpet' respectively (Figure 5). ${ }^{99}$

\footnotetext{
91 Thomas 1975; Dunnell and Dancey 1983.

92 E.g. Bintliff and Snodgrass 1985; Cherry et al. 1991

93 Jameson et al. 1994.

94 Bintliff 1977.

95 Bergemann 2012.

96 Belvedere and Burgio 2012.

97 Mayoral and Celestino Perez 2009; Mayoral et al. 2012; see also García Sánchez and Cisneros 2012; Grau Mira 2017.

98 Pelgrom et al. 2014.

99 Bintliff and Snodgrass 1985, 1988a; Wilkinson 1989; De Haas 2012.
} 

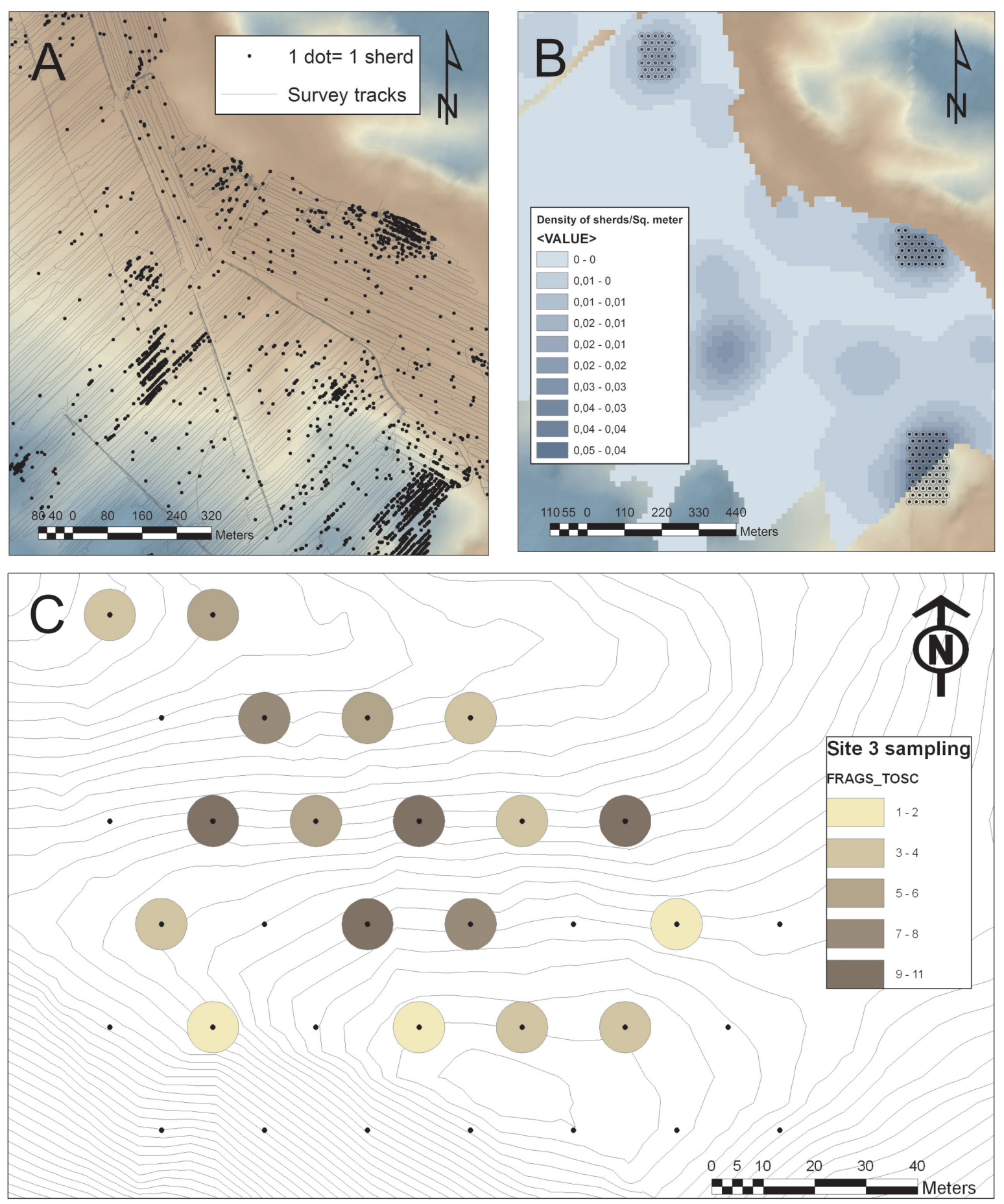

Figure 3. Geolocation of individual finds for sherd density estimation. A: GPS tracks of individual fieldwalkers and distribution of items along their tracks. B: Density estimation. C: Layout of point-based sampling over some of the areas of higher concentration of finds

\subsubsection{Site haloes}

Every field surveyor appreciates that surface sites become smeared across a wider area than their underlying deposits, as a result of slope processes and cultivation. Many scientific studies have measured the scale of such effects, largely confirming its spatial confinement except on steep slopes. ${ }^{100}$ Exceptions include natural taphonomic processes affecting more remote eras such as the

100 E.g. Baker 1978; Reynolds 1982. 


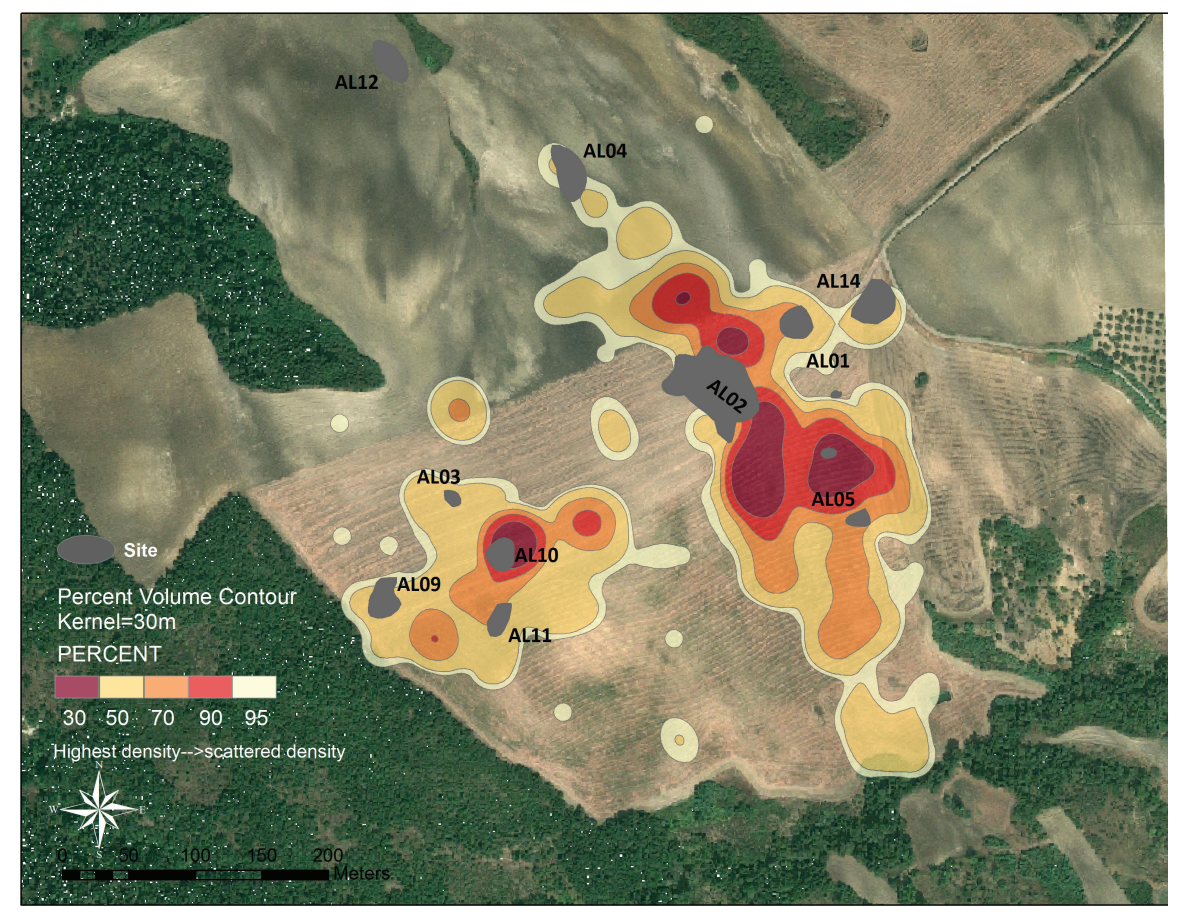

Figure 4. Density map of Black Gloss sherds found on the Allamprese site. For the interpolation a kernel method was used with a search radius of $30 \mathrm{~m}$. The densities represent Percent Volume Contours, which is a method to display the \% of a cumulative distribution (Pelgrom et al. 2014: fig. 8).

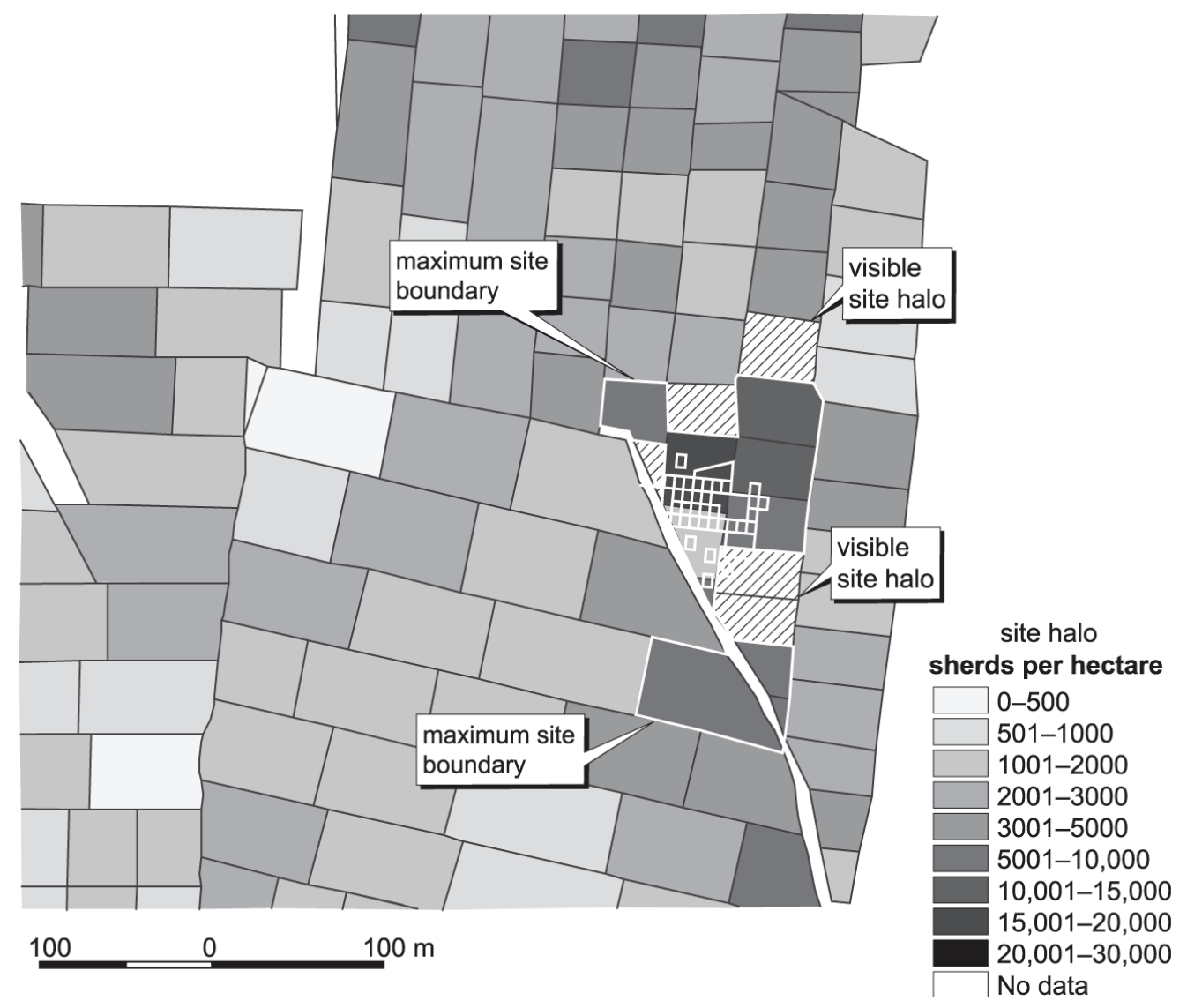

Figure LSE 3/9. Indication in gray scale of off-site densities within and beyond $200 \mathrm{~m}$, showing estimated boundaries of the site at its maximum extent, and of the visible halo areas.

Figure 5. Mapping of the site boundary and site halo of site LS3 in the Thespiai rural hinterland. Beyond lies the almost ubiquitous off-site sherd carpet emanating from the ancient city of Thespiai (Bintliff et al. 2007). 
Palaeolithic, giving rise to unusually extensive haloes. In the Negev Desert (Israel) the problem is acute, since prior to the Neolithic period there is no architecture. Mousterian lithic sites might cover entire hillslopes. Epipalaeolithic sites are also diffuse. ${ }^{101}$

There are two more cultural phenomena in the creation of site haloes. Firstly, observation of recent rural farms and villages demonstrates that in peripheral zones beyond formal buildings, varied activities occur and debris accumulates. Apart from site-margin rubbish dumps in societies where official collections are absent or inadequate, there can be kitchen gardens, pens or tiny fields for small livestock, equipment storage, shrines, burial zones, craft areas, and social event spaces. Surveys and excavations of Roman period urban sites in the Negev, Halutza and Avdat, have examined the chronologies of the rubbish mounds located around the periphery of the sites and found that they indicate the edges of the residential sectors of the settlements. ${ }^{102}$ In some historical societies, an area of cultivation immediately bordering the site, excluding kitchen gardens directly outside each house, sometimes called the 'infield' as opposed to the more distant 'outfield' belonging to a settlement's exploitation zone, was subjected to more intensive land use. Ducellier researched Byzantine rural cultivation practices from texts; ${ }^{103}$ infield haloes were cultivated by hand, although the outfield beyond might also receive manure. ${ }^{104}$

The 'halo' is therefore the product of post-depositional unintentional and intentional site use. The evidence of experimental archaeology and ethnography suggests that cultural activities are more significant than natural weathering and plough-smearing in increasing the 'impact zone' of a site. In any case 'site halo' is a generic term for this zone of enhanced debris, which nonetheless is distinct from the highest 'core' density supposed to mark habitation areas in residential sites. In cases where site size and hence population are estimated from the border of elevated finds' densities, there is thus high probability of overestimating those two parameters. ${ }^{105}$

\subsubsection{Off-site sherd 'carpets'}

Empirical results from numerous landscape surveys, using total sherd density mapping from the core of settlements, consistently reveals a core of highest values surrounded by a zone of lower but still elevated density (the halo, as defined above), which cannot be due solely to ploughing or weathering effects. Beyond this there is usually dispersed low-density material, believed to reflect a 'taskscape' of landscape exploitation (or vestigial sites, see infra). However in some landscapes and apparently only in rare periods, there also exist in the outfield extensive, medium-density, sherd 'carpets' that are most economically explained by the well-documented practice in many ethnohistoric accounts of manuring from settlements into the cultivated landscape. The gathering of waste material including organic and inorganic debris would leave over time a strong ceramic signal in the surface and upper subsurface, but an increasingly weak organic signal in the soil since the nutrients would have been successfully taken up by cultivated and wild plants. ${ }^{106}$

Pioneering research on off-site sherd carpets was undertaken by Wilkinson, who offered likely ranges for manure radii out of settlements of varying sizes, based on empirical research in several landscapes of the Near East. ${ }^{107}$ This practice was shown to be a feature of certain widely-separated periods, for example the Early Bronze Age, Late Antiquity and the pre-modern Islamic phase. He argued it arose from overpopulation, encouraging hyperintensive crop productivity. On the Boeotia Survey (Greece) the existence of large-scale off-site carpets stretching over kilometres

\footnotetext{
101 Goring-Morris 1987.

102 Fabian 2005.

103 Ducellier 1986.

104 See Vionis 2017b.

105 This method of defining site size has been very widely used however, e.g. Jameson et al. 1994 and Cherry et al. 1991, see further infra.

106 Rimmington 2000.

107 Wilkinson 1989.
} 
was recognised at an early stage of the project, and in one now-published district it could be demonstrated that almost all this material was confined to the Classical-Hellenistic era and emanated from a single large city which reached its maximum size at this time. ${ }^{108}$ In a subsequent district studied by the same project, the Tanagra Survey, further refinements were possible through comparing the first few kilometres around that ancient city with the outer part of its dependent territory some $7 \mathrm{~km}$ distant. ${ }^{109}$ Whereas the initial $2 \mathrm{~km}$ around Tanagra saw massive deposits of sherds, steadily declining in density with distance from the town, the outer territory lacked carpets and consisted solely of site cores, site haloes and low density sporadic off-site ceramics. Clearly increasing distance from the city limited and eventually prevented the manuring of the wider landscape, and intentional and unintentional rubbish dumping and manuring became confined to the immediate surroundings of rural sites, using their limited supplies for this 'halo'.

Systematic sampling of off-site carpets within distinct landscape zones in the Pontine Region (Italy) revealed variations at the sub-regional scale. ${ }^{110}$ Close to the coast, occupied by Roman villa complexes well-connected to urban centres via paved roads, off-site carpets are dense and extensive, reflecting intensive land use (possibly using refuse from the nearby city of Antium). Small-scale variations in density, fragmentation, and assemblage variability, however, pinpoint phenomena such as sheds, outbuildings, and rubbish heaps within this carpet, as suggested by recent excavations of 'off-site' localities in Etruria. ${ }^{111} \mathrm{~A}$ similar pattern appears along the footslopes of the Lepine Mountains, presumed to have been intensively used for olive and vine cultivation by local elites. By contrast, in a low-lying area in the inner plain, off-site distributions are limited to the direct surroundings or haloes of (small) sites, suggestive of less intensive cultivation by smallholders of this agriculturally more marginal area. Taken together, this case study clearly shows the variability in characteristics of off-site carpets as well as the potential interpretive possibilities in terms of land use strategies.

Off-site carpets raise issues of visibility for lesser sites submerged in areas of dense finds. As discussed earlier, such carpets can obscure or make hard to recognise vestigial sites or those with less recognisable ceramics, 'hidden landscapes', but normally do not prevent teams identifying local peaks created by sites with well-made and diagnostic surface debris. In one experiment, finds densities were measured in concentric $50 \mathrm{~m}$ bands from site cores into halo areas then offsite carpets: densities consistently declined with distance down to district background levels, while material fell off at different rates according to the size of rural site. ${ }^{112}$ The sites remained outstanding density-peaks. Alongside documenting the distinctive nature and date of extensive 'carpets' we can and should still pay attention to searching within it for localised variations which could signal non-residential activity foci ('taskscapes') and vestigial occupation sites. ${ }^{113}$

\subsubsection{Offsite distributions and (ancient) manuring}

An influential critique of manuring practices to explain off-site carpets appeared in $1994 .{ }^{114}$ Although its calculations were simultaneously challenged, ${ }^{115}$ more conclusive is the subsequent discovery that the Nemea Survey data used as evidence against manuring, are being published as showing large-scale Roman-era manuring carpets. ${ }^{116}$ Doubting the existence of landscape manuring using undifferentiated settlement waste appears strange when such practices are within living-memory in many Mediterranean countries, such as Croatia and Spain, as well as referred to in numerous

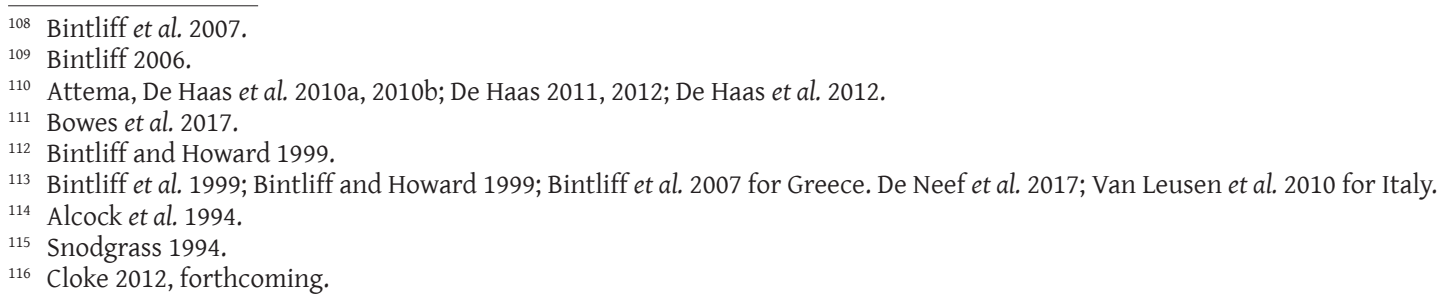


Greco-Roman historic sources. Intensive survey in the Guadiana Basin (Spain) documented an offsite carpet mostly generated after the replacement of woodland by cereal cultivation throughout the 19th century, creating a dense, homogeneous ceramic surface record. The practice, described by local farmers (estercolado), was maintained until the mass introduction of industrial fertilisers. ${ }^{117}$

Pettegrew has suggested that extensive sherd carpets around ancient cities in Greece are the debris of extensive habitation by poorer sectors of society living extramurally. ${ }^{118}$ However there are many examples of genuine, focused 'sites' representing small farms with very simple household finds and roofs made of recycled tiles, while the areas covered by extramural sherd carpets from minor cities, if taken as additional habitations, would make all such towns as large as Imperial Athens. Wilkinson's pioneer research on anthropogenic sherd carpets included test-pitting to confirm the absence of underlying settlement or burial origin, and such confirmation is also advisable in landscapes with diverse and rich surface finds.

Caution is required with the chronology of intentional dispersal in the Near East, where occupation layers of tell sites high in organic content are dug away and spread over the fields as fertiliser (sabakh). Fortunately in many instances the manure carpets are single-period rather than diverse as would suit recycled tell deposits, and may correlate with peaks in local landscape occupation. ${ }^{119}$ Similarly in the Pisa South Picenum Survey in Italy, situations were identified where an archaeological site was disturbed during building works and its materials dumped in distant fields. ${ }^{120}$ The materials consist of mixed ancient and modern items, located in fields alongside roads. Thus we should also consider past examples of modern 'fly-tipping', which are observable today when inadequacies in organised rubbish collection lead to dumping of mixed garbage, often along roads. ${ }^{121}$ This may be responsible for some localised clusters of ancient finds without clear site characteristics.

A case study from the Thespiai Hinterland study (Greece) illustrates several points just made. ${ }^{122}$ An apparent Classical-era sherd focus was identified as site LSE2, close to ancient Thespiai city. Gridding revealed a suitably dense surface scatter (Figure 6a), but this lay within a heavy Classical urban manuring zone (Figure 6b, visibility-corrected counts per hectare), characteristic for the entire environs of the town, nor did the scatter show the typical concentric rise to one or more inner foci. It was not an historic site, but through gridding this area a small prehistoric focus of finds emerged (Figure 7), arguably a heavily-degraded Bronze Age farm. As often such a vestigial site would not have been discovered without the chance position of a collection grid across it.

\subsection{Site-scale survey}

In this section we first discuss detection and sampling of small rural sites. Scatters of a few meters across easily go unnoticed in low-resolution surveys and at times such sites are only detected in the surface ceramic record during data and finds processing. Therefore dedicated artefact collection strategies are needed that allow us to detect and date the phasing of such sites. Next we discuss survey of complex rural and urban sites, whose sheer quantity of surface finds require sophisticated collection strategies, to establish shifting boundaries through time and to establish continuity and discontinuity, thus verifying that no periods that may be poorly represented in the surface record are missed. In this section we also discuss survey of settlement mounds where often only the most recent layers are exposed at the surface.

\footnotetext{
117 Mayoral et al. 2018.

118 Pettegrew 2001.

119 Wilkinson 2003: 117.

120 Menchelli 2008, 2012.

121 Cf. Bintliff et al. 2017 for Early Modern Greece.

122 Bintliff et al. 2007.
} 

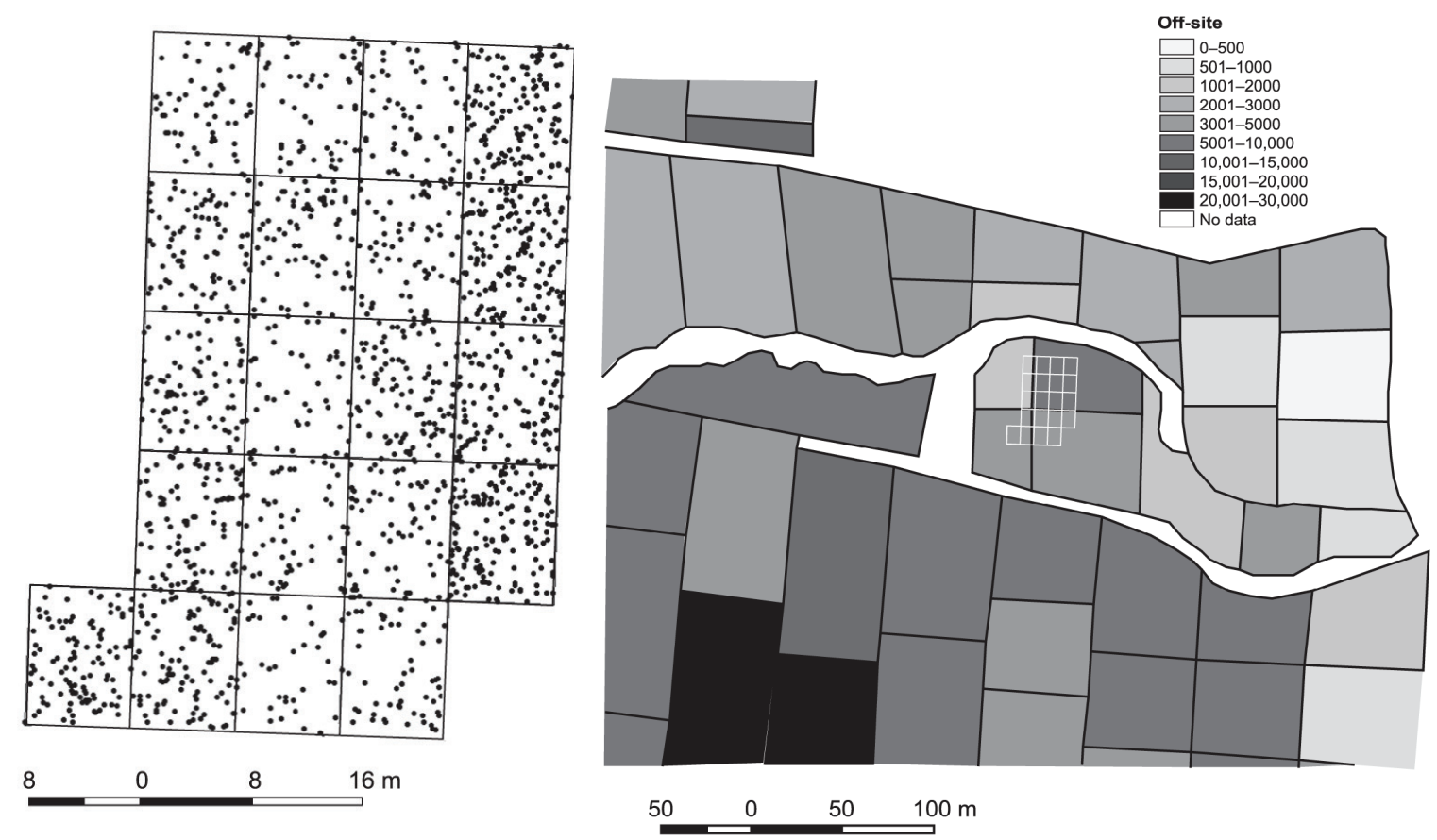

Figure 6. 6a: density map of artefacts on the site grid of site LSE2. 6b: overall field density of artefacts around the site grid.

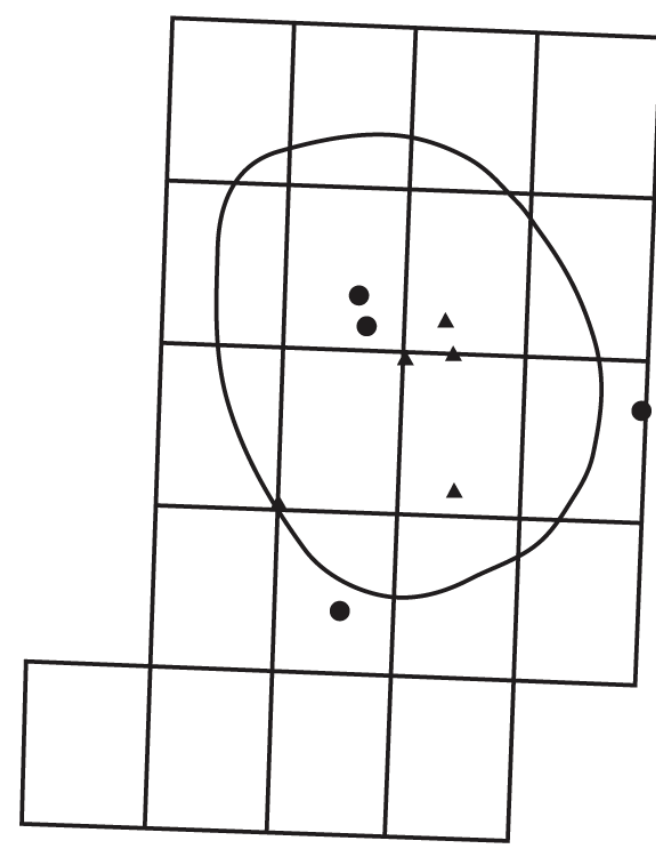

PREH lith

A 1 dot $=1$

PREH pot

- $1 \mathrm{dot}=1$
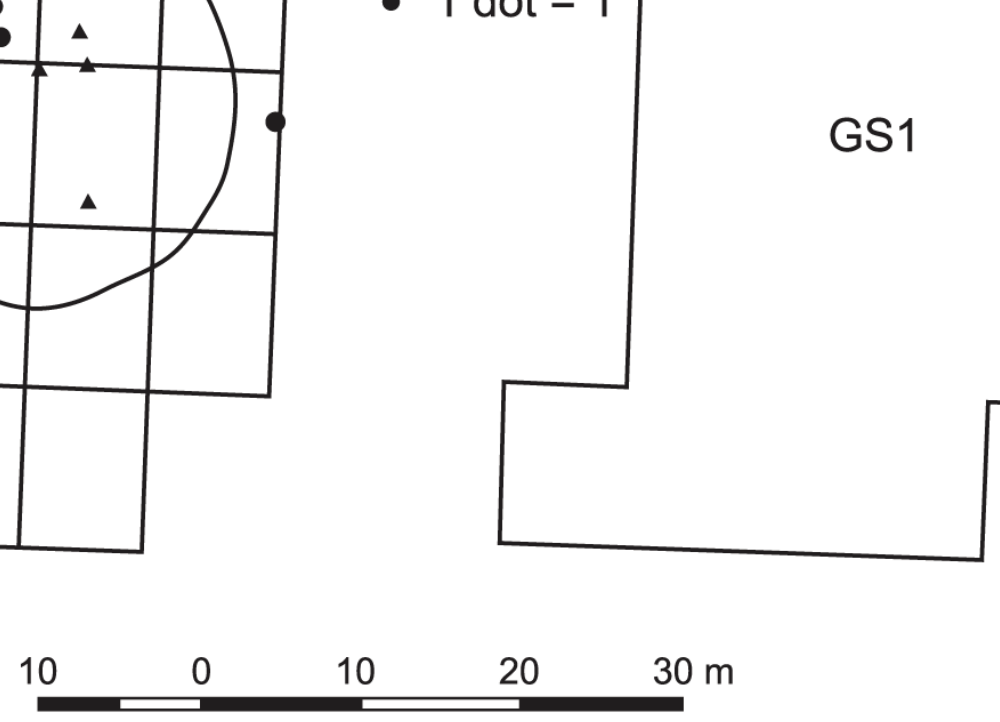

Figure LSE 2/17. Distribution of Prehistoric finds over the site.

Figure 7. Prehistoric sherds and lithics on site LSE2. 


\subsubsection{Survey of small rural sites}

As we saw in section 2.1, walker interval is the main parameter that determines how much land can be covered by a survey. However, this interval cannot be increased without incurring a significant penalty: intervals exceeding $10 \mathrm{~m}$ can miss the lower end of the rural site spectrum, sites a few metres across. If the aim includes picking up such microscale phenomena, as is the case in surveys by the Groningen Institute of Archaeology in Italy and the Crimea, this puts an upper limit on walker-spacing. ${ }^{123}$ Experiments with high walker coverage of landscapes lacking ploughed fields have led to the discovery of small rural and/or pastoral sites, as for instance in the uplands of mainland Italy and the Crimean steppes. ${ }^{124}$

Even small Mediterranean rural sites are frequently multi-period and we need to unravel their occupation phases, to establish chronological and (dis)continuities and functional changes. The aim is to recover their 'cultural biographies'; this necessitates adequate spatial differentiation of finds and sufficient numbers to deal with the site's likely changing size and function over time. ${ }^{125}$ Thus a general problem with the development of Mediterranean survey procedures has been the effect of sampling on the representativeness of the total surface assemblage. In the pre-intensive survey days, surface sites were walked randomly to collect a few bags of the most distinctive finds. ${ }^{126}$ In some cases large sites were divided roughly into sectors to identify differing occupation histories by separate collections. Once intensive survey became the norm, quantitative considerations led to larger collections and discussion of formal strategies for site sampling. ${ }^{127}$ Limited, defined zones were collected from carefully, with a 'grab' collection over the remaining larger areas of the site. The Argolid and Kea Surveys developed a site sampling method, widely adopted on later Aegean surveys. ${ }^{128}$ An X-shape was placed across the site within the borders of dense finds with total collection in each limb, followed by a grab sample in the four intervening quadrats. Apart from the lack of recognition of halo areas, or a quantified definition of the boundaries of genuine off-site, halo and site core, such a deceptively-easy definition of the site edge makes no allowance for alterations in site size over time. The single site edge was used for calculating population levels, with just a few large sites subjected to discrete area sampling to clarify spatial differences across time. In the Thespiai rural hinterland survey, ${ }^{129}$ with dense site-gridding and large surface collections, nearly all 17 sites were shown to change character dramatically over their multi-period use, getting larger or smaller, or shifting from permanent to seasonal/temporary use. Given the debate within Greek survey on the residential or non-residential nature of small Classical farm sites, ${ }^{130}$ such careful examination of sites is essential.

Collecting at points along close-spaced strips across the site, practised in Jordan (Figure 8) is comparable..$^{131}$ However recording small numbers of ceramics covering many periods at small sample points along a large grid, produces plots impossible to interpret. ${ }^{132}$ In this regard it is crucial to understand the degree to which the density of surface finds on-site may be affected by slope processes. Mayoral and colleagues determined that the correlation between counts and weights of different artefact categories collected in Spanish surveys with grid sampling on small Roman rural sites, and the topographic attributes of these sampling units (runoff, average slope\%) were weak or non-existent (Figure 9). ${ }^{133}$ A similar study testing the association between simulated erosion rates

\footnotetext{
123 Guldager Bilde et al. 2012; Tol et al. 2014; De Neef et al. 2017; Attema 2018.

124 Van Leusen et al. 2010; Guldager Bilde et al. 2012; De Neef 2016.

125 Tol 2012.

126 E.g. the Minnesota Survey, McDonald and Rapp 1972.

127 Cherry et al. 1978.

128 Cherry et al. 1991; Jameson et al. 1994.

129 Bintliff et al. 2007.

130 Osborne 1985; Lohmann 1992.

131 For Jordan see Kaptijn 2009. For Turkey see Kaptijn and Waelkens forthcoming.

132 E.g. the Sphakia Survey: Moody et al. 1998.

133 Mayoral and Sevillano Perea 2016.
} 

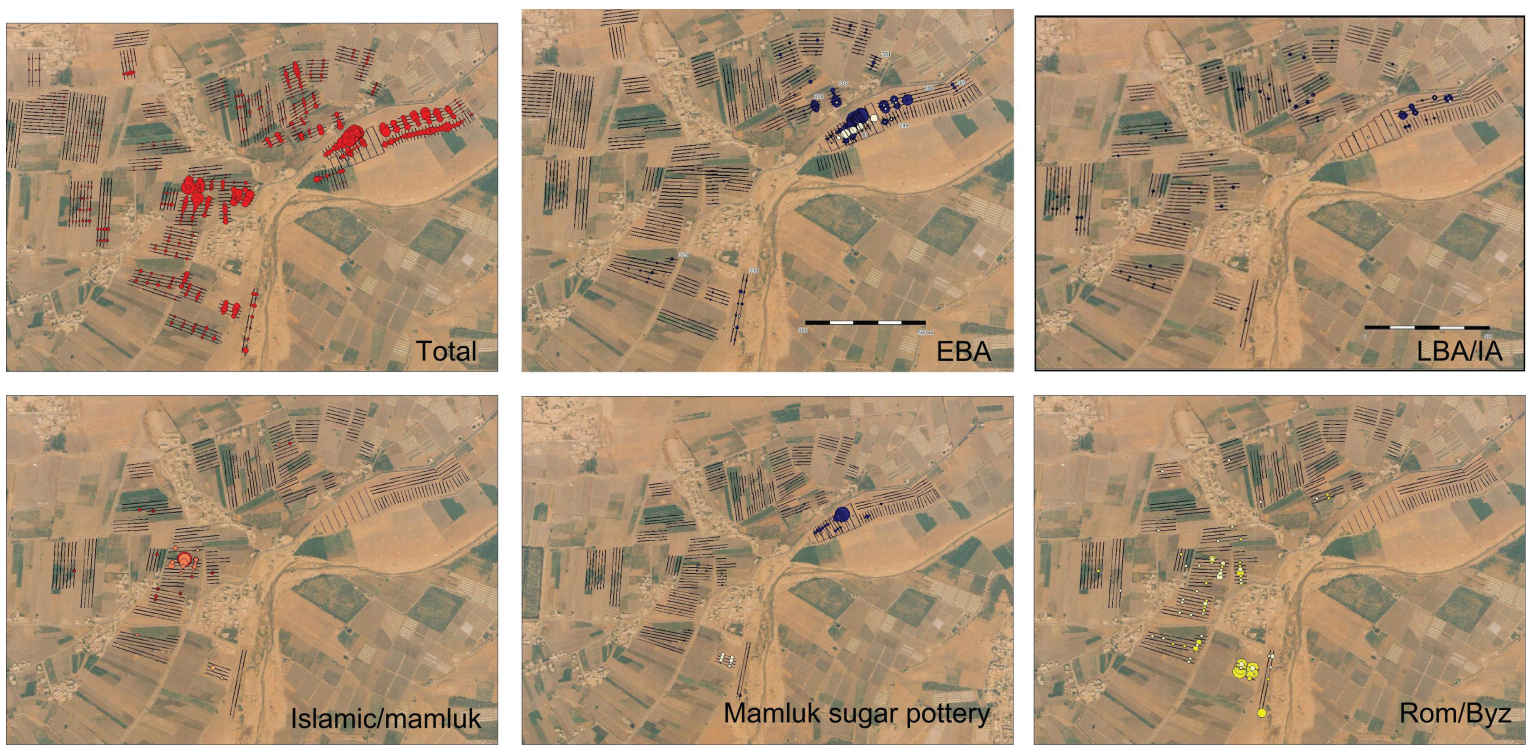

Figure 8. Overlapping concentrations from several periods in the Jordan Valley (Zerqa Triangle Survey) (Kaptijn 2009).

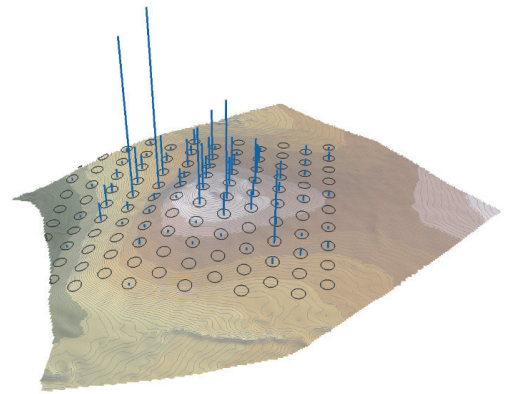

Cerámica común

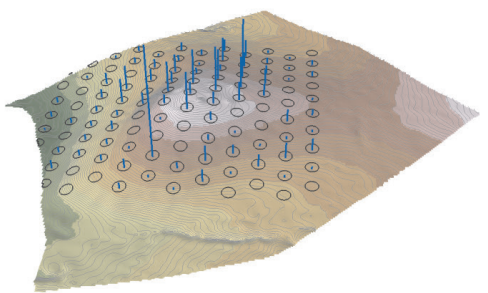

Tegulae

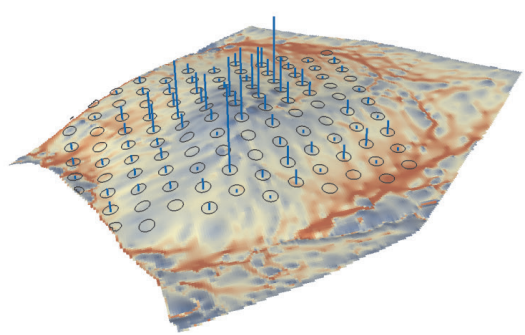

Figure 9. 3D visualization of the spatial distribution of surface finds (common ware, roof tiles) and variables derived from micro-topography (topographic wetness index) in the grid collection over a small Roman rural site in the Guadamez valley (Badajoz, Spain). After Mayoral and Sevillano, 2016:110.

\section{Índice topográfico de humedad}

and surface artefact density in the Inachos Valley, Greece again only had slight success; instead the anthropogenic role in the variable presence of sites and off-site finds was suggested to be a critical element, but was not included in the analysis. ${ }^{134}$

Separating cores, haloes and off-site needs quantification and local flexibility by district. Areas close to a major conurbation can see small rural sites barely elevated in finds' density above urban halo and manuring carpets. 'Residual analysis' compares background density values by period for each zone of a landscape to those from site haloes and cores. ${ }^{135}$ Finds at a site in one period may evidence occupation, whereas finds for another period are merely part of a continuum of similar density in the surrounding landscape.

\footnotetext{
134 Tetford et al. 2018.

135 Bintliff et al. 2007.
} 
How many artefacts represent a viable sample of the site to recover its biography? After the site has been collected from systematically, its finds washed, and period specialists have analysed the finds (ideally with the help of a study collection of forms and fabrics by period), it is too late to decide that artefact numbers for one or all periods, are too limited. Either resurvey is needed, or sampling inadequacies persist as interpretative problems. Surveys in the 1980s-1990s struggled with small collections: three sherds of one period might be assigned to temporary- or off-site activity, four or more signalled occupation. ${ }^{136}$

So what about total collection? Most contemporary projects involve selective collection of diagnostic pieces, together with shapes and fabrics potentially diagnostic. On the Koroneia survey (Greece) diagnostic collection was compared with total collection. ${ }^{137}$ Overall little additional information emerged from total collection, which involved far more work. The exceptions included cooking and other coarser wares, and comminuted tiny prehistoric pieces. Interestingly including body sherds did not significantly alter the assemblage composition compared to the results obtained from more diagnostic 'feature sherds' (rims, bases, and handles). A similar result emerged from experiments on the Methana Project. ${ }^{138}$ In the Pontine Region Project (Italy) experiments with total collection reached the same conclusion, although total coverage helped identify occupation periods difficult to identify (low pottery consumption, low diagnosticity). ${ }^{139}$ The results of the Leptiminus Survey, whose methods consisted of a $20 \%$ transect sample followed by a diagnostic 'grab' sample across a dense cityscape, indicated that this combination was effective; differences between the random and grab collections were minimal. ${ }^{140}$ Needless to say the largest Mediterranean sites exhibit sherd densities beyond conceivable collection (several hundred thousand sherds per hectare are not uncommon).

Rural site surveys have long relied on rather simple classifications (e.g. villas, farmsteads, and villages ${ }^{141}$ ). Excavations show a wider range of structures, both settlement and non-settlement, ${ }^{142}$ confirming ethnographic comparanda. ${ }^{143}$ Current research explores alternative classifications, ${ }^{144}$ interpreting site functions from surface assemblage variations, or on associations with architectural remains. ${ }^{145}$ The Pontine Region Project confirms that many sites have consistent assemblages to be interpreted as rural settlements, whereas others with anomalous assemblages point to cult, industry or agricultural adjuncts. ${ }^{146}$

\subsubsection{Survey of complex sites}

\section{Complex rural sites}

Survey of villages reveals interactions with wider economies and rural lifestyles. ${ }^{147}$ Many urban sites started as villages or rural site clusters, which grew into cities, often reverting to villages in post-Roman times. ${ }^{148}$ Surveys of abandoned Roman towns in the Potenza valley (Italy), combining artefact surveys with augering and C14-dating of the deepest anthropogenic levels, also uncovered such long-term trajectories in settlement size and changing character. ${ }^{149}$

\footnotetext{
136 For example on the Kea Survey, Cherry et al. 1991.

137 Van der Enden in Bintliff et al. 2012.

138 Mee and Forbes 1997.

139 Tol 2012

140 Stone et al. 2011: 77-84.

141 Witcher 2006.

142 Ghisleni et al. 2011; Vaccaro et al. 2013; Bowes et al. 2017.

143 De Haas 2012.

144 Attema and Schörner 2012.

145 De Haas et al. 2012.

146 De Haas 2011; Tol 2012; Attema et al. 2014; cf. Winther-Jacobsen 2010 for Cyprus.

147 Vionis 2016, 2017c.

148 Bintliff et al. 2017.

149 Vermeulen et al. 2017: 88-95.
} 
Projects have recently focussed on more complex rural sites (large villages, 'secondary agglomerations', 'minor centres'), ${ }^{150}$ lacking formal civic status but often performing central place functions for rural areas and housing considerable populations. ${ }^{151}$ Textual sources provide other names: komopolis, statio, mansio, canabae, conciliabulum..$^{152}$ The range of this group is extensive: from 2ha in size, showing little spatial differentiation, whilst the largest, rival urban centres in extent and possess similar features: markets, temples, aqueducts, baths, orthogonal grids, and paved road surfaces. At the Forum Appii site on the Pontine Plain (Italy) the Minor Centres Project undertook a $25 \%$ surface-sample within $25 \mathrm{~m}$ by $25 \mathrm{~m}$ grids. ${ }^{153}$ The site chronology spanned the 4 th century BC to the 7th century AD, with peak size over $10 \mathrm{ha}$. The variety of imported and locally-manufactured pottery suggested redistributive marketing functions, suiting its river harbour, quay and industrial facilities. In later Roman Sicily, unofficial agglomerations in the interior form the main settlement and economic foci. ${ }^{154}$

\section{Complex urban sites}

Despite the pioneering sophisticated survey of the Mesoamerican city of Teotihuacan, ${ }^{155}$ Mediterranean urban sites were usually avoided till recently, or dealt with superficially - too big to cope with and yielding humungous finds quantities. The Kea Survey for example, catalogued a mere 137 finds from 20-ha Koressia city. ${ }^{156}$ In retrospect, we are sure the team would now consider this as far too small a sample for such a long-occupied site. In the Knossos Survey a fine $20 \mathrm{~m}$ by $20 \mathrm{~m}$ grid has been used to map this very large and long-occupied urban site, within each of which a sample of $10 \mathrm{~m}^{2}$ is taken; this project already has at least 500000 sherds to map. ${ }^{157}$ A limited experiment during the initial years of the Boeotia project, compared finds from sample circles across sites, only a few percent of the site area, with similar amounts of finds from the total site. Only the latter produced a reliable range of forms and dates, suggesting that spatial variability, especially on multi-period sites, is too great to allow limited samples to be secure guides, unless like Knossos, the samples are dense and almost innumerable. ${ }^{158}$ Luckily future Mediterranean urban surveys now have new 'cookbooks' for dealing with large, complex sites. ${ }^{159}$

The condition of large sites can however impede analysis, if surfacelayers are biased taphonomically: the long unploughed town of Sagalassos shows surface finds poorly reflecting underlying deposits when excavated. ${ }^{160}$ Even regularly ploughed ancient towns, such as Thespiai, Greece, revealed taphonomic filtering combined with ceramic visibility problems, impeding easy recognition for all twenty-seven phases of site use (Figure 10). Urban contraction between Greek and Roman times additionally led to massive ceramic swamping during the latter period in the urban centre, making it seem empty in pre-Roman times. 'Sector analysis', dividing large sites into zones by terrain or archaeological arguments, then investigating their varying surface period representation, can tease apart such filters (Figure 11). ${ }^{161}$

\section{Establishing the boundaries of urban sites}

Urban haloes are still widely ignored; the boundary of dense finds is taken as the edge of the builtup area. There is uncertainty regarding activities on the fringes of domestic and public buildings, although historical sources, chance finds and excavations offer the possibilities of industry, market

\footnotetext{
150 Vroom 1999; Tol et al. 2014; Caraher et al. 2014.

151 Pelgrom 2012.

152 See Tol et al. 2014 for terminological discussion.

153 Tol et al. 2014.

154 Vaccaro 2012.

155 Millon 1964, 1973; Millon et al. 1973.

156 Cherry et al. 1991.

157 Whitelaw et al. 2006-2007.

158 Bintliff and Snodgrass 1985.

159 Lolos et al. 2007; Vermeulen et al. 2012; Corsi et al. 2013; Johnson and Millett 2013.

160 Martens 2005.

161 Bintliff 2012a, 2014; Bintliff et al. 2017.
} 


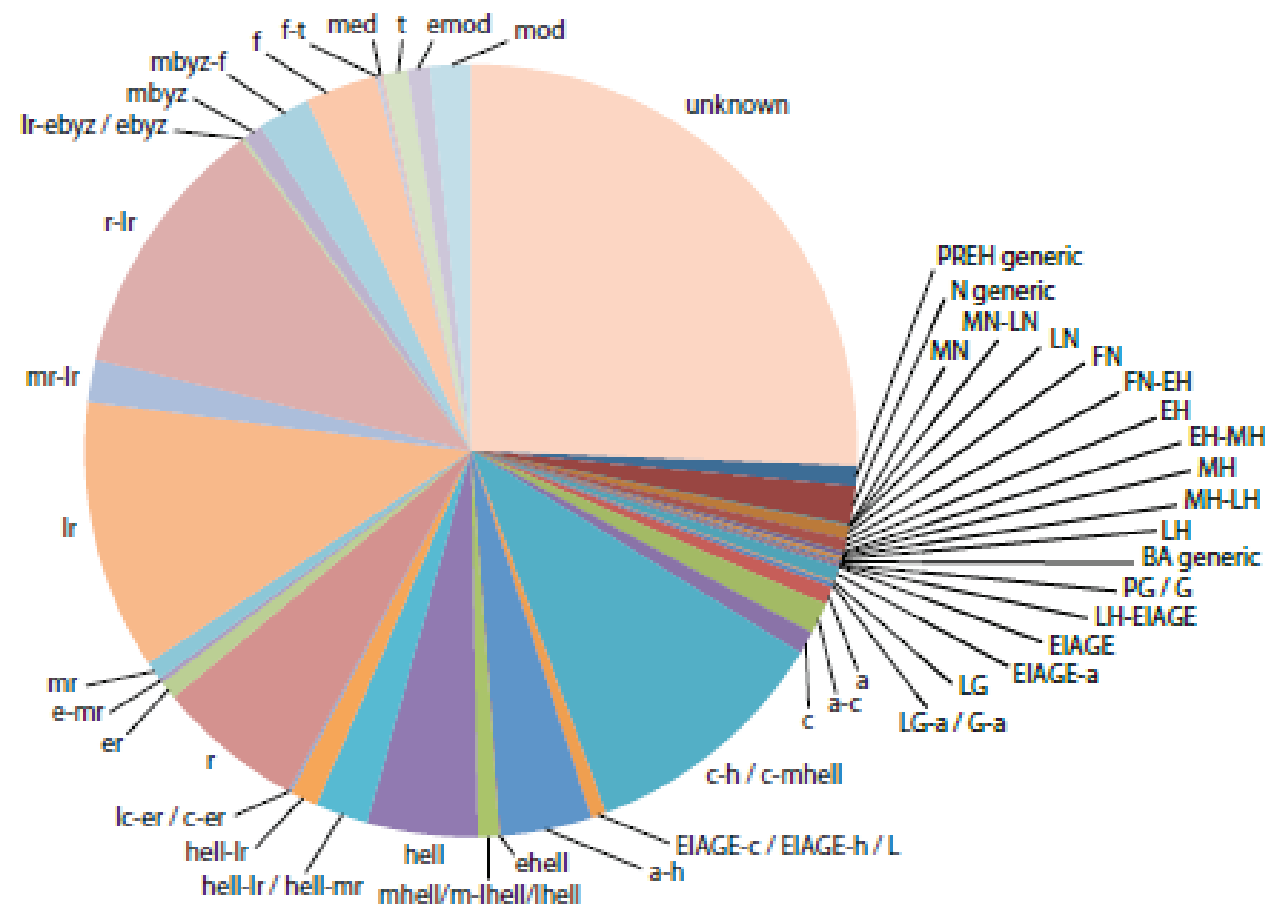

Figure 3.27. Pie chart of the City Transect Sherd databrse. Abbrevintions: $P R E H=$ Prehistoric, $B A=B r o n z e$ Age, $N=$ Neolithic, $H=$ Helladic or Bronze Age, EIAGE = Early Iron Age, $P G=$ Proto-Geometric, $G=$ Geometric, $a-$ Archaic, $c=$ Classical, $c-h=$ Classical to early Hellenistic, $h=$ Hellenistic, $r=$ Roman, $h-r=$ late Hellenistic to early Roman, med $=$ Medieval, byz $=$ Byzantine, $f=$ Frankish,$f-t=$ Frankish $/$ Late Byzantine or early Turkish, $t=$ Turkish, $\bmod =$ Modern; $\mathrm{e} / \mathrm{E}, \mathrm{m} / \mathrm{M}, \mathrm{L} / \mathrm{L}$ and $\mathrm{F}$ before period terms are respectively early, middle, late and Final.

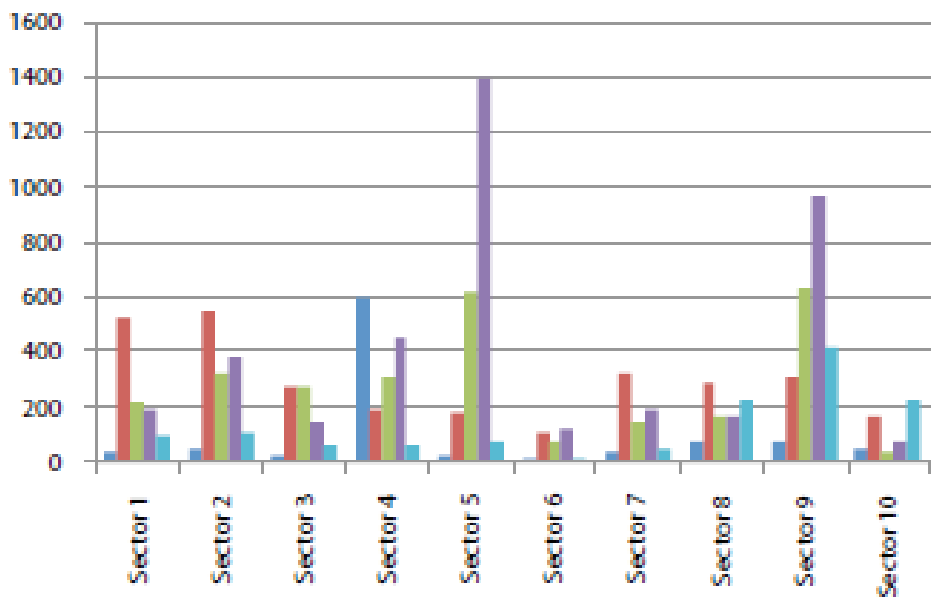

Figure 3.30. The Sector Analysis: the sherd data-base with the Transect and Samples collections merged.

Figures 10 and 11 . Figure 10 shows a pie-chart of the chronological phases identified in the ceramics from the total urban survey of ancient Thespiai city. Figure 11 shows the variable representation of the main groups of periods by 10 sectors of the city grid.

gardens, cemeteries and extramural sanctuaries, dispersed semi-rural homes, and large-scale rubbish dumping. Lacking systematic institutions for rubbish collection, pre-modern and even many modern Mediterranean communities have used vacant urban plots and the periphery of the settlement for waste dumping. ${ }^{162}$ These deposits by their nature appear as occupation deposits, their secondary or even tertiary depositional character not apparent from the finds themselves (at Sagalassos, sherd degradation measurements have been used to identify rubbish dumps ${ }^{163}$ ).

\footnotetext{
162 For the latter within urban sites cf. Fentress 1994; Johnson 2010.

163 Putzeys et al. 2004: 34.
} 
These problems remain even in the high-quality urban survey at Leptiminus, Tunisia. ${ }^{164}$ The Aphrodisias survey, Turkey, has attempted to tackle this problem by what they refer to as the 'donut' survey; intensive survey in a 500m-wide band outside the city wall supplemented by four transects radiating outward to get an understanding of the surrounding environment. ${ }^{165}$ Evidence for extramural burial can clarify urban boundaries, at least for periods where this was legally confined to the urban periphery. This seems to be a question which can be helpfully approached using other methods of field prospection.

Thespiai city is illuminating: large-scale use of city rubbish to fertilise the inner countryside ceased by Roman times, while the mapping of that period's surface finds within the former walled town, matched with the incursion of burials into former suburbs and the recycling of architecture from the same suburbs, demonstrated that the town shrank by two-thirds. Thus urban waste accumulated within vacant urban spaces and on the contracted edge of the settlement. The roman sherd distribution already revealed significant decline in the extent of the town, but adding increases in the rubbish halo, a more drastic shrinkage of the domestic area emerged. ${ }^{166}$

\section{Detecting pre- and protohistoric phases in the survey of urban sites}

Prehistoric and protohistoric activity at historical urban sites frequently exhibit long timespans and thin artefact distributions for the earliest periods. Thespiai city was a village from Neolithic to Early Iron Age times. After its long urban phase, c. 700 BC to AD 600, it reverted to village status till abandonment in the 19th century AD. Prehistoric sherds and lithics represented a tiny finds' percentage, their recognition in the 925 grid units being primarily dependent on the varying size of the sherd sample from each unit: less than 30 sherds would normally miss prehistoric finds, and also other less common periods. Experiments showed that multiplying sample size by a factor of three restored the missing periods. Since the 'Sample Factor' (the percentage between the size of the artefact collection and the counted density per grid) was $0.2815 \%$, with a mere 14300 artefacts of all periods, the small prehistoric collections must be extrapolated to a far larger body of material, even without allowing for a major loss of early pieces through degradation. ${ }^{167}$

For Veii near Rome, debate has centred on the distribution of Iron Age sherds: does it show overall occupation of such Italian plateau settlements, or rather several distinct clusters that merged by later periods to form the Archaic city. This giant site (200ha) underwent extensive surface survey in the 1950 s. ${ }^{168}$ Five main sherd clusters around the plateau fringes, linked to extramural cemeteries, were identified as sub-settlements during Iron Age times, cohering into a larger but still loose-knit community in Archaic Etruscan times. The plateau interior was partly used for intensive farming. More systematic survey by Guaitoli in 1982, mapped four times as many early foci across the entire plateau, suggesting a continuous unified nucleation. ${ }^{169}$ The original Ward Perkins data have been re-examined and the finds restudied, ${ }^{170}$ assisted by recent localised Italian excavations. The Iron Age remains a very partial cover, with the densest clusters around the plateau edge, although 69 foci are now mapped (but some are cemeteries). For the subsequent Etruscan phase, 73 foci were mapped, but the plateau remains patchily covered and the denser concentrations are discrete from each other. Indeed the interpretation resembles an early suggestion by Tim Potter, ${ }^{171}$ with separate zones of occupation and of specialised functions (domestic, ritual and manufacturing). A protourban settlement of multifocal character, as still argued for Archaic Greek towns, ${ }^{172}$ where each

\footnotetext{
164 Stone et al. 2011.

165 Ratté and De Staebler 2012.

166 Bintliff et al. 2017.

167 Bintliff et al. 2017.

168 Ward Perkins 1961; Potter 1979.

169 Spivey and Stoddart 1990.

170 Cascino et al. 2012.

171 Potter 1979.

172 Snodgrass 1980; Bintliff 2012b.
} 
discrete habitation focus was ringed by site haloes, would in fact create a sherd pattern of almost total site cover but at fluctuating densities.

Similarly, surveys on a prehistoric to Late Roman oppidum in the Vardar valley, Macedonia ${ }^{173}$ and on a Late Roman agro-town in the Xeros Valley, Cyprus, ${ }^{174}$ showed Iron Age-Archaic to Early Classical sherd spreads twice as extensive as Roman-Late Roman finds. Yet the spread of Iron Age finds is less compact than the Antique surface remains, consisting of numerous cores separated by zones of intermediate density. This obviously reflects changes in land use patterns and demographic density variations.

Giribaile, a large protohistoric Spanish site in Spain, was studied by Gutiérrez with a systematic stratified random sample of 14 ha. ${ }^{175}$ Figure $12 \mathrm{a}-\mathrm{c}$ shows the grid scheme, total artefact densities and fabric groups, the last-named being very significant for pre- and protohistoric sites where finewares and distinctive feature sherds may be in the minority or even absent.

Tells

Settlement mounds (tells, magoulas, khirbes, tepes, hüyöks), are very obtrusive human activity foci in the Balkan and Eastern Mediterranean landscapes, with a particular taphonomy. Interpretation of the uppermost layer is relatively straightforward (often enormous numbers of surface artefacts), but the buried layers are highly problematic. Mounds range from $<1$ ha to structures $40 \mathrm{~m}$ high and covering $100 \mathrm{ha}$. On the site edges older layers may be exposed (through erosion), elsewhere layers can be exposed through later digging for siloes, burials, to extend farmland, use tell soil as fertiliser, or for looting and military trenches.

Past surveys often collected single, spatially unspecified, samples, but recent surveys apply grid sampling, ${ }^{176}$ to identify differences in density, chronology and function of the surface artefacts. Tells consist mainly of mudbrick thus suiting non-destructive geophysical prospection. Electrical resistivity tomography can penetrate tens of metres, with a resolution revealing superimposed layers (see below under section 3.2). ${ }^{177}$

\subsection{Revisiting sites}

Sites change surface appearance over the years. Graeme Barker, ${ }^{178}$ experienced in Italian survey, wrote "small sites come on and off like traffic lights". Recent revisits to Boeotia Project sites recorded in the 1980s found that more than half no longer appeared as artefact concentrations, although they had previously registered a clear site density; furthermore the areal extent of some sites had changed, and new sites had appeared in fields previously recorded as off-site. Other projects show a more positive outcome: $20 \%$ of sites in the Potenza Valley were revisited, and $90 \%$ of those where terrain visibility remained adequate were confirmed. ${ }^{179}$ This suggests that local soil and cultivation conditions are highly influential on site recognition.

Predictably the larger sites suffer little from variable surface manifestation. García Sánchez terms 'shooting stars' sites which ephemerally appear following deep-ploughing activities but after a few seasons dissolve into background noise. ${ }^{180}$ Waagen has highlighted locations displaying richness and variability in their few finds, as likely to become clearly identifiable as sites during revisits in

\footnotetext{
173 Donev 2018.

174 Vionis 2017a.

175 Gutiérrez 2010.

176 Ur 2010; Momigliano et al. 2011.

177 Casana et al. 2008; Momigliano et al. 2011; Papadopoulos et al. 2014.

178 Barker 1984

179 Vermeulen et al. 2017: 15.

180 García Sánchez et al. 2017.
} 

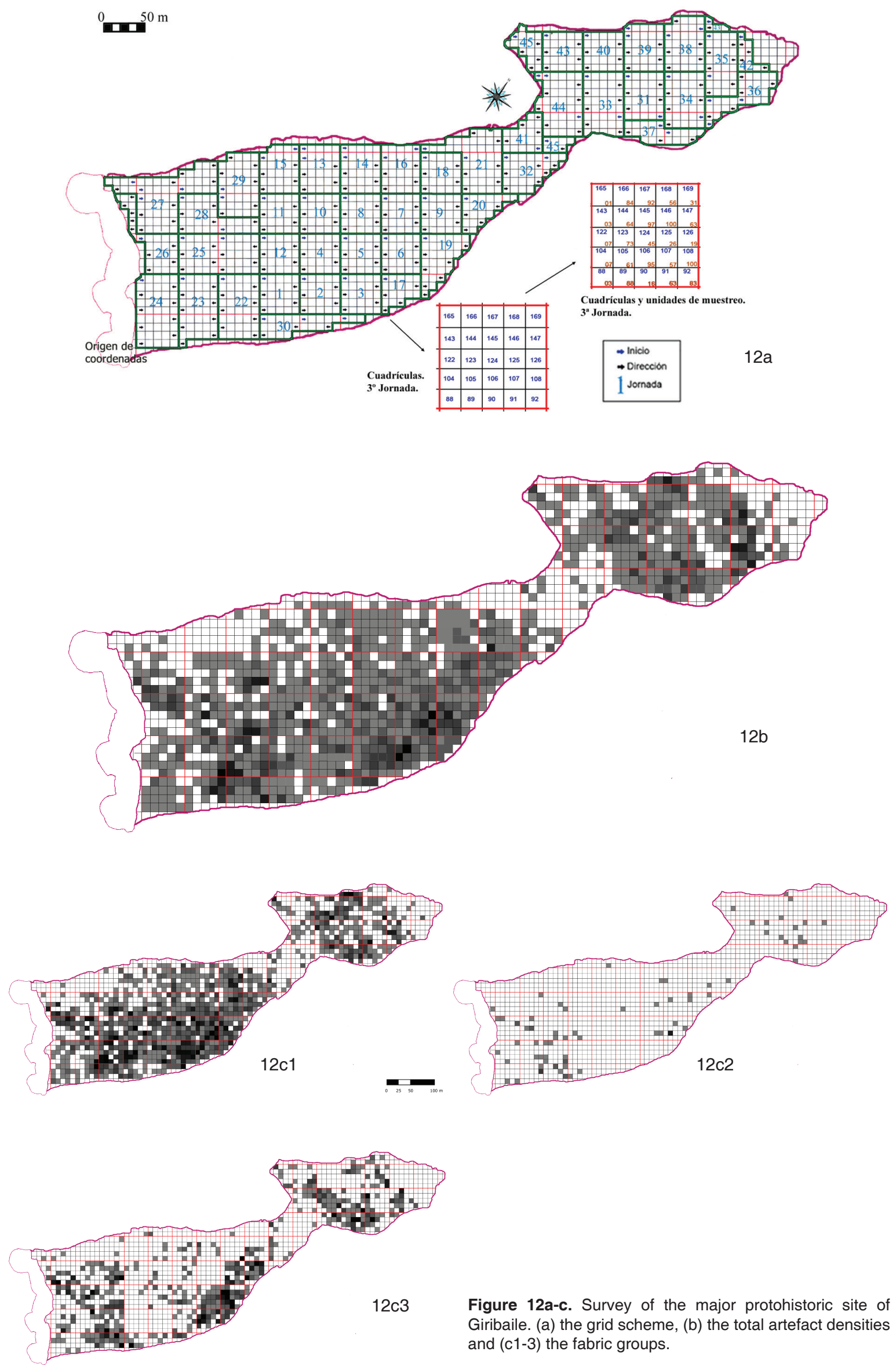

Figure 12a-c. Survey of the major protohistoric site of Giribaile. (a) the grid scheme, (b) the total artefact densities and (c1-3) the fabric groups. 
another year. ${ }^{181}$ Monitoring the effects of changing land use is therefore fundamental, particularly through resurvey in different years and under varying forms of local exploitation of the site area.

Revisiting together with geophysical surveying (on which see section 3.2) disproves claims that intensive survey in certain landscapes finds all the sites, as was clearly demonstrated by the Rural Life in Protohistoric Italy project. ${ }^{182}$ Temporarily or permanently invisible sites must be allowed for when calculating settlement patterns and demographic levels. Clearly some small sites are permanently lost through erosion, burial, sea-level changes and human destruction. In dune areas, as noted earlier, shifting sand covers and reveal sites, even over a few years. ${ }^{183}$

Projects are currently evaluating the relationship between their intensive survey data and that from older, usually extensive surveys and topographic reports, as well as excavations and chance finds. Disregarding all but the clearest indications of sites in older reports removes potentiallyuseful information. Since surveys only cover a small percentage of any landscape, the intensive windows become a possibly small, unrepresentative sample. A thorough critique of such legacy data remains fundamental, as the evidential basis for these older site records is often very thin. In a comparative study of surveys on Crete, Gkiasta found that site maps prepared after extensive surveys had mixed extensive sherd scatters with chance finds or even a single sherd. ${ }^{184}$ Similarly Farinetti, preparing an archaeological gazetteer of the Greek province of Boeotia, categorised all sites in terms of the level of evidence reported, and often found minimal levels of justification. ${ }^{185}$

Revisits to legacy sites, with the aim of confirming previous interpretations and where possible adding new information, are a normal part of any regional archaeological survey, but have met with mixed success. The evidence of past activity noted in the legacy records may no longer be present, or visible, for many reasons. A relevant case study was carried out by Attema in the coastal area of the Pontine region, where it was calculated that $60 \%$ of sites documented in the 1970s had disappeared by 2005 due to urban expansion, relief-levelling for mechanised agriculture, and the aforementioned fluctuation in surface site appearance. ${ }^{186}$ Attempts by Van Leusen to identify legacy sites in the Lepini mountains in central Italy, and the Sibaritide plain in south Italy, were often inconclusive because the location of the legacy site could not be determined with enough precision, or was shown to be incorrect. ${ }^{187}$

\subsection{Good practice in the artefact-based survey and sampling of small rural sites and complex rural and urban sites}

Site-based, as opposed to landscape-based, survey designs must achieve feasible goals, that is, the design must balance the scientific goals with the pragmatic limitations imposed by the available resources (time, money, specialist knowledge). The main parameters to consider are site size, site structure, finds density, land use/land cover, and topography. The main thing here is to be explicit about your site definition, and to allow for the possibility that some sites may not be recognised in the field but only later during analysis of the data. The latter requirement argues for the use of survey units that are smaller than the modal expected site size (i.e. have a spatial resolution of no more than $25 \mathrm{~m}$ ), or for the recording of individual find locations.

Once a site area has been defined, the potential for internal structure must be evaluated. In the smallest single-period scatters encountered by surveyors - perhaps only a few meters in diameter

\footnotetext{
181 Waagen 2014.

182 De Neef 2016. Contra Cavanagh 2004 "What you see is what you get".

183 Bar-Yosef and Goren 1980; Ammerman et al. 2013.

184 Gkiasta 2008.

185 Farinetti 2011.

186 Attema et al. 2008; Attema, De Haas et al. 2010a; Tol 2012: 52.

187 Van Leusen 2010; Van Leusen and Ryan 2001.
} 
- the potential for internal structure is virtually absent, and the amount of material is so small that a 'total' collection (if not always advisable for other reasons) presents no problems. By contrast, large, complex (e.g. urban) sites require both a sampling approach (as the amount and weight of material is far beyond what could be studied) and a consideration of the size and position of the spatial units into which it should be divided. Thus, topography and structural remains that are either visible in the field or detected by other means (cf. section 3) should generate hypotheses regarding the possibly different activities that might have been ongoing in different parts of the site, and current and historical land use/land cover should determine the resolution of the survey: for example, if unploughed, much less 'smearing' of surface finds is likely to have occurred, so more of the original structure in the surface scatter might still be detectable. To deal with overwhelming amounts of surface material, various sampling strategies may be applied depending on what it is that the survey director intends to achieve. If a quantitative comparison between all of the survey units covering the site is desired, with no distinction between finds classes, then the sample design can focus on obtaining a random sample of a given size from each survey unit; if the main goal is to detect functional or chronological differences between units, a more 'diagnostic' approach should be taken.

No matter whether we are dealing with off-site, 'background', scatters, simple small or complex large sites, the survey intensity (time and effort expended per area covered) is the parameter that determines both how much area can be covered, and how large the effect of visibility biases is likely to be. The probability that unobtrusive find types (chronological phases) and small or low-density finds scatters will be detected rises with greater intensity, and the intensity can be increased by reducing the walker interval (increasing the coverage), the walker speed (improving the detection of small and unobtrusive finds), or (at a pinch) the walker's stance (crouching and even on-yourknees surveys having been tried out).

\section{Integration of artefact-based surveys with other approaches to the archaeological landscape}

In this section we focus on complementary approaches to ground-based artefact survey to the mapping of archaeological landscapes. Aerial photography, traditionally an effective tool to map larger scale features in the landscape, is now supplemented by a range of high-resolution remote sensing techniques at all scales, from satellites to drones. On the ground, geophysical prospection methods offer the possibility to detect subsurface archaeological features, but also natural features, that can be correlated with the surface artefact record, enhancing the interpretation of both. As mentioned earlier, the integration of surface survey with the study of the palaeoenvironment, of slope processes and other aspects of geoarchaeology leads to a greater understanding of the gaps in our data. Finally we discuss survey in relation to the recording of field systems and still standing buildings.

\subsection{Remote sensing}

Active and often oblique low altitude aerial photography of the archaeological landscape has a major role to play in survey, allowing an appreciation of a site's size and its relation to roads, field systems, geomorphological features etc. ${ }^{188}$ Flying over the same landscape at different moments of the year, under changing visibility conditions, detects a wider range of sites and features. The Aerial Photographic Archive of the Middle East (APAAME) initiated by David Kennedy is an excellent example of the worth of aerial photography for archaeology. Repeated revisits in different seasons and weather conditions provide a wealth of information on archaeological sites, their environmental setting and state of preservation. ${ }^{189}$ In the Potenza Valley, integration of aerial

\footnotetext{
188 Bourgeois and Meganck 2005; Barber 2011; Vermeulen 2013.

189 www.apaame.org
} 


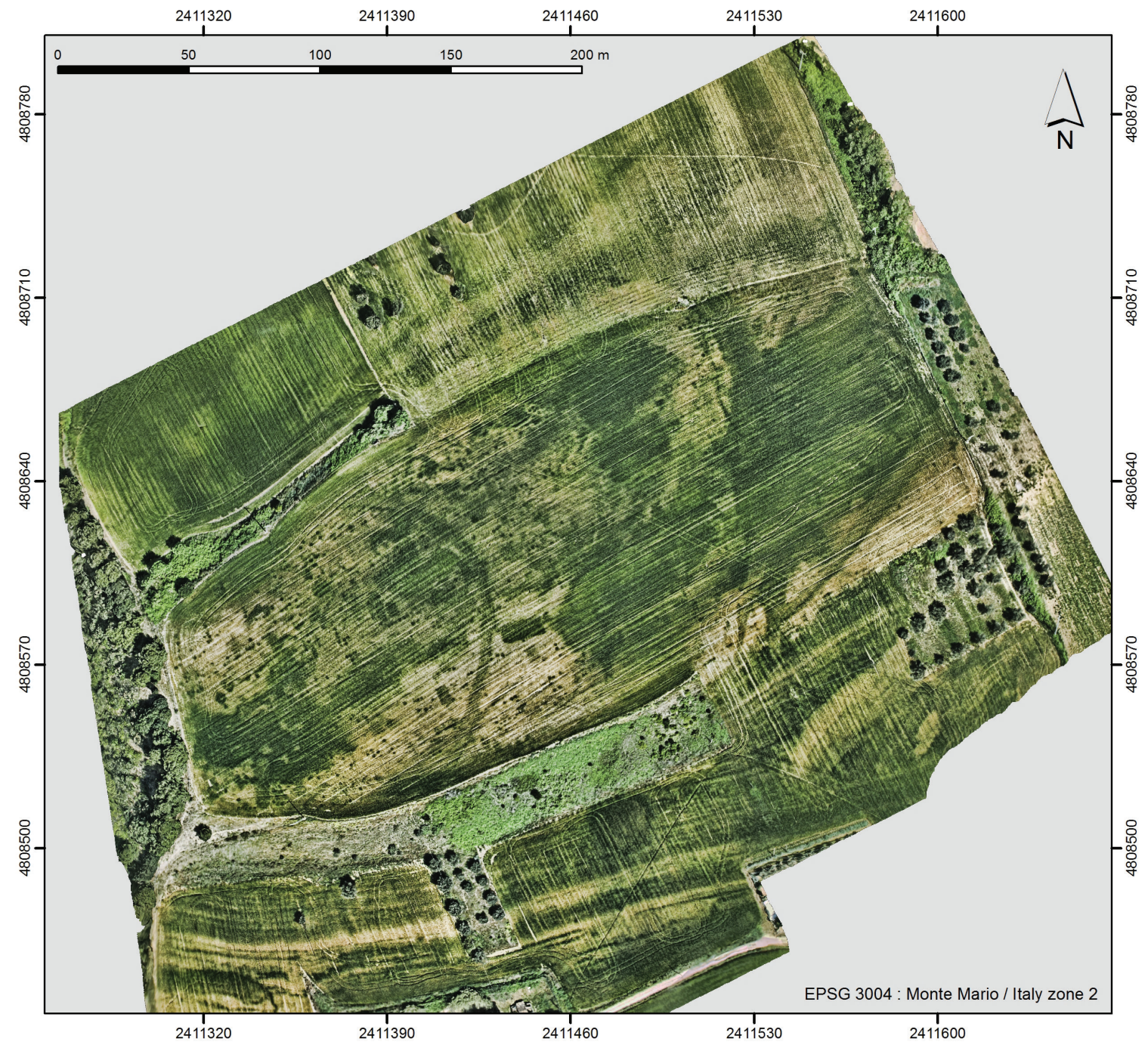

Figure 13. Enhanced orthophoto, based on oblique aerial photography, of the site of Montarice (Marche, Italy) with many crop marks, mostly belonging to an Iron Age village-type of settlement discovered within the Potenza valley Survey project (Vermeulen et al. 2017).

prospection with artefact surveys teaches that both approaches complement each other, notably for protohistoric sites with minimal surface architecture (Figure 13). ${ }^{190}$ Similar results were obtained in Spain (Figure 14). ${ }^{191}$ Alternative devices to planes (kites, balloons, drones) currently are being used to gather aerial imagery, combining speed, image quality and low-cost, and now adding near-infrared and LiDAR (Light Detection and Ranging) to their capabilities. ${ }^{192}$ The use of inexpensive drones to create medium-altitude images of survey sites from some $100-150 \mathrm{~m}$ altitude is an invaluable tool for highlighting locational decisions, ${ }^{193}$ but experiments with very low altitude drones to record surface ceramic densities (e.g. $3 \mathrm{~m}$ ) raise legal difficulties and risk missing fine detail of diverse ceramic spreads of varying age and visibility. ${ }^{194}$

It is important for recording land use changes over time, to access historical cartography in pre remote sensing times, to understand modified geomorphology and allow the 'restitution' of the surface record to changed or even vanished landforms. Historical photographs (e.g. the excellent

\footnotetext{
190 Vermeulen 2016b; Vermeulen et al. 2017.

191 Garcia Sanchez and Carmona Ballestero 2017.

192 Forte and Campana 2016.

193 Bintliff 2019.

194 Orengo and Garcia-Molsosa 2019.
} 


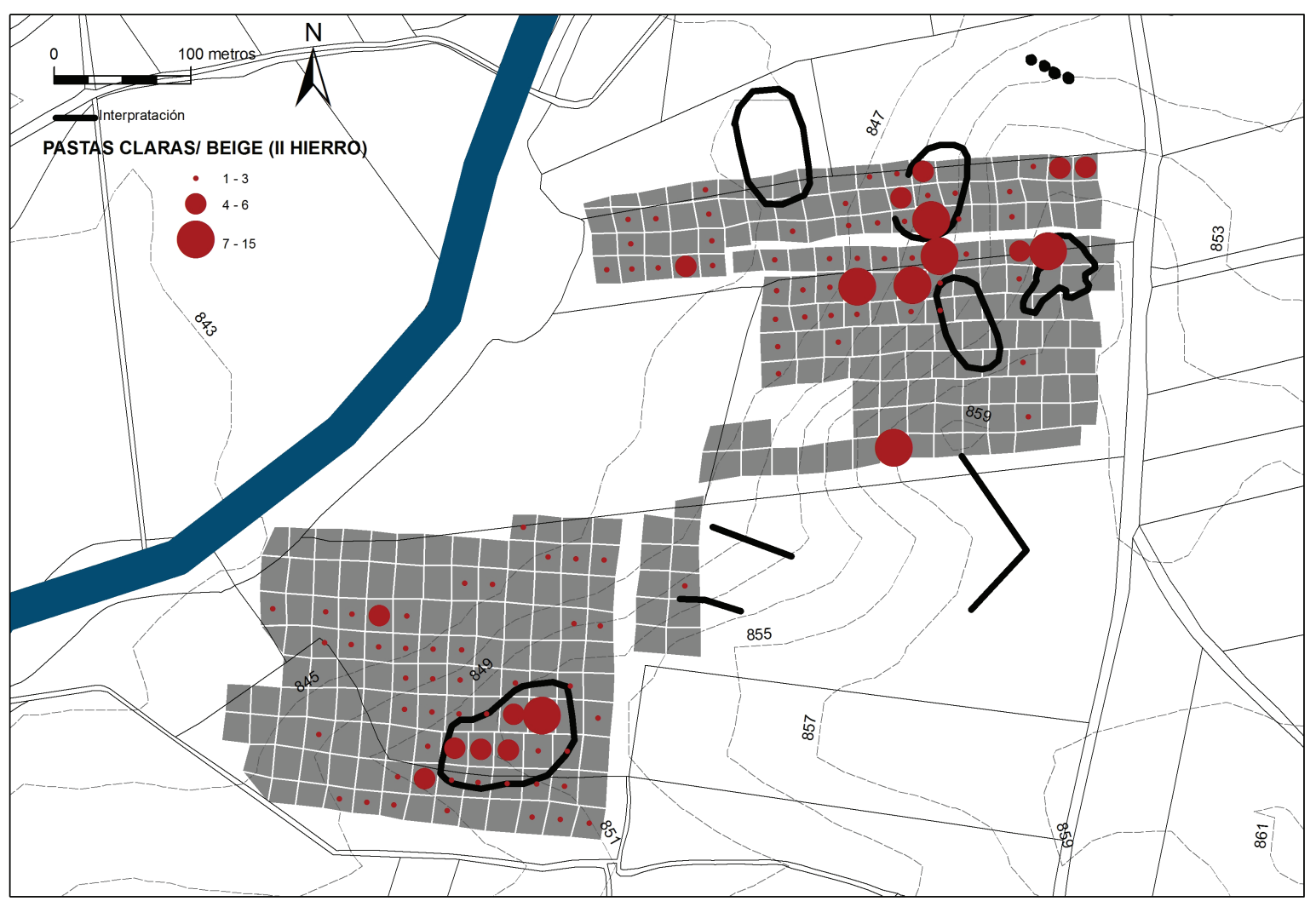

Figure 14. Distribution of beige fabric over the Iron Age dump area and settlement of El Espinillo (Villadiego, Burgos, Spain). In grey: survey grids of $20 \mathrm{~m}$ by $20 \mathrm{~m}$. In black: aerial photography interpretation of features associated with the site (García Sánchez and Carmona Ballestero 2017: fig. 12).

Second World War imagery), as well as widely available, high-resolution views from Google Maps or Bing Maps, are useful in regions where aerial archaeology flights have seldom been achieved. ${ }^{195}$ Corona satellite photographs taken in the 1960s offer perspectives in the Near East on landscapes prior to the massive development of the post-1960s (e.g. the Euphrates Valley). ${ }^{196}$ The visibility of surface sites in the form of soil discolouration and sherd scatters varies greatly according to climate, vegetation and geomorphology, but remote sensing can yield spectacular results in arid terrains. ${ }^{197}$ 'Groundtruthing' by inspection of potential sites is required to accurately evaluate the remote signals, however, and achieve chronological attribution. In the Guadiana Valley, Spain, the USAF 1956 and other photogrammetric flights were used to quantify terrain modifications produced by intensive agriculture and changes of the river course, helping to understand how sites and off-site distributions were affected and to explain empty areas or surface exposure of finds. ${ }^{198}$ Some surveys are now being carried out entirely on this basis where political conditions require (large areas of the Near East).

LiDAR has been popular since the start of the 21st century, mostly for detecting archaeological features located in inaccessible terrains or covered by dense vegetation, ${ }^{199}$ but increasingly used for analysing survey results. ${ }^{200}$ In southwestern Spain, LiDAR allowed teams to penetrate nonploughed terrains to detect Roman rural sites and medieval field systems. ${ }^{201}$ In the Italian Matese mountains, field survey aided by a LiDAR-derived DEM (digital elevation model) and intra-site

\footnotetext{
195 Vermeulen 2013.

196 Pournelle 2007.

197 E.g. Philip et al. 2005.

198 Pérez Alvarez et al. 2013.

199 Opitz 2016.

200 Ainsworth et al. 2013.

201 Parini et al. forthcoming.
} 
sampling survey has been applied to a Samnite fortification. ${ }^{202}$ At an intra-site level, Grau Mira used LiDAR visualisations to interpret Iron Age settlements in the southeast of Spain. ${ }^{203}$ In the heavily-wooded peninsula of Istria in Croatia, LiDAR has allowed an entire Roman centuriated landscape to be discovered. ${ }^{204}$

\subsection{Geophysical survey}

Since the 1980s, we observe the revolutionary impact of multiple, swift geophysical techniques to sites of all sizes. ${ }^{205}$ Since magnetic survey detects most types of archaeological features, other geophysical survey techniques are less commonly applied, being more time consuming and expensive. However, feature detection through multiple parameters enhances interpretation, while DGPS equipped multi-instrument platforms and towed arrays allow rapid collection of more extensive but also higher resolution geophysical datasets. Total survey of large, complex sites requires all relevant geophysical approaches: geomagnetic survey, earth resistance prospections and georadar survey. Examples of terrain modelling, geomagnetism and localised excavation, are at the Roman urban site of Ammaia, Portugal (Figure 15) and the Roman town of Mariana, Corsica (Figure 16). ${ }^{206}$

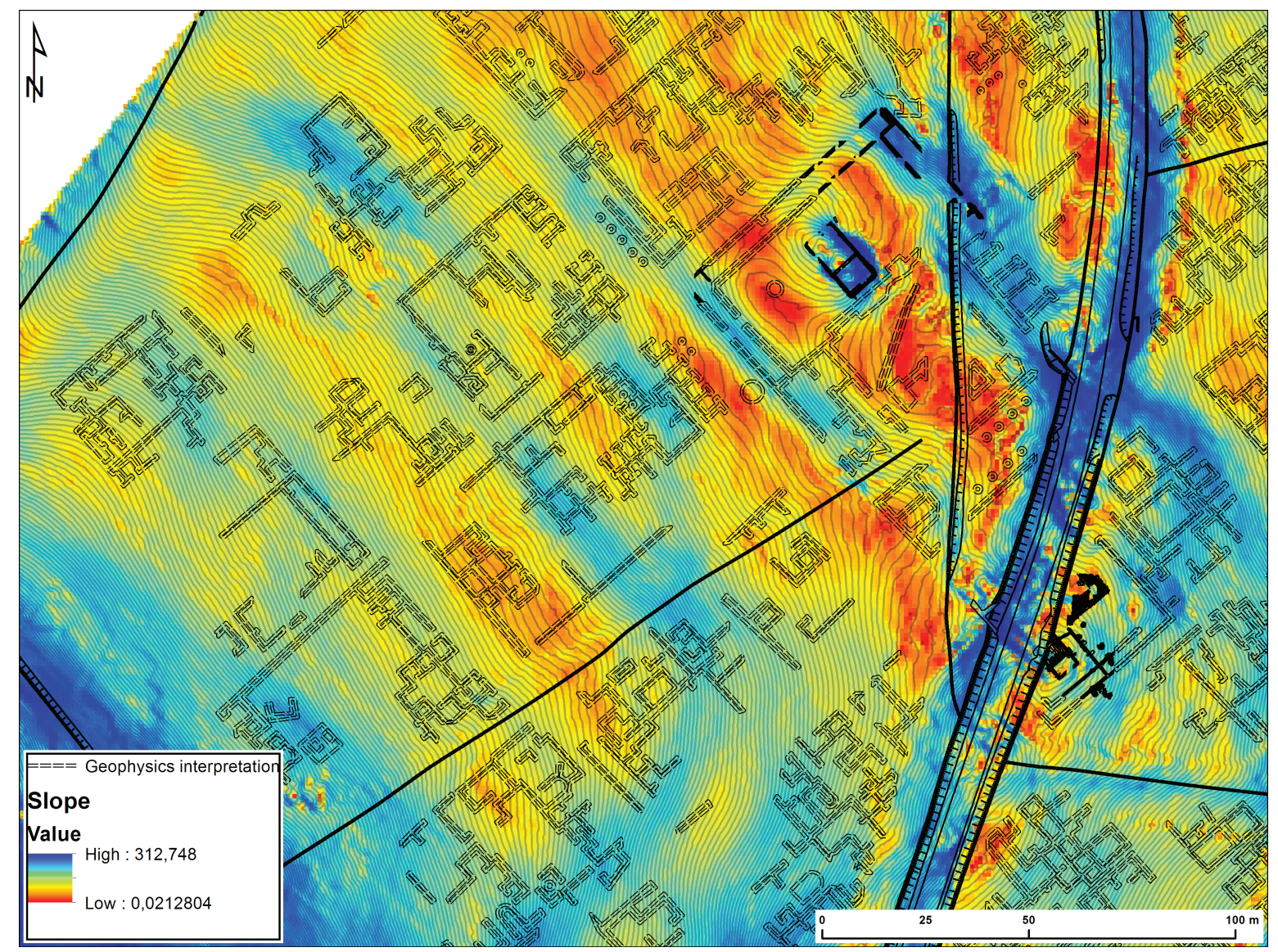

Figure 15. Integrating a Digital Terrain Model, obtained with total station and Differential GPS instruments, and interpreted data from geomagnetic prospections and point excavations in the central area of the urban site of Ammaia (Alentejo, Portugal) (after Vermeulen 2016a, elaboration E. Paliou).

\footnotetext{
202 García Sánchez and Termeer forthcoming.

203 Grau Mira 2017.

204 Popovic, Bulic et al. in press

205 For overviews cf. Corsi et al. 2013; Sarris 2015.

206 Vermeulen 2016a; Vermeulen et al. 2017.
} 

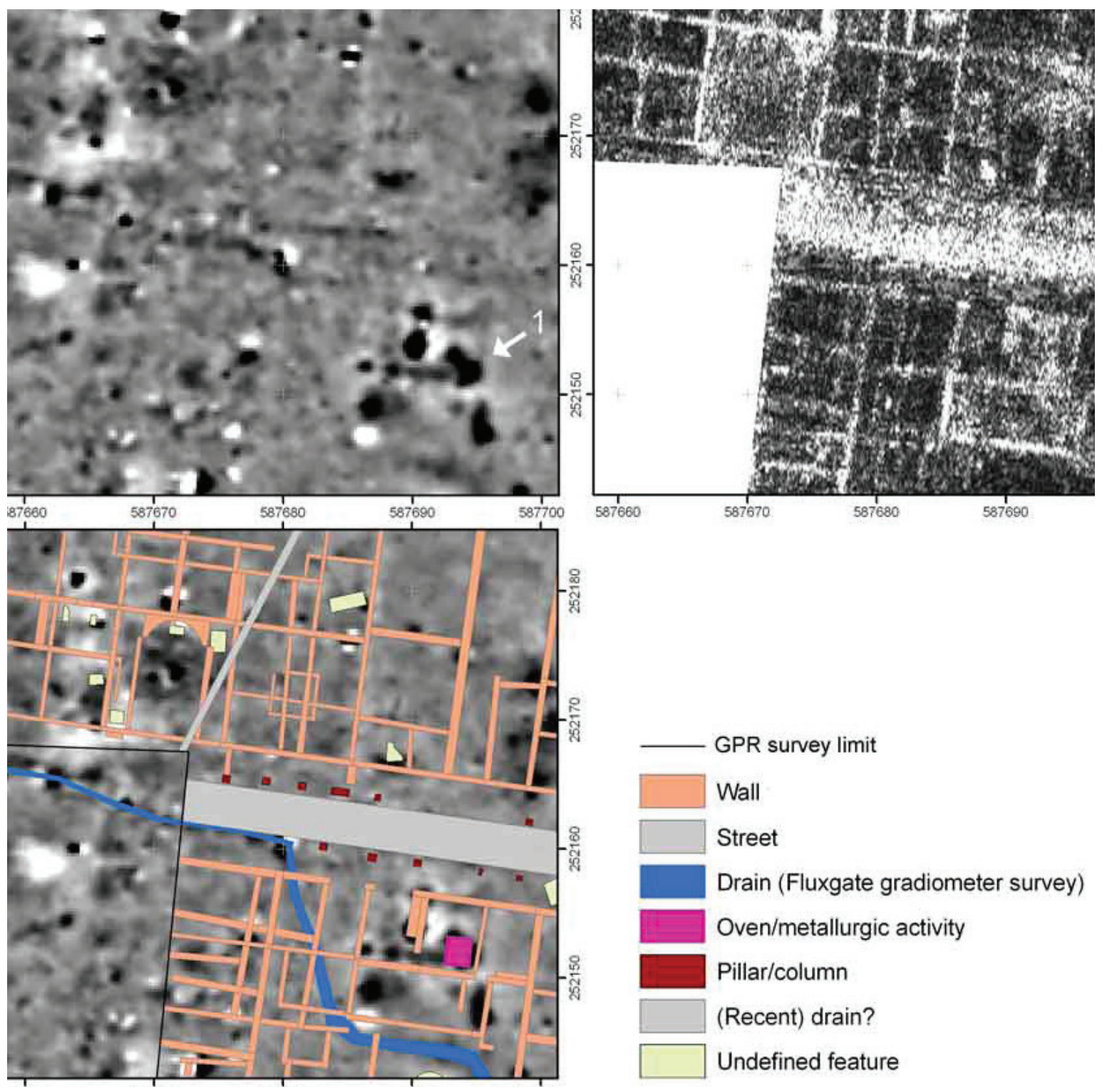

Figure 16. Integration of GPR (Georadar) (right) and geomagnetic (left) prospection imagery allowed advanced interpretation of the buried evidence of a probable metallurgic workshop and a porticoed street at the Roman town site of Mariana (Corsica, France) (after Vermeulen 2016a, elaboration L. Verdonck).

The recurrent problem of the suburbs of large complex sites, where they begin and end, and what activities went on inside them, can also be addressed through geophysics. At the ancient city of Tanagra in Greece, massive extramural manuring for kilometres from the standing city walls obscures the specifics of activities immediately beyond the standing urban enceinte through the study of surface finds. Large-scale geophysical survey revealed that the current wall line is of Late Antiquity, whereas the earlier Greek town was one-and-a-half times larger, since both housing blocks and an earlier town wall could be identified. ${ }^{207}$

Recent large-scale geophysics shows that off-site features are preserved in rural areas, invisible to pedestrian surveys: canals, centuriation, pits and other structures without ceramic or stone building material. ${ }^{208}$ In landscapes of extensive plains and large fields, geophysical survey now performs over several contiguous square kilometres, deploying vehicular arrays, as with Italian

207 Bintliff et al. 2013; Meyer et al. 2017.

208 Tol et al. 2014. 
projects in the Po Valley and Tuscany; entire landscapes of fossil watercourses, field systems and sites are revealed. ${ }^{209}$ Moreover, concerning 'hidden landscapes' leaving only vestigial artefact scatters, remote sensing can now tie these to subsurface structures. ${ }^{210}$

However, geophysics is not a straightforward shortcut to evaluate sites where excavation evidence is poor to non-existent. These approaches have varied success dependent on the geology, land use and nature of sites, and even when plans are well-exposed, multi-period sites pose serious problems in disentangling structural remains by date. The most impressive results derive from single period plans rather than multi-period settlements.

\subsection{Geoarchaeological approaches}

The regional character of survey data make them very suitable for integration and comparison with palaeoenvironmental data, such as palynological and geomorphological studies. This not only helps us evaluate and understand the environmental basis of the cultural patterns emerging from our surveys; it also helps us understand the biases introduced in our dataset by natural landscape processes and past and anthropogenic actions.

Modern land evaluation according to FAO rules, combined with palaeogeographical reconstructions based on extensive geoarchaeological studies, can be used to evaluate the suitability of past landscapes for various agricultural uses, but if we combine it with the geological concept of 'erosion response units' we can also use it to evaluate the processes affecting the integrity and visibility of the surface archaeological record over time. In the Pontine Region, Italy, the combined survey, pedological and palynological research has led to a model of land evaluation by archaeological phase and types of land use from prehistory to Late Antiquity, ${ }^{211}$ while geoarchaeological research has led to a better understanding of biases in the surface record caused by erosion and sedimentation. ${ }^{212}$ These results could not have been attained by any of the disciplines in isolation. A similar multidisciplinary approach was taken in southwestern Turkey by the Sagalassos project, where geomorphologists, geologists, palynologists and archaeologists worked together. ${ }^{213}$ For remoter periods, notably in the pre-Holocene era, contemporary surface deposits may only survive as residual palimpsests, so that Palaeolithic survey may benefit by targeting presently-accessible palaeosols and other geomorphic surfaces identified by geomorphologists as belonging to this vast period. ${ }^{214}$

In all cases, the first step in evaluating the effects of the physical landscape on the presence and detectability of the cultural materials on its surface consists of landscape classification. ${ }^{215}$ This is a systematic segmentation of the study area into geomorphological units, each with its own set of relevant past and surface processes, soil types, and land use history, that allows us to evaluate both its suitability for past land use and the likely state of preservation and visibility of the archaeological surface record. Rather than focusing on a single landscape unit or process as has been typical of many otherwise excellent geoarchaeological studies in the past, this approach systematically evaluates all of the study area, including identifying units where further research is needed to make the evaluation possible. Tony Wilkinson usefully borrowed Christopher Taylor's concept of 'landscapes of survival and landscapes of destruction' to offer generalisations on the differential visibility of surface archaeology across the Near East. ${ }^{216}$

\footnotetext{
${ }^{209}$ Campana 2011a, 2011b, 2016, 2017

210 Campana 2017; De Neef 2016.

211 Kamermans 2004; Van Joolen 2003; cf. Chapman et al. 1996 for a Croatian parallel.

212 Feiken 2014; see Attema 2016 for a more general view on sedimentation as a geomorphological bias in survey of the coastal plains of Italy.

213 Dusar et al. 2012; Bakker et al. 2012; Dirix et al. 2013.

214 E.g. Tourloukis 2011.

215 Feiken 2014; Van Leusen and Feiken 2007.

216 Wilkinson 2004.
} 


\subsection{Survey and field systems}

The widespread creation of regular field grids by Greek, Roman and later state-societies to publicly apportion land (especially after drainage or state-sponsored colonisation), has long been visible from air photographs and can be checked through field survey. ${ }^{217}$ In the centuriated territory of Pisa with considerable continuity of use since Antiquity, place names derived from Roman roads and milestones link aerial photos and surface survey to pre-modern roads and settlement foci such as Roman road-stations. ${ }^{218}$

Recent European heritage initiatives encourage retaining historic field systems. ${ }^{219}$ Characterising them by phase offers a new framework for associated surface artefacts. On Naxos, Greece, mapping field systems of different age was successfully combined with ceramic survey and historic church survey. ${ }^{220}$ Roman field systems in France and Spain are being analysed through field survey and palaeoenvironmental records. ${ }^{221}$ In the Negev, aerial photography has documented run-off irrigation systems, ${ }^{222}$ while the OSL technique can now date the accumulated sediments tied to canals and terraces ${ }^{223}$ and attest the presence of water-logged conditions, thereby positively identifying run-off irrigation between $1000 \mathrm{BC}$ and $\mathrm{AD} 1000 .{ }^{224}$

In this context it is also worth mentioning the potential of combining LiDAR data (see infra) with historical air photography, to map spaces that by mid-20th century were still cultivated, but today completely abandoned, but where extensive systems of terraces, stone boundaries and many other rural facilities survive.

\subsection{Survey and standing buildings}

Mediterranean landscapes are bristling with pre-modern fortifications; 225 early topographers focussed on these recognisable signs of ancient places. Their recording preceded artefact survey by a century, but generally styles were dated either by a 'rough to sophisticated' typology, or by reference to historical events. The rise of GIS, GPS, photogrammetry, laser-documentation and other digital tools has given new impetus to recording standing architecture. Excavation and critical analysis of previous assumptions have made clear that 'Archaic' walls may be a deliberate ornament or a reconnection to mythical pasts, indeed can be contemporary to 'advanced' and 'sophisticated' geometric shapes. ${ }^{226}$

More complex to analyse are the ubiquitous cut-stones from public and domestic structures, or burial monuments; the vast majority lack architectural pretension and till recently in the Northern and Western Mediterranean rarely received attention. However in North Africa and the Levant the Segermes, Thugga, Kasserine, Libyan Valleys, and Wadi Faynan survey reports recorded a 'fossilised agricultural landscape ${ }^{227}$ where houses can be planned from the surface. Light, mobile Differential GPS devices can send three-dimensional point data up to $7 \mathrm{~km}$ to a base station, rapidly locating all blocks shaped artificially, while digital photos document scaled dimensions, linked to descriptions

\footnotetext{
217 Bradford 1957; Caillemer and Chevallier 1959; Clavel-Lévêque and Tirologos 1998, 2002; Pasquinucci 2013.

218 Pasquinucci and Ceccarelli Lemut 1991; Marchisio et al. 2000: 234 and fig. 23.3.

219 Fairclough and Rippon 2002.

220 Crow et al. 2011.

221 Palet and Orengo 2011.

222 E.g. Kedar 1967.

223 Avni et al. 2012.

224 Bruins and Van der Plicht 2017.

225 For an overview of current methodology for studying ancient fortifications, and the interpretative possibilities see Frederiksen et al. 2016; Muth et al. 2016.

226 E.g. at Haliartos, Greece: Donnellan et al. in prep.

227 Hitchner 1995: 133.
} 


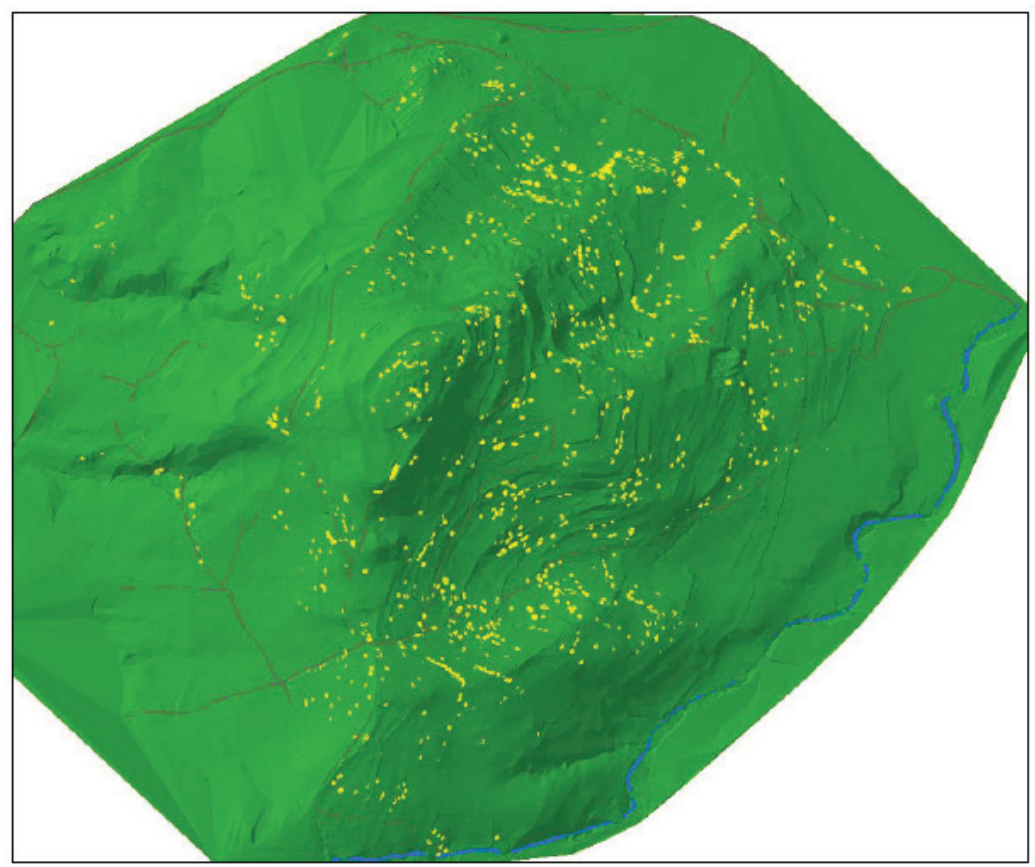

Figure 17. Plot of more than 2000 cut stone blocks on the DEM for the ancient city of Koroneia (Y. Boswinkel, B. Noordervliet and J. van Zwienen).

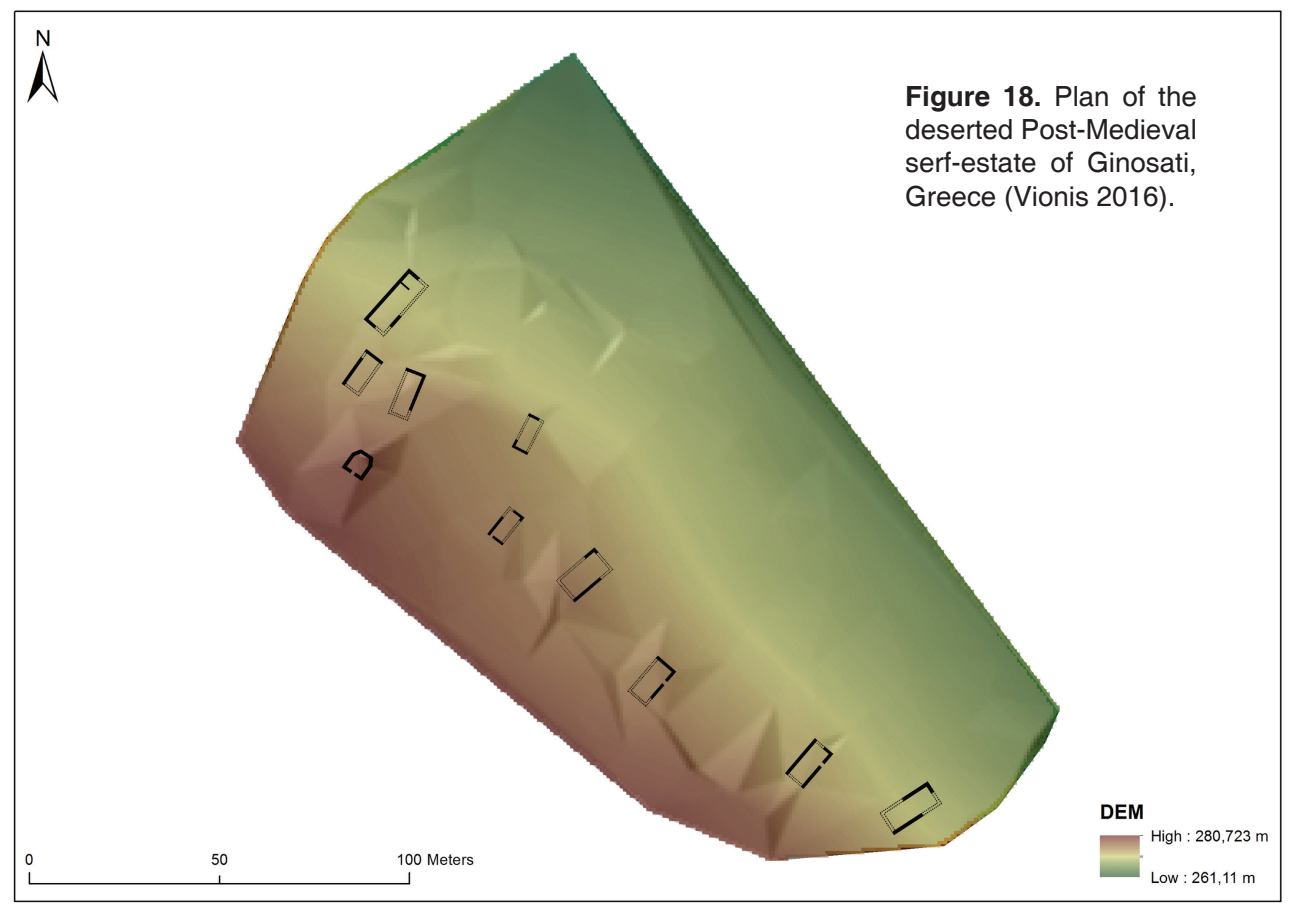

on palmtop devices. At ancient Koroneia city, Greece, over 2000 cut blocks were recorded and integrated into artefactual evidence for the urban infrastructure (Figure 17). ${ }^{228}$

Less obvious is the link between Medieval to modern vernacular architecture, the study of private domestic buildings, and surface survey. Deserted villages from the 14th to the 19th centuries AD reveal surface ceramics for reconstructing village life, but also house foundations. They frequently resemble rare surviving buildings in contemporary villages where they are rapidly being replaced by modern alternatives. Sub-projects can document these traditional structures, including virtual reality reconstruction, in parallel to their recording as ruins on deserted settlements (Figure 18).229

\footnotetext{
228 Boswinkel 2015; Bintliff et al. 2016.

229 Sigalos 2004; Piccoli 2012; Bintliff 2012b: chap. 21 and 22; Vionis 2016.
} 
Ethnohistoric and tax-census accounts can provide many details of the associated lifestyle and material culture in such dwellings. ${ }^{230}$

\subsection{Good practice in integrating artefact-based surveys with other approaches to the archaeological landscape}

It goes without saying that the integration of artefact-based survey data with remote sensing, geophysical, geomorphological, and topographic data is best achieved in a GIS environment, but this presupposes that all data can be brought into a single map projection and coordinate system and has comparable precisions (scales) and resolutions (detail). Careful management of these aspects is therefore needed when collating these disparate datasets, especially when highresolution comparisons and analyses are intended. ${ }^{231}$ 'Ready-made' geodata from Google or Bing Maps are a very important resource in the design and conduct of field surveys, and a potential source for crop- and soil marks visible (sometimes after simple image enhancement) in aerial photographs. This is further enhanced by the 'historical' feature that offers photos of the area of interest in different years, seasons and stages of crop growth. Satellite and airborne remote sensing data, including historical airphotos, obtained straight from the source (nowadays, often a national or regional geoportal), if of sufficiently high resolution, can often add important new information about the state of the landscape in the mid-20th century, before it was substantially altered by recent development. However, historical airphotos will need to be digitised and adequately georeferenced before they can be integrated, enhanced and interpreted in the GIS.

The integration of geophysical work is fast becoming easier, as modern equipment produces high-quality georeferenced datasets, but generating those data is relatively costly because of the specialist work and expensive equipment involved. As noted above, the interpretation of geophysical anomalies is not a trivial matter, nor is the correlation of geophysical anomalies with other types of evidence such as surface artefact patterns and soil marks; this is a field that needs greater attention in the future.

The integration of earth science data and the results of palaeoenvironmental studies into a GIS environment poses some new technical challenges that have not been explored yet. The introduction of a third (vertical) dimension with, e.g., soil coring data and erosion/deposition simulations flags up the problems that current GIS have with true 3D data (that is, volumes), and the point-based character of many palaeoenvironmental studies introduces mapping uncertainties. For example, we use pollen cores to reconstruct vegetation types for various past periods, but there is no systematic way in which we can then place those vegetation types on the map of that period.

One growing aspect that appears to us as retrograde is the use of online databases to undertake major parts of, or even complete landscape and settlement studies without personal fieldwork at an intensive level. Available geology maps, soil maps and other published databases lack the necessary refinement at rural site level, and for the 'site catchment' radius of land utilisation, are very frequently just incorrect, as most surveyors will have observed when comparing these sources at specific locations. Site locations can only be reliably investigated through careful mapping of the terrain in the field, ground-truthing online information in every detail. 'Learning with your feet' is essential, and this is how past occupants of your landscape settled and utilised their world.

\section{Laboratory artefactual study}

Permits for field survey in some Mediterranean countries may restrict a team to recording in the field rather than collecting finds for laboratory study. This has become a feature of some Greek

\footnotetext{
230 Kiel 1990, 1997; Karidis and Kiel 2002.

231 Armstrong and Van Leusen 2012.
} 
survey projects and throughout Turkey. Surveyors have responded by studying finds merely on the fields concerned, even photographing diagnostic pieces. The enforced reliance on field recording for the vast majority of finds has even encouraged a shortcut, the 'chronotype' to be operated even where site collection is permitted (where just one piece of each diagnostic type-sherd is registered and not its numerical occurrence). ${ }^{232}$ This approach has now been extended to surveys where collection limitations do not operate. ${ }^{233}$ We do not consider it possible to provide artefact study to modern scientific standards without significant numbers brought back to base, washed and analysed with care, and with reference collections, fabric series and textbooks to hand.

In most Mediterranean landscapes with normal soil development, surface material represents a minority of the finds within surface horizons, as field experiments have shown. ${ }^{234}$ However in semi-desert environments, notably with small pre-modern encampments, intensive collection may denude the site significantly. ${ }^{235}$ One could collect everything to create the most complete documentation, or collect the minimum for identification of periods of occupation, but leave material for future reference. Revisits are a common solution to clarify the picture emerging from laboratory analysis of the finds, especially for the minor periods represented at a site, which may only emerge at that post-sampling stage.

\subsection{Ceramic collections}

Survey pottery allows us to interpret at chronological and geographical resolutions that excavation cannot match.

Basic parameters. Fabric, shape and surface treatment/decoration form the basics for classifying and understanding pottery. Peacock's methodology for describing fabrics offers a useful hands-on approach. ${ }^{236}$ Pincers (for a fresh break), a good hand lens and a USB microscope, are affordable tools to capture the essential data. The Boeotia Project profits immensely from a reference collection begun 15 years ago, growing ever since, which revolves around fabric and shape. The Pontine Region Project in the late 1990s developed a regional fabric classification to date survey pottery more securely, thereby departing from the restricted, stratigraphically-anchored excavated materials from the site of Satricum. ${ }^{237}$ Recent work has elongated this classification into the Roman period. ${ }^{238}$ The deployment of fabric classes has allowed the principle of diagnosticity to extend well beyond the traditional reliance on shape, surface finish or decoration for dating and sourcing ceramics.

What to study, and how? Diagnostic fragments, traditionally the rim, base and/or handle(s), undoubtedly comprise the core material with which to enter the fields of chronology, typology and provenance, but for many categories of more commonly encountered vessels these constitute only a small part of a vessel. Body sherds, undecorated/untreated and decorated/treated, can nonetheless add significant information, for example, currents in exchange and style that are not represented among the diagnostic material. Fabric analysis should be an essential component to distinguish function (e.g, between cooking and storage wares). Extremely helpful is the manual published by the ACSG (the Ancient Ceramics Studies Group). ${ }^{239}$ This manual (A Standard for Pottery Assemblages in Archaeology) details methodological and interpretive approaches for the study of ancient pottery.

\footnotetext{
${ }^{232}$ Caraher et al. 2006.

${ }^{233}$ Caraher et al. 2014.

${ }^{234}$ Reynolds 1982; Bintliff and Snodgrass 1988a.

${ }^{235}$ E.g. Rosen 1993b, 1994.

236 Peacock 1977.

237 Attema and Van Oortmerssen 1997; Attema et al. 2003.

${ }^{238}$ Borgers and Tol 2016; Borgers et al. 2016.

239 The publication is downloadable from https://medievalceramics.wordpress.com/a-standard-for-pottery-studies-in-archaeology/
} 
Research foci. Beyond the classificatory stage: what knowledge do we wish to extract? First, chronology remains a prime focus. Without understanding the chronological nature of the pottery, we simply would not, or much less, understand settlement and landscape change and continuity. Published typologies and related literature of course are essential guides here. Second, shape, which combined with fabric and/or decoration potentially informs us about function, in turn assisting in understanding the character of areas or sites in terms of functional zoning. Determining the (potential) provenance through fabric and shape situates a site or region with regard to manufacture and exchange on local, regional and/or supra-regional scales, and how these aspects also may have fluctuated over time. In turn, the resultant knowledge can form the basis for larger intra- and interregional, diachronic comparative exercises. ${ }^{240}$

What next? Despite increasing efforts in improving the methodology, for now we should accept a greater proportion of unidentifiable material in comparison to excavation archaeology. Projects, however, greatly benefit from returning to their stored material at a later stage, because of the idea of progressive insight, especially relevant for long-running projects. The toolkit of those working in the field will undoubtedly increase, with devices and apparatus becoming smaller and easier to transport (e.g. portable XRF-readers).

\subsection{Lithic collections}

With surface lithics on intensive survey, the nature of the site and pre-determined goals of the survey are central. Materials disturbed by ploughing represent a fraction of material in situ. ${ }^{241}$ Intensive sampling of all lithic materials (debris, debitage, and tools) offers better appreciation of technology, a better reflection of actual lithic activities, and better collection of fossil indices for dating. Given that most surveyors have little understanding of lithic assemblages, a non-selective process reduces the chances of biases in collection caused by the 'pretty piece' syndrome. ${ }^{242}$

For small surface sites intensive partial collection can seriously impact the original assemblage. For surveys where the focus is site chronology, minimal collection of diagnostic artefacts is preferable. However, given that most surveyors will not be sufficiently acquainted with lithic types to identify diagnostics, intensive photography of numerous artefacts (now possible with digital cameras) offers a partial solution, boosting the sample collected where helpful. Ideally, intensive collection of the entire in situ surface assemblage, one not disturbed by ploughing, by scraping the surface to $5-10 \mathrm{~cm}$ depth and sieving, ${ }^{243}$ essentially offers full comprehension of small sites (of the order of $\left.50 \mathrm{~m}^{2}\right)$.

\subsection{Good practice in the study of survey artefact collections}

The procedures followed in survey artefact studies should always ensure the integrity of the documentation, that is, they should never 'break' the link between the physical artefacts and their metadata established during the survey. This can be hard to achieve especially when finds specialists operate independently, and at different times, from the survey director. Protocols should therefore be in place that help prevent accidental loss of the 'origin' of the finds, and that ensure that storage records are kept up-to-date.

While for the classical periods certain ceramic wares are well studied, such as Greek and Roman finewares, and fragments found in survey can be dated in some cases fairly precisely using reference works, the bulk of survey ceramic is in the first instance non-diagnostic and needs to be studied

\footnotetext{
$\overline{240}$ Bes and Poblome 2017; Tol 2017.

241 Ammerman 1985.

242 Rosen 1997: 37.

243 Goring-Morris 1987.
} 
with the help of regional reference collections, if available, and specialist knowledge. It is therefore recommended in each survey project to build a reference collection of fabrics and wares right from the start and to include ceramic specialists in the survey team. Ceramic samples need to cover all fabric and ware groups that occur in the field from site and off-site contexts, and a relation must be established between diagnostic forms (rims, bases, handles) and body sherds to increase the chronological and functional value of the latter. The analysis of lithics needs a dedicated specialist. Careful documentation and publication of finds assemblages and individual sherds is imperative. Creating floating assemblages for fabric types, artefact and assemblage groups not reported previously, allows new phases and novel assemblage combinations to be created, with the aim of later tying them to chronological sequences or specific cultural behaviours.

\section{The search for wider interpretations of survey results}

The ultimate goal of intensive survey in the Mediterranean is to offer integrated insights into regional and interregional trends, and historical processes in the short-, medium- and long-term. ${ }^{244}$ The central interdisciplinary, historical issues to which Mediterranean Survey may significantly contribute are historical ecology, demography, economy, and the social complexity of past societies, all these at different spatial and temporal scales.

The rural sector is traditionally perceived as slow-changing, and non-receptive to higher level, socio-economic dynamics. Despite numerous theoretical and historical studies exploring the role of the countryside in ancient society and economy, and despite the number of regional projects carried out over recent decades, it is clear that survey archaeology has still much to contribute to this field. We assume that the organisation of settlement in the countryside (the settlement network and settlement types) must be closely related to contemporary agrarian and social relations. Changes in the relations, or the strategies, of production should be traceable in rural settlement patterns. A number of studies have addressed this topic, ${ }^{245}$ but survey archaeology must do more to enrich socio-economic or historical debates. It seems that the reasons behind this situation reside in fundamental problems which survey archaeologists face when interpreting the data gathered in the field: the difficulty of relating site types to social hierarchies and forms of land-ownership, of linking historical sources in the short-term to ceramic dates often spanning centuries or more, and the issue of distinguishing residential from seasonal and non-residential sites. Related issues: is one dealing with a villa or a hamlet or a cluster of dispersed peasant farms? Is a small farm an independent peasant, a sharecropper, or a serf or slave? Can surface finds detect any distinctions to guide us?

Studies of economic exchange and systems of production and distribution have long focused on long-distance trade, easily investigated through distribution patterns of well-known ceramic classes (e.g. finewares such as terra sigillata and African Red Slip, or Roman amphorae). With increasing knowledge of regional ceramics (particularly coarsewares), it is now possible to address such questions in more detail, allowing a fuller understanding of economic exchange and the integration of rural landscapes. Crucial in such work are detailed ceramic studies, which should combine typological and petrographic analyses of survey ceramics, linking evidence from production contexts with consumption contexts. ${ }^{246}$ Such research is now showing that on Roman Imperial rural sites, in even relatively remote parts of Roman Italy, a substantial proportion of the ceramics is imported, either from the wider region or from further away. ${ }^{247}$ This hints at the rather high degree of integration of rural areas in the Roman economy of Italy. ${ }^{248}$ In contrast in

\footnotetext{
244 Braudel 1972; Bintliff 1991; Horden and Purcell 1998; Bintliff 2012b; Broodbank 2013.

245 Alcock 1993; Cavanagh et al. 2002; Bintliff et al. 2007; De Haas et al. 2011.

246 Borgers and Tol 2016.

247 Menchelli 2012.

248 De Haas and Tol 2017.
} 
Greece, the majority of ceramics throughout Classical Antiquity are made within individual city landscapes or their wider region, with only a minority of imports from interregional commerce. ${ }^{249}$

For the Late Roman Mediterranean, survey archaeologists have underlined the astonishing proliferation of Late Roman eastern ceramics (c. AD 400-650). However Pettegrew, using Eastern Corinthia Survey data, has challenged whether immense amounts of amphorae and finewares reflect real population boom or heightened pottery visibility and diagnosticity. ${ }^{250}$ Nonetheless close-dating for the Middle to Late Roman era for widely-traded ceramics, allows sophisticated analyses of the varying access of provincial towns, villages, villas and farms to interregional trading systems. Peeters used survey assemblages to track African Red Slip tableware in different Central Greek city landscapes. ${ }^{251}$ Clear contrasts emerged regarding access to Late Roman commercial systems between individual cities, correlated with a greater or lesser import penetration into their rural hinterlands, and this changed significantly over the centuries.

Beyond deepening our understanding of prehistoric and ancient domestic life, survey reveals information for periods where traditional excavation has made only limited progress, for example rural life in the Ottoman Empire. Vionis studied everyday life on two Post-Medieval villages in Greece, the deserted hamlets of Panaya and Ginosati (see earlier Fig. 15), where standing remains of simple one-storey houses survived, in the latter case alongside the estate-manager's tower house (konak). ${ }^{252}$ Panaya, a large independent community of relative wealth, is mostly occupied from the Early Ottoman period, 15th to 16th century AD, showing a wide range of wares including many exotic imports. In contrast, the surface ceramics at the small serf-estate of Ginosati, mostly later, late 16th to 18th century $\mathrm{AD}$, were of rough quality, lacking exotic or expensive imports. The comparison from ceramics could be linked directly to the tax records where crop and animal production as well as other details of village wealth were carefully recorded. This study firstly documents the grass-roots effects of the decline of the Ottoman state from Early to Middle Imperial times, but also allows a general characterisation of the degree of access of rural peasants to longdistance products or alternatively their reliance on regional ceramic products, as well as their relative prosperity (developing ideas pioneered by Hugo Blake ${ }^{253}$ for Italian rural life using ceramic assemblages).

Archaeologists currently find themselves in a situation in which data are increasingly being delivered online. This 'data deluge' comes in many formats, from digitised archives and digital repositories, to newly scanned grey literature and legacy publications, to newly-born digital photographs, geophysical results and satellite imagery. ${ }^{254}$ This deluge is not so much a single event as a constantly expanding stream of material flowing onto the internet and making itself available for consultation. How does the intrepid researcher begin to tackle the 'big data revolution' that will no doubt form a key part of the future of archaeological survey?

An important reason for creating good practices in archaeological surface survey is to facilitate the aggregation of data from multiple projects so that combined datasets can be easily consulted and analysed simultaneously. It may sound overly optimistic to say, but big data should play to the strengths of survey archaeology. Field survey research has rarely been undertaken out of an interest in just one river valley, but in that valley as part of a larger society and economy. A logical corollary of this approach is that good practices for surveys need to be established so that important historical issues, such as standards of living and demographic trends, can be assessed comparatively through the aggregation of datasets. Likewise, archaeological questions concerning

\footnotetext{
249 Bes and Poblome 2017

250 Pettegrew 2007.

251 Peeters 2012; Peeters et al. forthcoming.

252 Vionis 2006, 2016.

253 Blake 1980.

254 Bevan 2015.
} 
the distribution of artefact types (not necessarily from a culture-historical perspective) are also tailor-made for big-data analyses.

While there is no single location for the deposit of data pertaining to Mediterranean surveys, our aim is to encourage researchers to share their data in easily accessible formats in places where other archaeologists will find them. These places include well-known locations designed for archaeologists (Archaeology Data Service, DANS-Easy, tDAR, and Open Context, ${ }^{255}$ in addition to resources linked to presses and academic web sites. University research repositories may be good locations for academic researchers to place their data, as they often entail far lower costs than commercially-available options. Whatever repository is chosen, the more critical decision concerns which data files are included and how they are formatted. Here, it is helpful to follow the guidelines of experienced services. ${ }^{256}$ These guidelines give clear advice about topics like file formats and metadata so that files are not only readable by other archaeologists, but also capable of integration with the results of many other projects. It goes without saying that while some of the greatest value of surveys lies in the possibility to aggregate their data, this aggregation will be useful only if data collection and publication are transparent, and permit datasets to be connected without great efforts.

Archaeologists conducting analyses of multi-project survey data sets face no easy task. Even when methodologies are clearly explained and metadata adequately demonstrate the steps taken from collection to data entry through analysis and publication, a number of problematic issues concerning the comparison of survey data have been well-considered elsewhere. ${ }^{257}$ The available data will undoubtedly be incomplete, leaving the researcher with some level of uncertainty. In such cases, a Bayesian method that expresses results according to a percentage of certainty may present the best analytical option for researchers. A recent study of the published ceramic assemblages from 14 Italian archaeological projects (both excavations and surveys) utilised Bayesian inferences to examine the convergence and divergence of vessel types and wares from $200 \mathrm{BC}$ to AD $20 .{ }^{258}$ The analysis showed that, despite scholarly arguments that the reign of Augustus inaugurated a period of convergence in material culture, ceramic assemblages from different Italian regions did not indicate such a convergence - with at least $90 \%$ certainty. In fact, these assemblages showed that "distinctions in the habits of eating and drinking proceed according to their own logic and are not necessarily tied to singular causes or events." ${ }^{259}$ The number of similar studies of large datasets is increasing. One of the skills of the archaeologist of the future will certainly be to understand how to maximise the potential of linked open data. Current pressures to move academic publications from commercial outlets to open-access will play a key role in these future developments.

However some final cautionary remarks on such developments. A growing tendency to produce syntheses of long-term multi-regional trends in settlement, by combining data from multiple separate survey publications, bypasses the essential requirement to carry out a 'source-critical' assessment of the way each project has collected and analysed its data. This can create historical 'factoids' where apparent contrasts are the result of divergent survey methodologies. It is currently extremely difficult to make easy comparisons of separate survey projects where the personnel do not overlap. One of the best examples relies on firsthand experience by the authors of many of the surveys being brought into synthesis. ${ }^{260}$

\footnotetext{
255 Note especially the contribution of Kansa's work here: https://opencontext.org/about/bibliography.

256 cf. the DANS guide to social science data archiving (https://dans.knaw.nl/nl/over/organisatie-beleid/publicaties/ DANSpreparingdataforsharing.pdf) and the ADS guidelines for depositors (https://archaeologydataservice.ac.uk/advice/ guidelinesForDepositors.xhtml).

257 Alcock and Cherry 2004

258 Collins-Elliott 2017.

259 Collins-Elliott 2017: 47.

260 Wilkinson et al. 2014.
} 


\section{Good practice in Mediterranean survey in 17 recommendations}

Below we outline standards of good practice in the form of 17 recommendations, subdivided in sections covering the research design (A), the primary data recording and collection (B), the finds' processing (C), and post-survey data elaboration, publication, storage and archiving (D).

What constitutes good practice of archaeological field survey in the Mediterranean depends to a large degree on the time of writing. From a technological point of view, the use of GPS and PDAs or smartphones has allowed us to make increasingly detailed and accurate digital field records, and the day seems not far away when the recording of each individual walker, and even each individual find, becomes standard practice. Similarly, analogue record-taking on field and processing forms is increasingly giving way to 'digital-born' recording and real-time server connections - though here, as the reader will see below, we are more cautious in advocating fully digital procedures in view of potential issues with data safety. So these recommendations necessarily cover current good practice.

Furthermore, these recommendations cannot cover all forms of systematic archaeological field survey, which range from the 'topographic' via the 'extensive' and 'intensive' to such experimental approaches as Van der Velde's point sampling survey on Sardinia. ${ }^{261}$ We will here assume that the current standard Mediterranean survey project employs student teams (whether trained or untrained) to conduct systematic counting, collecting and documenting of artefacts and sites within contiguous areas, using standardised survey units, in order to produce as reliable a map of the surface archaeological record as possible.

\section{A. Recommendations for good practice in research design}

\section{Recommendation 1: Produce a formal research design}

Before starting the actual survey a well-thought-out written research design is needed that is in line with standards of good practice for intensive survey in the Mediterranean. This should state the research aims and goals, and describe in detail the procedures and protocols that will be followed to achieve those goals. Procedures and protocols should be designed for maximum clarity, minimum risk of recording errors and data loss, and maximum ease of data archiving, and should be the basis for training survey participants. Recording forms and labels should contain clear headings that prompt unequivocal information.

\section{Recommendation 2: Delineate your survey area}

In any intensive survey project there should be, as part of the research design, a clear relation between the research questions asked and the choice and delineation of the survey area. Is the size of the survey area suited to capture the data needed and is sufficient environmental diversity included? Is intensive survey possible in most of the survey area or only in very limited and/ or specific parts of the landscape causing uneven coverage and therefore representativity of the archaeological record? Parts of the landscape that, for some archaeological periods, are inaccessible due to excessive erosion or sedimentation must be excluded from the design unless that design includes alternative research approaches. Be explicit in your choices and state why in some cases standard gridded survey was not possible and you had to revert to other survey methods.

\section{Recommendation 3: Decide on your survey intensity and spatial resolution}

Within the limits of your resources, the survey must be able to yield the kinds and quality of data that you need for your interpretations. Quality is determined, other than by the composition

$\overline{261}$ Van der Velde 2001. 
of your survey team, mainly by survey intensity (time spent per area surveyed) and resolution (extent of standard survey unit). The higher your resolution, the lower the risk that finds' scatters are not recognised in the field or during later analysis of the data. Therefore not only should walker intervals be less than the diameter of the smallest scatter that you wish to reliably detect, but standard survey units should be smaller than the modal expected site size (i.e. have a spatial resolution of no more than $25 \mathrm{~m}$ ). To decide upon the minimum necessary intensity of your survey, teams should be field-tested to ensure they can reliably detect the finds' classes of interest.

\section{Recommendation 4: Evaluate post-depositional processes and visibility/accessibility}

Since survey results are obtained through the 'filters' of current land use/land cover (LULC) plus historical natural and anthropogenic post-depositional processes, the research design should be explicit about whether and how the investigator will study and record these filters. In practice, this means that the investigator must have sufficient knowledge of physical geography or obtain the help of a physical geographer. Ideally, a geoarchaeological study of the survey area should precede and guide the survey itself.

A desktop assessment of available geological and topographic cartography should suffice to segment the study area into landscape units that are internally homogeneous but have distinct affordances for past settlement and land use and distinct overall post-depositional histories; these can serve as the strata for your stratified landscape sampling design. However, for a more specific assessment of post-depositional histories a physical geographer should also be involved in the survey itself, identifying and mapping slope processes at approximately the same scale or resolution as has been chosen for the archaeological survey - typically, 1:5000 to 1:1000. The scale of published geological and soil maps is too large to record the effects of slope process or indeed most other relevant geographical information in sufficient detail.

Where there are significant concerns about the quality of the records made during the survey, especially on sites, a program of revisits is recommended. Revisits will allow the collection of more diagnostic material, or material of more periods (especially when specialists are brought along), or they may lead to a more reliable record of the size, shape, density and other aspects of the site under better visibility circumstances.

\section{Recommendation 5: Be aware of and document research biases ${ }^{262}$}

Research biases operate at three levels that occur at any stage from the definition of research aims through the design and execution of the fieldwork, and into the analytical and interpretive stages. Conceptual biases are biases caused by the classification of data under preconceived concepts - notably the tendency to study only some geographical, typological, and chronological parts of the available archaeological record. Visibility biases are research biases caused by regional and local variations in the visibility of the archaeological record, quantifiable as a retrieval rate, i.e. the probability that artefacts lying within a walker's transect will be recorded. Observer biases are concerned with the ability of the observer to record information which is available in principle to be recorded; this varies considerably across individual walkers who 'see' different artefact types.

Recommendation 6: Balance team composition (specialists, training students) against survey goals

The reliability/reproducibility of your survey results is directly related to the abilities of your survey team. Students new to survey first need to be trained in fieldwalking by experienced team members and made familiar with the variety of artefacts that can be found in a survey by specialists. They should also be taught how some types of finds will be obscured by certain soil conditions

${ }^{262}$ From Van Leusen 2002: chap. 4: 5-7. 
while others stand out. Where there are significant differences in the abilities of members of the survey team (e.g., when a lithics specialist takes part in a 'pottery' survey), it is not good practice to assume lithics have been adequately covered by the survey; nor will 'randomising' the starting position of the specialist result in better data. An experienced team leader should accompany each transect to monitor the implementation of the agreed field practices, surface visibility, and carry out a first inspection of artefact collections to allow incremental improvements in the range of pieces being brought home.

\section{Recommendation 7: Take ample time for practical preparations, planning, and logistics}

A survey can usually only start with a permit in hand issued by local authorities. To convince landowners of the aims and relevance of your survey a leaflet in the local language will help. Emphasise the non-invasive character of the work and give a realistic indication of the amount of time the team needs to be present. Check accessibility of the terrain to be surveyed. Have the units of a grid set out in advance on, for instance, a Google image so that, using GPS, the grid can be quickly staked out in the field by one team member followed by the systematic survey of the team. Make the team survey the field unit by unit using good quality zip finds' bags that carry, in waterproof ink, the number of the unit and swathe they survey. Have them add waterproof labels carrying the standard information in the finds' bags. Demand at all times a professional attitude from team members, including behaving properly within the team and towards the local population and authorities. Define clear responsibilities for the recording of survey circumstances on standard forms (using a calibration chart) and for the final administrative control of all find bags before leaving the field. Take care that the time spent in the field and in the full sun is not unreasonably long - tired and overheated students make for poor field data. And feed your team well - a survey army 'marches on its stomach', both with snacks and water during the fieldwork and at main mealtimes.

\section{B. Recommendations for good practice in primary data collection/recording}

\section{Recommendation 8: Provide redundancy and monitor quality control in digital and analogue field recording}

In field recording, forms, tags and protocols should have built-in redundancy and other safety measures to avoid accidental loss of data and/or finds. Digital-only recording is not safe enough for crucial data unless they can be immediately uploaded to a server; otherwise analogue forms with space for a sketch map should be used. Conventions should be established for the sketch mapping as well, so that field observations will be correctly interpreted later on. It is recommended that team leaders and team members keep diaries to record observations not covered by standard recording sheets; these also form part of the survey archive.

The accuracy and precision of mapping nowadays mainly depends on GPS equipment. Be aware that the accuracy of single-receiver GPS coordinates, being dependent on satellite constellations, local topography and tree cover, is variable and may not under all circumstances be sufficient for the purposes of your survey. It is good practice to state the desired accuracy of GPS locations, and how you intend to achieve this, in your research design. Field sketches and photographs of find locations with good reference points are useful as additional data to retrace find locations. In some cases the use of a Total Station/DGPS may be required to measure in find locations precisely.

Recommendation 9: follow a clear strategy, methodology and protocol for the counting ('clicking') and collecting of finds

Defining counting and collection strategies is of prime importance in the research design of any survey project (see recommendation 1). Modern intensive survey projects attempt to record both 
site- and off-site artefact distributions over the landscape so that both settlement organisation and land use are diachronically recorded. Between and within regional landscapes artefact densities may vary considerably. It is recommended that a preliminary evaluation of artefact density within the survey universe is executed before starting the actual survey, so that an appropriate recording and collection strategy can be established. Consistency of execution, to be achieved by following survey protocols, is imperative for reliable comparative density interpretations.

a. Counting finds (with the help of manual clickers, PDA or smartphone) will give information on artefact density. Instruct teams clearly what and how to count, what to record and how to collect finds from units for further processing. It is crucial to indicate type(s) and minimum size(s) of artefacts to be counted or collected (typically 'thumbnail-size' upwards $-1 \mathrm{~cm}^{2}-$ when pottery is concerned). If find densities exceed the possibility of total collection for chronological and functional study, a sampling strategy needs to be implemented to collect a representative artefact sample for diachronic and functional study and publication. That strategy can be either to reduce the intensity of the survey (i.e., lower the coverage) or to shift to 'diagnostic' collecting. The latter typically focuses on feature sherds suitable for typo-chronological analysis, a good selection of body-sherds, together with samples of the variety of fabrics.

b. For surveying the landscape at large, fields should be subdivided in collection units of the desired resolution (for example, $50 \mathrm{~m}$ by $50 \mathrm{~m}$ or $25 \mathrm{~m}$ by $25 \mathrm{~m}$ ) to obtain data on absolute and relative artefact densities and to establish thresholds between off-site and site artefact densities. While working in standard units is easy in ploughed open landscapes with clear field boundaries, surveys of vegetated and/or rugged land with extreme low visibility may require more sophisticated methods, for instance by taking GPS records of the GPS actual tracks walked and the locations of every single artefact; a more labour-intensive approach would be to use point sampling where a defined ground surface (e.g., $\left.2 \mathrm{~m}^{2}\right)$ is cleared around each point.

c. On-site surveys should be gridded finer to obtain more precise chronological and functional data $(10 \mathrm{~m}$ by $10 \mathrm{~m}$ and $20 \mathrm{~m}$ by $20 \mathrm{~m}$ units have proven efficient for smaller and larger sites respectively). For extremely low-density or low-visibility finds scatters, for example of protohistoric or Medieval hand-made pottery, intensification of the survey to $100 \%$ is recommended on finding the first object; Orton's cluster sampling ${ }^{263}$ approach can then be used to find the scatter boundaries, but allowing for the likely existence of site haloes for residential sites.

d. Recording of collection unit parameters (land use, visibility factors): for each unit within a gridded survey, a set of collection parameters should be recorded that may add up to an estimation of surface visibility. These parameters are percentage and nature of vegetation cover, plough conditions, presence/absence of geological materials (stones, pebbles) and/or recent (building) debris, dust conditions, light.

\section{Recommendation 10: role of artefact specialists in the field}

It is not realistic to believe that field teams, even with various specialists present, will be able to reliably recognise and collect all targeted finds' categories. Therefore, in all cases, the specialisms of the team members should be recorded so that differences between individual's collections can be traced and analysed. In the pursuit of a 'representative' sample of the targeted categories it is recommended that all team members receive training by appropriate specialists (for example, use

263 Orton 2000. 
the first survey day for this), and that regular checks are made by these specialists throughout the survey to see if the team has not missed significant sections of the record. Pottery specialists should take samples of ware categories to be used for fabric and archaeometric studies and to build up a reference collection.

When removal of surface artefacts from the field is prohibited, the presence of specialists in the field is crucial, but such field study alone is not likely to produce reliable results for all periods and finds categories and is therefore not advisable.

Recommendation 11: Appoint a person responsible for the registration of in-coming bags and processing of finds and one for downloading and updating the project's databases and the archiving of analogue data.

To avoid unrepairable errors and data loss, precision and consistency is needed in the storing of incoming finds before post-survey treatment starts, so that control of written identification data (labels) against digital data entries is imperative. The same holds for all incoming digital and analogue field data. These controls should be done immediately after the actual field visits when memory of the fieldwork is still fresh. Analog data (maps, written notes and data to be entered into databases) should be elaborated and digitised the same day in GIS, daily reports and database.

\section{Recommendations for good practice in finds processing}

Recommendation 12: The procedures followed in survey artefact studies should guarantee the integrity of the evidence, that is, they should not be allowed to break the connection between the physical artefacts and their metadata as established during the survey.

Any handling of the artefacts following the initial ingestion of bags from the field introduces the risk that finds become separated from their descriptive data. This happens not only when inexperienced people are involved! Since finds processing can happen long after the survey itself has been finished, and after deposition of the finds in the approved regional storage facilities managed by heritage organisations, a strict protocol should be imposed to avoid people 'temporarily' removing finds from their context and neglecting to update storage records after each intervention.

Recommendation 13: Cleaning of finds can be done by any team member following a clear set of instructions. Data entry, including basic description of finds can be successfully carried out by students after initial training, but for final classification of the finds experienced team members are required (preferably specialists), who should make use of a reference collection appropriate to the region being studied.

It is crucial to take appropriate action to avoid disassociation of the drying finds and the contextual information on bags and tags. While cleaning may seem simple, hard brushing with unsuitable tools or soaking sherds in water may damage diagnostic features of sherds (core, surface treatment). The use of chemicals to remove incrustation or resistant dirt should only be done with the help and advice of specialists. Finds need to be dried very well before repacking them in clean bags. All final classificatory work of finds is done by specialists, but with increasing numbers of survey samples initial data entry can be accomplished by students under supervision. Especially in the Mediterranean climate, a long morning fieldwork can be followed by afternoon laboratory data entry, in which find numbers and initial fabric and form descriptions can be undertaken by students. The presence of ceramic specialists in the same space allows constant availability of advice and control, but an added advantage is the deepened knowledge students gain into the objects they have recovered. For the specialist, freeing them up from time-consuming basic entry allows them sufficient scope for increasingly elaborate study, especially on large complex sites 
where the finds' count is in the tens or even hundreds of thousands. It is not uncommon that this secondary experience with survey finds encourages some students to become pottery specialists themselves.

A reference collection, valid for the study region, is needed to ensure consistency of classification especially for the bulk of nondiagnostic and regional wares and fabrics. This should be built up by a ceramics specialist right from the start of the project, and should cover all fabric and ware groups for all periods. Class descriptions should include data on colour, clay composition, texture and surface treatment, as well as form. If colour as a classification criterion is important, it should be applied as objectively as possible, e.g. by using a printed colour scale based on Munsell colours. Surface treatment should be described in clearly defined terms: presence/absence of same, in the form of slip, gloss, glaze, paint, burnish, polish. Temper/fabric: distinguishing depurated from coarsewares, powdery from firm. For documenting this, use clear definitions and provide ranges where appropriate. The classification should also establish a relation between diagnostic forms (rims, bases, handles) and body sherds to increase the chronological and functional value of the latter. It is a very sensitive stage in finds processing, as phase-by-phase distribution maps of the surveyed area may be wholly dependent on the decisions taken at this stage, especially in case quantity and quality of diagnostic materials are low.

Recommendation 14: Collection counting by finds category must deal with the problem of fragmentation and wear, hence must be accompanied by size and/or weight measurements. Counting classified artefacts is thus only one of two fundamental approaches to obtain useful density maps.

Weighing provides a robust measurement of how much material there is for each category, and by combining it with finds' counts one obtains the fragmentation. Weighing is best done by class, in grams, with reliable scales. Materials should be measured, at a minimum, separately by finds' class and, if possible, by period. If more information about pottery fragmentation is needed, the individual artefact sizes can be measured by comparison with printed circles of set sizes, e.g. 10, $5,2.5,1.25 \mathrm{~cm}$ diameter. In combination with data on the type and degree of wear, the weight/size data serve as a good indicator of post-depositional processes. For instance, large fragments with sharp breaks and well-preserved surface treatment indicate the material was freshly ploughed-up. However we note that some experienced finds' specialists do not consider that the considerable time involved in such procedures produces vital additional information.

\section{Recommendations for good practice in interpretive post-survey studies, publication, storage of finds and archiving}

Recommendation 15: Keep your finds and records centrally organised at all times and document post-survey processes. Keep a record of interpretive decisions regarding finds and sites.

Following a survey, it is likely that multiple researchers will work with the data collected and on the interpretation of the data. It is important to establish who has access to the project database and who is also permitted to make changes, all of which need to be documented. This also holds for interpretive decisions, for instance regarding chronological and functional analysis of the archaeological record of sites and their subsequent classification, including who diagnosed what when.

Recommendation 16: Final project publications (paper, digital or both) should furnish the raw quantitative survey data and indicate any correction formulae used in the preparation of distribution maps. Qualitative data on which chronological and functional interpretation is based should preferably be published in the form of a catalogue containing professional artefact drawings and descriptions. 
In view of the possibility for outsiders to critically evaluate survey data, for its own sake and for use in a comparative format, it is important that the reader is provided with methodological details on how data were classified, datasets created (and possibly converted) to create distribution maps and how the threshold between site, halo and off-site was defined. From the same perspective detailed insight into the chronological and functional classification of materials is necessary. Publications should contain reporting on the limitations and biases that may affect the robustness of interpretations given. Given the bulk of transect data, and sherd and lithic catalogues, the wide availability of cd-pockets in final monographs or as online-databases allows all possible details of survey and finds data to be made available alongside the interpretative texts.

\section{Recommendation 17: Guarantee safe storage, proper archiving of your data including metadata and open access.}

Safe and controlled storage of data in an institutional repository after (a phase of) a project has terminated will guarantee that data will survive for future use for yourself and others. To do this data have to be properly archived and provided with metadata. This entails not only the selection and 'cleaning' of primary data files and documentation, but also the compilation of codebooks and protocols (e.g., explanations of the procedures followed in fieldwork and data processing), the conversion of digital files to appropriate platform-independent formats, and the deposition on a sustainable server or, preferably, with a digital repository such as ADS in the UK, or DANS in the Netherlands, that guarantees long-term controlled access. It is important to include this aspect in the research design right from the start.

\section{References}

Ainsworth, S., A. Oswald and D. Went 2013. Remotely Acquired, Not Remotely Sensed: Using LiDAR as a Field Survey Tool, in R. Opitz and D. Cowley (eds) Interpreting Archaeological Topography: 3D Data, Visualisation and Observation: 206-222. Oxford: Oxbow Books.

Alcock, S.E. 1993. Graecia Capta. The Landscapes of Roman Greece. Cambridge: Cambridge University Press.

Alcock, S.E. and J.F. Cherry (eds) 2004. Side-bySide Survey, Comparative Regional Studies in the Mediterranean World. Oxford: Oxbow Books.

Alcock, S.E., J.F. Cherry and J.L. Davies 1994. Intensive Survey, Agricultural Practice and the Classical Landscape of Greece, in I. Morris (ed.) Classical Greece: Ancient Histories and Modern Archaeologies: 137-170. Cambridge: Cambridge University Press.

Ammerman, A.J. 1985. Plow-Zone Experiments in Calabria, Italy. Journal of Field Archaeology 12/1: 33-40.

Ammerman, A.J., H. Koster and E. Pfenning 2013. The Longitudinal Study of Land-Use at Acconia: Placing the Fieldwork of the Survey Archaeologist in Time. Journal of Field Archaeology 38/4: 291-307.

Ansart, A., F. Braemer and G. Davtian 2016. Preparing an Archaeological Field Survey: Remote Sensing
Interpretation for Herding Structures in the Southern Levant. Journal of Field Archaeology 41: 699-712.

Ariño, E. 2006. Modelos de Poblamiento Rural en la Provincia de Salamanca (España) entre la Antigüedad y la Alta Edad Media. Zephyrus 59: 317-337.

Armstrong, K. and P.M. van Leusen 2012. Rural Life in Protohistoric Italy: Using Integrated Spatial Data to Explore Protohistoric Settlement in the Sibaritide, in G. Earl, T. Sly, A. Chrysanthi, P. Murrieta-Flores, C. Papadopoulos, I. Romanowska and D. Wheatley (eds) Archaeology in the Digital Era, Volume II: e-Papers from the 40th Conference on Computer Applications and Quantitative Methods in Archaeology: 645-654. Amsterdam: Amsterdam University Press.

Attema, P.A.J. 1993. An Archaeological Survey in the Pontine Region. A Contribution to the Settlement History of South Lazio 900-100 BC. Doctoral Dissertation. Groningen: University of Groningen.

Attema, P.A.J. 2016. Sedimentation as Geomorphological Bias and Indicator of Agricultural (Un)sustainability in the Study of the Coastal Plains of South and Central Italy. Journal of Archaeological Science: Reports 15: 459469.

Attema, P.A.J. 2018. Power at a Distance: The Hellenistic Rural Exploitation of the 'Farther' 
Chora of Chersonesos (Crimea, Ukraine) from the Perspective of the Džarylgač Survey Project, in B.S. Düring and T.D. Stek (eds) The Comparative Archaeology of Imperial Countrysides. Investigating the Transformations of Rural and Peripheral Landscapes and Societies in Ancient Old World Empires: 115-144. Cambridge: Cambridge University Press.

Attema, P.A.J., A.J. Beijer, M. Kleibrink, A.J. Nijboer and G.J.M. van Oortmerssen 2003. Pottery Classifications: Ceramics from Satricum and Lazio, Italy, 900-300 BC. Palaeohistoria 43/44: 321-396.

Attema, P.A.J., G.L.M. Burgers and P.M. van Leusen 2010. Regional Pathways to Complexity. Settlement and Land-Use Dynamics in Early Italy from the Bronze Age to the Republican Period. Amsterdam: Amsterdam University Press.

Attema, P.A.J., T.C.A. de Haas and G.W. Tol 2010a. Between Satricum and Antium: Settlement Dynamics in a Coastal Landscape in Latium Vetus. Leuven: Peeters.

Attema, P.A.J., T.C.A. de Haas and G.W. Tol 2010b. The Astura and Nettuno Surveys of the Pontine Region Project (2003-2005), 2nd and Final Report. Palaeohistoria 51/52: 169-327.

Attema, P.A.J., T.C.A. de Haas and G.W. Tol 2014. Villas and Farmsteads in the Ager Setinus (Sezze, Italy). Palaeohistoria 55/56: 177-244.

Attema, P.A.J. and T.C.A. de Haas 2012. Intensive Onsite Artefact Survey and Proto-Urbanization. Case Studies from Central and South Italy, in F. Vermeulen, G.L.M. Burgers, S. Keay and C. Corsi (eds) Urban Landscape Survey in Italy and the Mediterranean: 1-12. Oxford: Oxbow Books.

Attema, P.A.J., H. Feiken, T.C.A. de Haas, G.W. Tol and M. La Rosa 2008. The Astura and Nettuno Surveys of the Pontine Region Project (2003-2005), 1st Interim Report. Palaeohistoria 49/50: 415-516.

Attema, P.A.J., A. Larocca and W. de Neef 2019. Questioning the Concept of Marginality: Early Modern Ethnography and Bronze Age Archaeology of the Foothills and Uplands of the Raganello Basin (Northern Calabria, Italy). Journal of Eastern Mediterranean Archaeology \& Heritage Studies 7/4: 482-502.

Attema, P.A.J., E. van Joolen and P.M. van Leusen 2000. A Marginal Landscape: Field Work on the Beach Ridge Complex near Fogliano (South Lazio). Palaeohistoria 41/42: 149-162.

Attema, P.A.J. and G.J.M. van Oortmerssen 1997. Ceramics of the First Millennium BC from a Survey at Lanuvium in the Alban Hills, Central Italy: Method, Aims and First Results of Regional Fabric Classification. Palaeohistoria 39/40: 413439.
Attema, P.A.J. and G. Schörner (eds) 2012. Comparative Issues in the Archaeology of the Roman Rural Landscape: Site Classification Between Survey, Excavation and Historical Categories (Journal of Roman Archaeology Supplementary Series 88). Portsmouth: Journal of Roman Archaeology.

Peter Attema, P.A.J. and J. Sevink, in press. The Peoples and Landscapes of Protohistoric and Classical Italy, in M. Maiuro (ed.) The Oxford Handbook of pre-Roman Italy, 1000-49 BCE.

Avni, Y., N. Porat and G. Avni 2012. Pre-Farming Environment and OSL Chronology in the Negev Highlands, Israel. Journal of Arid Environments 86: 12-27.

Baker, C.M. 1978. The Size Effect and Explanation of Variability in Surface Artefact Assemblage Content. American Antiquity 43: 288-293.

Bakker, J., E. Paulissen, D. Kaniewski, V. De Laet, G. Verstraeten and M. Waelkens 2012. Man, Vegetation and Climate during the Holocene in the Territory of Sagalassos, Western Taurus Mountains, SW Turkey. Vegetation History and Archaeobotany 21: 249-266.

Banning, E.B. 2002. Archaeological Survey. New York: Kluwer Academic.

Banning, E.B., A.L. Hawkins and S.T. Stewart 2006. Detection Functions for Archaeological Survey. American Antiquity 71: 723-742.

Banning, E.B., A.L. Hawkins and S.T. Stewart 2011. Sweep Widths and Detection of Artifacts in Archaeological Survey. Journal of Archaeological Science 38: 3447-3458.

Banning, E.B., A.L. Hawkins, S.T. Stewart, P. Hitchings and S. Edwards 2017. Quality Assurance in Archaeological Survey. Journal of Archaeological Method and Theory 24: 466-488.

Barber, M. 2011. A History of Aerial Photography and Archaeology. Mata Hari's Glass Eye and Other Stories. Swindon: English Heritage.

Barker, G. 1984. The Montarrenti Survey, 1982-83. Archeologia Medievale 11: 278-289.

Barker, G. 1995. A Mediterranean Valley. Landscape Archaeology and Annales History in the Biferno Valley. London: Leicester University Press.

Barker, G., D.D. Gilbertson, G.D.B. Jones and D.J. Mattingly (eds) 1996. Farming the Desert: The Unesco Libyan Valleys Archaeological Survey. Volume 1. Synthesis. Paris: UNESCO, Society for Libyan Studies.

Barker, G., D.D. Gilbertson and D.J. Mattingly (eds) 2007. Archaeology and Desertification: The Wadi Faynan Landscape Survey, Southern Jordan (Wadi Faynan 2). Oxford: Oxbow Books.

Barker, G. and D.J. Mattingly (eds) 1999-2000. The Archaeology of Mediterranean Landscapes. 5 vols. Oxford: Oxbow Books. 
Barker, G., C. Mee, W. Cavanagh, R. Schon and S.M. Thompson 2000. Responses to 'The Hidden Landscape of Prehistoric Greece'. Journal of Mediterranean Archaeology 13: 100-123.

Bar-Yosef, O. and N. Goren 1980. Afterthoughts Following Prehistoric Surveys in the Levant. Israel Exploration Journal 30: 1-16.

Bar-Yosef, O. and J. Phillips (eds) 1977. Prehistoric Investigations in Gebel Maghara, Northern Sinai (Qedem 7). Jerusalem: Hebrew University.

Belvedere, O. and A. Burgio (eds) 2012. Carta Archeologica e Sistema Informativo Territoriale del Parco Archeologico e Paesaggistico della Valle dei Templi di Agrigento. Palermo: Regione Siciliana.

Bergemann, J. 2012. Überlegungen zur Methode und zum Vergleich zwischen den Ergebnisse verschiedener Surveys in Sizilien, in J. Bergemann (ed.) Griechen in Ubersee und der Historische Raum: 35-38. Rahden: Verlag Marie Leidorf.

Bes, P. and J. Poblome 2017. Urban Thespiai: the Late Hellenistic to Late Roman pottery, in J.L. Bintliff, E. Farinetti, B. Slapšak and A.M. Snodgrass (eds) Boeotia Project, Volume II: The City of Thespiai. Survey at a Complex Urban Site: 317-349. Cambridge: McDonald Institute.

Bevan, A. 2002. The Rural Landscape of Neopalatial Kythera: a GIS Perspective. Journal of Mediterranean Archaeology 15: 217-256.

Bevan, A. 2015. The Data Deluge. Antiquity 89/348: 1473-1484.

Bevan, A. and J. Connelly 2013. Mediterranean Islands, Fragile Communities and Persistent Landscapes. Antikythera in Long-term Perspective. Cambridge: Cambridge University Press.

Bintliff, J.L. 1977. Natural Environment and Human Settlement in Prehistoric Greece: Based on Original Fieldwork (British Archaeological Reports Supplementary Series 28). Oxford: BAR.

Bintliff, J.L. (ed.) 1991. The Annales School and Archaeology. Leicester: Leicester University Press.

Bintliff, J.L. 1996. The Archaeological Survey of the Valley of the Muses and its Significance for Boeotian History, in A. Hurst and A. Schachter (eds) La Montagne des Muses: 193-224. Geneva: Librairie Droz.

Bintliff, J.L. 1997. Regional Survey, Demography, and the Rise of Complex Societies in the Ancient Aegean: Core-Periphery, Neo-Malthusian, and other Interpretive Models. Journal of Field Archaeology 24: 1-38.

Bintliff, J.L. 2006. The Leiden University Ancient Cities of Boeotia Project: 2005 Season at Tanagra. Pharos. Journal of the Netherlands Institute at Athens 13: 29-38.
Bintliff, J.L. 2012a. Contemporary Issues in Surveying Complex Urban Sites in the Mediterranean Region: the Example of the City of Thespiai (Boeotia, Central Greece), in F. Vermeulen, G.L.M. Burgers, S. Keay and C. Corsi (eds) Urban Landscape Survey in Italy and the Mediterranean: 44-52. Oxford: Oxbow Books.

Bintliff, J.L. 2012b. The Complete Archaeology of Greece, from Hunter-Gatherers to the 20th Century A.D. Chichester: Wiley-Blackwell.

Bintliff, J.L. 2014. Intra-Site Artefact Surveys, in C. Corsi, B. Slapšak and F. Vermeulen (eds) Good Practice in Archaeological Diagnostics: Non-Invasive Survey of Complex Archaeological Sites: 193-207. Cham: Springer International Publishing Switzerland.

Bintliff, J.L. 2019. Report of the Research Carried out by the Boeotia Project in 2019. Teiresias 49/2:2-5.

Bintliff, J.L., E. Farinetti, B. Slapšak and A.M. Snodgrass 2017. Boeotia Project, Volume II: The city of Thespiai. Survey at a Complex Urban site. Cambridge: McDonald Institute.

Bintliff, J.L. and P. Howard 1999. Studying Needles in Haystacks: Surface Survey and the Rural Landscape of Central Greece in Roman times. Pharos. Journal of the Netherlands Institute at Athens 7: 51-91.

Bintliff, J.L., P. Howard and A.M. Snodgrass 1999. The Hidden Landscape of Prehistoric Greece. Journal of Mediterranean Archaeology 12/2: 139-168.

Bintliff, J.L., P. Howard and A.M. Snodgrass (eds) 2007. Testing the Hinterland: the Work of the Boeotia Survey (1989-1991) in the Southern Approaches to the City of Thespiai. Cambridge: McDonald Institute.

Bintliff, J.L., M. Kuna and N. Venclova (eds) 2000. The Future of Archaeological Field Survey in Europe. Sheffield: Sheffield Academic Press.

Bintliff, J.L., B. Noordervliet and J. van Zwienen 2016. The Leiden Ancient Cities of Boeotia Project: the 2013-2014 Seasons. Pharos. Journal of the Netherlands Institute at Athens 21/2: 1-15.

Bintliff, J.L., B. Slapšak, B. Noordervliet, J. van Zwienen, I. Uytterhoeven, K. Sarri, M. van der Enden, R. Shiel and C. Piccoli 2012. The LeidenLjubljana Ancient Cities of Boeotia Project 2009 Seasons. Pharos. Journal of the Netherlands Institute at Athens 17: 1-58.

Bintliff, J.L., B. Slapšak, B. Noordervliet, J. van Zwienen and J. Verweij 2009. The LeidenLjubljana Ancient Cities of Boeotia Project. Summer 2007-Spring 2008. Pharos. Journal of the Netherlands Institute at Athens 15: 18-42.

Bintliff, J.L., B. Noordervliet, J. van Zwienen, K. Wilkinson, B. Slapšak, V. Stissi, C. Piccoli and A. Vionis 2013. The Leiden-Ljubljana Ancient Cities of Boeotia Project, 2010-2012 Seasons. Pharos. 
Journal of the Netherlands Institute at Athens 19/2: $1-34$.

Bintliff, J.L. and A.M. Snodgrass 1985. The Cambridge/Bradford Boeotian Expedition: The First Four Years. Journal of Field Archaeology 12: 123-161.

Bintliff, J.L. and A.M. Snodgrass 1988a. OffSite Pottery Distributions. A Regional and Interregional Perspective. Current Anthropology 29: 506-513.

Bintliff, J.L. and A.M. Snodgrass 1988b. Mediterranean Survey and the City. Antiquity 62: 57-71.

Blake, H. 1980. Technology, Supply or Demand? Medieval Ceramics 4: 3-12.

Blanton, R.E. 2001. Mediterranean Myopia. Antiquity 75: 627-629.

Bommeljé, L.S. 2009. Three Forts in a Sea of Mountains, in J.L. Bintliff and H. Stöger (eds) Medieval and Post-Medieval Greece: the Corfu Papers (British Archaeological Reports International Series 2023): 1-13. Oxford: Archaeopress.

Borgers, B. and G.W. Tol 2016. An Integrated Approach to the Study of Local Production and Exchange in the Lower Pontine Plain. Journal of Roman Archaeology 29: 349-370.

Borgers, B., G.W. Tol and T.C.A. de Haas 2016. Pottery Production in the Pontine Region, Central Italy, in S. Biegert (ed.) Conference Proceedings of the 44th Congress of Rei Cretariae Romanae Fautores: 1-7. Bonn: Rudolf Habelt GmbH Verlag.

Boswinkel, Y. 2015. Architecture as an Archaeological Proxy. Unpublished MPhil Dissertation, Leiden University, Leiden.

Bourgeois, J. and M. Meganck (eds) 2005. Aerial Photography and Archaeology 2003. A Century of Information. Ghent: Academia Press.

Bowes, K., A. Mercuri, E. Rattigheri, R. Rinaldi, A. Arnoldus-Huyzendveld, M. Ghisleni, C. Grey, M. MacKinnon and E. Vaccaro 2017. Peasant Agricultural Strategies in Southern Tuscany: Convertible Agriculture and the Importance of Pasture, in T.C.A. de Haas and G.W. Tol (eds) The Economic Integration of Roman Italy. Rural Communities in a Globalizing World: 170-199. Leiden: Brill.

Bradford, J. 1957. Ancient Landscapes. London: Bell.

Braidwood, R. 1937. Mounds in the Plain of Antioch (Oriental Institute Publications 48). Chicago: Oriental Institute.

Braudel, F. 1972. The Mediterranean and the Mediterranean World in the Age of Philip II. London: Collins.

Broodbank, C. 2013. The Making of the Middle Sea. A History of the Mediterranean from the Beginning to the Emergence of the Classical World. London: Thames and Hudson.

Bruins, H.J. and J. van der Plicht 2017. Iron Age Agriculture - A Critical Rejoinder to Settlement Oscillations in the Negev Highlands Revisited: the Impact of Microarchaeological Methods. Radiocarbon 59/1: 1-16.

Caillemer, A. and R. Chevallier 1959. Atlas Des Centuriations Romaines De Tunisie. Paris: Institut Géographique National.

Cambi, F. and N. Terrenato 1994. Introduzione all'Archeologia dei Paesaggi. Rome: La Nuova Italia Scientifica.

Campana, S. 2011a. From Space to Place or from Sites to Landscape? Mind the Gap, in P.M. van Leusen, G. Pizziolo and L. Sarti (eds) Hidden Landscapes of Mediterranean Europe (British Archaeological Reports International Series 2320): 34-45. Oxford: Archaeopress.

Campana, S. 2011b. 'Total Archaeology' to Reduce the Need for Rescue Archaeology: the BREBEMI Project (Italy), in D. Cowley (ed.) Remote Sensing for Archaeological Heritage Management: 33-41. Budapest: Archaeolingua.

Campana, S. 2016. Sensing Ruralscapes. Third-Wave Archaeological Survey in the Mediterranean Area, in M. Forte and S. Campana (eds) Digital Methods and Remote Sensing in Archaeology: Archaeology in the Age of Sensing: 113-145. New York: Springer.

Campana, S. 2017. Emptyscapes: Filling an 'Empty' Mediterranean Landscape at Rusellae, Italy. Antiquity 91: 1223-1240.

Caraher, W.R., R.S. Moore and D.K. Pettegrew 2014. Pyla-Koutsopetria I: Archaeological Survey of an Ancient Coastal Town. Boston: American Schools of Oriental Research.

Caraher, W.R., D. Nakassis and D.K. Pettegrew 2006. Siteless Survey and Intensive Data Collection in an Artifact-rich Environment: Case Studies from the Eastern Corinthia, Greece. Journal of Mediterranean Studies 19: 7-43.

Carter, J.C. and A. Prieto (eds) 2011. The Chora of Metaponto 3. Austin: The University of Texas Press.

Casana, J., J.T. Herrmann and A. Fogel 2008. Deep Subsurface Geophysical Prospection at Tell Qarqur, Syria. Archaeological Prospection 15/3: 207-225.

Casana, J. and T.J. Wilkinson 2005. Settlement and Landscapes in the Amuq Region, in K.A. Yener (ed.) The Amuq Valley Regional Projects. Vol. 1: Surveys in the Plain of Antioch and Orontes Delta, Turkey, 1995-2002 (Oriental Institute Publications 131): 25-98. Chicago: Oriental Institute. 
Cascino, R., H. Di Giuseppe and H. Patterson 2012. Veii. The Historical Topography of the Ancient City: A Restudy of John Ward-Perkins's Survey (Archaeological Monographs of the British School at Rome 19). London: British School at Rome.

Cavanagh, W. 2004. WYSIWYG: Settlement and Territoriality in Southern Greece during the Early and Middle Neolithic periods. Journal of Mediterranean Archaeology 17/2: 165-189.

Cavanagh, W., J. Crouwel, R.W.V. Catling and G. Shipley (eds) 2002. Continuity and Change in a Greek Rural Landscape. The Laconia Survey, Volume 1. London: The British School at Athens.

Chang, C. 1993. Ethnoarchaeological Survey of Pastoral Transhumance Sites in the Grevena Region, Greece. Journal of Field Archaeology 20/3: 249-264.

Chang, C. and H.A. Koster 1986. Beyond Bones: Toward an Archaeology of Pastoralism. Advances in Archaeological Method and Theory 9: 97-148.

Chapman, J.C., R. Shiel and S. Batovic (eds) 1996. The Changing Face of Dalmatia. Leicester: Leicester University Press.

Cherry, J.F. 1983. Frogs Round the Pond: Perspectives on Current Archaeological Survey Projects in the Mediterranean Region, in D.R. Keller and D.W. Rupp (eds) Archaeological Survey in the Mediterranean Area (British Archaeological Reports International Series 155): 375-416. Oxford: BAR.

Cherry, J.F., J.L. Davis and E. Mantzourani (eds) 1991. Landscape Archaeology as Long-Term History. Los Angeles: Institute of Archaeology, University of California.

Cherry, J.F., C. Gamble and S. Shennan (eds) 1978. Sampling in Contemporary British Archaeology (British Archaeological Reports 50). Oxford: BAR.

Clavel-Lévêque, M. and G. Tirologos (eds) 1998. Atlas historique des cadastres d'Europe I. Luxembourg: Office des Publications Officielles des Communautés Européennes.

Clavel-Lévêque, M. and G. Tirologos (eds) 2002. Atlas historique des cadastres d'Europe II. Luxembourg: Office des Publications Officielles des Communautés Européennes.

Cloke, C.F. 2012. Nemean Neighbors: Reconstructing Rural Life Through Survey. AIA/APA Annual Meeting, Abstracts.

Cloke, C.F. forthcoming. Farming on the Fringe: a GIS- and Survey-Based Perspective from the Nemea Valley, in Ancient Greek Agriculture Conference. Aarhus: Aarhus University.

Collins-Elliott, S. 2017. Bayesian Inference with Monte Carlo Approximation: Measuring Regional Differentiation in Ceramic and Glass
Vessel Assemblages in Republican Italy, ca. 200 BCE - 20 CE. Journal of Archaeological Science 80: 37-49.

Corsi, C., B. Slapšak and F. Vermeulen (eds) 2013. Good Practice in Archaeological Diagnostics. Non-Invasive Survey of Complex Archaeological Sites. Cham: Springer International Publishing Switzerland.

Crawford, M.H. 2016. Johannes the Last Agrimensor, in C. Carsana and L. Troiani (eds) I Percorsi di un Historikos. In Memoria di Emilio Gabba: 216-228. Como: New Press Edizioni.

Crow, J., S. Turner and A.K. Vionis 2011. Characterizing the Historic Landscapes of Naxos. Journal of Mediterranean Archaeology 24: 111-137.

Davis, J.L., A. Hoti, I. Pojani, S.R. Stocker, A.D. Wolpert, P.E. Acheson and J.W. Hayes 2003. The Durrës Regional Archaeological Project: Archaeological Survey in the Territory of Epidamnus/Dyrrachium in Albania. Hesperia 72: 41-119.

Dirix, K., P. Muchez, P. Degryse, E. Kaptijn, B. Mušič, E. Vassilieva and J. Poblome 2013. Multi-Element Soil Prospection Aiding Geophysical and Archaeological Survey on an Archaeological Site in Suburban Sagalassos (SW-Turkey). Journal of Archaeological Science 40/7: 2961-2970.

De Haas, T.C.A. 2011. Fields, Farms and Colonists. Intensive Field Survey and Early Roman Colonization in the Pontine Region, Central Italy. Doctoral Dissertation. Groningen: Barkhuis \& Groningen University Library.

De Haas, T.C.A. 2012. Beyond Dots on the Map: Intensive Survey Data and the Interpretation of Small Sites and Off-Site Distributions, in P.A.J. Attema and G. Schörner (eds) Comparative Issues in the Archaeology of the Roman Rural Landscape: Site Classification Between Survey, Excavation and Historical Categories (Journal of Roman Archaeology Supplementary Series 88): 55-79. Portsmouth: Journal of Roman Archaeology.

De Haas, T.C.A., P.A.J. Attema and G.W. Tol 2012. Polygonal Masonry Platform Sites in the Lepine Mountains (Pontine Region, Lazio, Italy). Palaeohistoria 53/54: 195-282.

De Haas, T.C.A. and G.W. Tol (eds) 2017. The Economic Integration of Roman Italy. Rural Communities in a Globalizing World, Leiden: Brill.

De Haas, T.C.A, G.W. Tol and P.A.J. Attema 2011. Investing in the Colonia and Ager of Antium. Facta 5: 111-144.

De Neef, W. 2016. Surface <> Subsurface. A Methodological Study of Metal Age Settlement and Land Use in Calabria (Italy). Doctoral Dissertation. Groningen: University of Groningen. 
De Neef, W., K. Armstrong and P.M. van Leusen 2017. Putting the Spotlight on Small Metal Age Pottery Scatters in Northern Calabria (Italy). Journal of Field Archaeology 42/4: 283-297.

Donev, D. 2015. Rural Landscapes Along the Vardar Valley: Two Site-Less Surveys Near Veles and Skopje, Republic of Macedonia. Oxford: Archaeopress.

Donev, D. 2018. Argos on the Vardar: the First Contribution of a Ceramic Survey. Patrimonium 11: 51-78.

Donnellan, L., A.M. Snodgrass and Y. Boswinkel in prep. The Walls of Haliartos, Boeotia, Greece.

Ducellier, A. (ed.) 1986. Byzance et le Monde Orthodoxe. Paris: Armand Colin.

Dunnell, R.C. and W.S. Dancey 1983. The Siteless Survey: A Regional Scale Data Collection Strategy. Advances in Archaeological Method and Theory 6: 267-287.

Düring, B.S. and C. Glatz (eds) 2016. Kinetic Landscapes: The Cide Archaeological Project: Surveying the Turkish Western Black Sea Region. Berlin: Walter de Gruyter.

Dusar, B., G. Verstraeten, K. D’Haen, J. Bakker, E. Kaptijn and M. Waelkens 2012. Sensitivity of the Eastern Mediterranean Geomorphic System towards Environmental Change during the Late Holocene: a Chronological Perspective. Journal of Quaternary Science 27/4: 371-382.

Efstratiou, N., P. Biagi, P. Elefanti, P. Karkanas and M. Ntinou 2006. Prehistoric Exploitation of Grevena Highland Zones: Hunters and Herders along the Pindus Chain of Western Macedonia (Greece). World Archaeology 38: 415-435.

Fabian, P. 2005. Avdat During the Establishment of Provincia Arabia. Doctoral Dissertation. Beersheva: Ben-Gurion University.

Fairclough, G. and S. Rippon (eds) 2002. Europe's Cultural Landscape: Archaeologists and the Management of Change. Exeter: Europae Archaeologiae Consilium.

Farinetti, E. 2011. Boeotian Landscapes: A GIS-Based Study for the Reconstruction and Interpretation of the Archaeological Datasets of Ancient Boeotia (British Archaeological Reports International Series 2195). Oxford: Archaeopress.

Feiken, H. 2014. Dealing with Biases. Three GeoArchaeological Approaches to the Hidden Landscapes of Italy (Groningen Archaeological Studies 26). Groningen: Barkhuis.

Feiken, H., G.W. Tol, P.M. van Leusen and C. Anastasia 2012. Reconstructing a Bronze Age Hidden Landscape: Geoarchaeological Research at Tratturo Canio (Italy, 2009). Palaeohistoria 53/54: 109-159.
Fentress, E. 1994. Cosa in the Empire: the Unmaking of a Roman Town. Journal of Roman Archaeology 7: 209-222.

Flannery, K.V. (ed.) 1976. The Early Mesoamerican Village. New York: Academic Press.

Forte, M. and S. Campana (eds) 2016. Digital Methods and Remote Sensing in Archaeology. Archaeology in the Age of Sensing. Quantitative Methods in the Humanities and Social Sciences. New York: Springer.

Francovich, R. and R. Hodges 2003. Villa to Village: The Transformation of the Roman Countryside. London: Duckworth.

Frederiksen, R., S. Muth, P. Schneider and M. Schnelle (eds) 2016. Focus on Fortifications: New Research on Fortifications in the Ancient Mediterranean and the Near East. Oxford: Oxbow Books.

Galaty, M., O. Lafe, W.E. Lee and Z. Tafilica (eds) 2013. Light and Shadow: Isolation and Interaction in the Shala Valley of Northern Albania (Monumenta Archaeologica 28). Los Angeles: Cotsen Institute of Archaeology Press.

García Sánchez, J. and E. Carmona Ballestero 2017. El Cenizal de la Segunda Edad del Hierro de El Espinillo (Villadiego, Burgos). Nailos 4: 55-85.

García Sánchez, J. and M. Cisneros 2012. An OffSite Approach to Late Iron Age and Roman Landscapes on the Northern Plateau, Spain. Journal of European Archaeology 16/2: 1-26.

García Sánchez, J., J. Pelgrom and T.D. Stek 2017. Comparative Re-Surveys by Statistics and GIS in Isernia and Venosa (Molise and Basilicata, Italy). Mediterranean Archaeology \& Archaeometry 17/3:39-52.

García Sánchez, J. and M.K. Termeer forthcoming. New Approaches to Hilltop Settlements around Isernia, in T.D. Stek (ed.) Proceedings of the State of the Samnites International Conference Rome, Italy 28-30, 2016. Rome: Babesch.

Gerrard, C. and M. Aston 2007. Shapwick Project Somerset: a Rural Landscape Explored. Leeds: Maney Publishing.

Ghisleni, M., E. Vaccaro, K. Bowes, A. ArnoldusHuyzendveld, M. MacKinnon and F. Marani 2011. Excavating the Roman Peasant I: Excavations at Pievina (GR). Papers of the British School at Rome 79: 95-145.

Given, M. and A.B. Knapp 2003. The Sydney Cyprus Survey Project: Social Approaches to Regional Survey. Los Angeles: Cotsen Institute of Archaeology.

Gkiasta, M. 2008. The Historiography of Landscape Research on Crete (Archaeological Studies Leiden University 16). Leiden: Leiden University.

Goring-Morris, A.N. 1987. At the Edge: Terminal Pleistocene Hunter-Gatherers in the Negev and Sinai 
(British Archaeological Reports International Series 361). Oxford: BAR.

Grau Mira, I. 2017. Archaeological Surveys in Areas with a High Density of Artefacts: Analysis and Interpretation Proposals. Quaternary International 435: 71-80.

Guldager Bilde, P., P.A.J. Attema and K. WintherJacobsen (eds) 2012. The Džarylgač Survey Project. Aarhus: Aarhus University Press.

Gutiérrez,L.M.2010.Microprospección Arqueológica en Giribaile (Vilches, Jaén): Protocolo de Trabajo. Trabajos de Prehistoria 67/1: 7-35.

Hitchner, R.B. 1995. Historical Text and Archaeological Context in Roman North Africa: the Albertini Tablets and the Kasserine Survey, in D.B. Small (ed.) Methods in the Mediterranean: Historical and Archaeological Views on Texts and Archaeology: 124-142. Leiden: E.J. Brill.

Horden, P. and N. Purcell 1998. The Corrupting Sea. Oxford: Blackwell.

Jameson, M.H., C.N. Runnels and T.H. van Andel 1994. A Greek Countryside: The Southern Argolid from Prehistory to the Present Day. Stanford: Stanford University Press.

Johnson, P.S. 2010. Investigating Urban Change in Late Antique Italy through Waste Disposal Practices, in D. Sami and G. Speed (eds) Debating Urbanism within and beyond the Walls, A.D. 300-700. Proceedings of a Conference Held at the University of Leicester, 15th November 2008 (Leicester Archaeology Monographs 17): 167-193. Leicester: Leicester University.

Johnson, P.S. and M. Millett (eds) 2013. Archaeological Survey and the City. Oxford: Oxbow Books.

Kamermans, H. 2004. Archaeology and Land Evaluation in the Agro Pontino (Lazio, Italy), in S. Holstrom, A. Voorrips and H. Kamermans (eds) The Agro Pontino Archaeological Survey (Archaeological Studies Leiden University 11). Leiden: Leiden University.

Kaptijn, E. 2009. Life on the Watershed. Reconstructing Subsistence in a Steppe Region Using Archaeological Survey: a Diachronic Perspective on Habitation in the Jordan Valley. Leiden: Sidestone Press.

Kaptijn, E. and M. Waelkens forthcoming. Before and After the Eleventh Century $A D$ in the Territory of Sagalassos.

Karambinis, M. 2015. The Island of Skyros from Late Roman to Early Modern times: an Archaeological Survey (Archaeological Studies Leiden University 28). Leiden: Leiden University.

Karidis, D.N. and M. Kiel 2002. Mitilinis Astigraphia ke Lesvou Chorographia. Athens: Olkos.

Kedar, Y. 1967. Ancient Agriculture in the Negev Highlands. Jerusalem: Bialik Institute.
Kiel, M. 1990. Studies on the Ottoman Architecture of the Balkans. Aldershot: Variorum.

Kiel, M. 1997. The Rise and Decline of Turkish Boeotia, 15th-19th Century, in J.L. Bintliff (ed.) Recent Developments in the History and Archaeology of Central Greece: 315-358. Oxford: Tempus Reparatum.

Knodell, A.R., S.E. Alcock, C.A. Tuttle, C.F. Cloke, T. Erickson-Gini, C. Feldman, G.O. Rollefson, M. Sinibaldi, T.M. Urban and C. Vella 2017. The Brown University Petra Archaeological Project: Landscape Archaeology in the Northern Hinterland of Petra, Jordan. American Journal of Archaeology 121/4: 621-683.

Kolb, F. 2008. Burg - Polis - Bischofssitz. Geschichte der Siedlungskammer van Kyaneai in der Sudwestturkei. Mainz: Philipp von Zabern.

Kuna, M. 2000. Surface Artefact Studies in the Czech Republic, in J.L. Bintliff, M. Kuna and N. Venclova (eds) The Future of Archaeological Field Survey in Europe: 29-44. Sheffield: Sheffield Academic Press.

Lehmann, H. 1939. Die Siedlungsräume Ostkretas. Geographische Zeitschrift 45: 212-228.

Leone, A., R.E. Witcher, F. Privitera and U. Spigo 2007. The Upper Simeto Valley Project: an Interim Report on the First Season, in M. Fitzjohn (ed.) Uplands of Ancient Sicily and Calabria: the Archaeology of Landscape Revisited: 49-58. London: Accordia Research Institute.

Leveau, P. 1984. Caesarea de Maurétanie: une Ville romaine et ses Campagnes (Collection de l'École française de Rome 70). Rome: École française de Rome.

Lohmann, H. 1992. Agriculture and Country Life in Classical Attica, in B. Wells (ed.) Agriculture in Ancient Greece: 29-60. Stockholm: Paul Åström Förlag.

Lohmann, H. 1993. Atene. Forschungen zu Siedlungsund Wirtschaftsstruktur des Klassischen Attika. Cologne: Boehlau Verlag.

Lolos, Y., B. Gourley and D.R. Stewart 2007. The Sicyon Survey: A Blueprint for Urban Survey. Journal of Mediterranean Archaeology 20: 267-296.

Marchi, M.L. and G. Sabbatini 1996. Venusia (IGM 187 I NO / I NE) (Forma Italiae 37). Florence: Leo S. Olschki.

Marchisio, E., M. Pasquinucci, E. Pranzini and G. Vigna Guidi 2000. The Pisa Territory Project, in F. Trement and M. Pasquinucci (eds) NonDestructive Techniques Applied to Landscape Archaeology: 233-244. Oxford: Oxbow Books.

Martens, F. 2005. The Archaeological Urban Survey of Sagalassos (South-West Turkey): the Possibilities and Limitations of Surveying a 'Non-Typical' 
Classical Site. Oxford Journal of Archaeology 24: 229-254.

Mayoral Herrera, V., F.B. Barrera, et al. 2018. The evolution of an agrarian landscape. Methodological proposals for the archaeological study of the alluvial plain of Medellin (Guadiana basin, Spain). In S.J. Kluiving and E. GuttmannBond (eds) Landscape Archaeology between Art and Science: 97-114. Amsterdam: Amsterdam University Press.

Mayoral, V., F. Borja, C. Borja, J.Á. Martínez and M. De Tena 2012. The Evolution of an Agrarian Landscape. Methodological Proposals for the Archaeological Study of the Alluvial Plain of Medellin (Guadiana basin, Spain), in S.J. Kluiving and E.B. Guttmann-Bond (eds) Landscape Archaeology Between Art and Science - From a Multi- to an Interdisciplinary Approach: 97-114. Amsterdam: Amsterdam University Press.

Mayoral, V. and S. Celestino Perez 2009. Métodos de Prospección Arqueológica Intensiva en el Marco de un Proyecto Regional: el Caso de la Comarca de La Serena (Badajoz). Trabajos de Prehistoria 66/1: 7-25.

Mayoral V. and L. Sevillano Perea 2016. Tecnologías de Información Geográfica y Prospección Arqueológica: Problemática General y algunos Casos de Studio, in M. Minguez and E. Capdevila (eds) Manual de Tecnologías de Información Geográfica Aplicadas a la Arqueología: 79-114. Alcalá de Henares: Museo Arqueológico Regional.

McDonald, W.A. and G.R. Rapp 1972. The Minnesota Messenia Expedition: Reconstructing a Bronze Age Regional Environment. Minneapolis: University of Minnesota Press.

Mee, C. and H. Forbes (eds) 1997. A Rough and Rocky Place. The Landscape and Settlement History of the Methana Peninsula, Greece. Liverpool: Liverpool University Press.

Menchelli, S. 2008. Surface Material, Sites and Landscape in South Picenum (Marche, Italy), in H. Vanhaverbeke, J. Poblome, F. Vermeulen and M. Waelkens (eds) Dialogue with Sites. The Definition of Space and Time in the Roman Period: 31-43. Turnhout: Brepols.

Menchelli, S. 2012. Paesaggi Piceni e Romani nelle Marche Meridionali: l'Ager Firmanus dall'Età TardoRepubblicana alla Conquista Longobarda. Pisa: Pisa University Press.

Menchelli, S. 2016. Ploughsoil Assemblages and Beyond: Some Interpretative Challenges, in R. Hermans, S. Kluiving, G.L.M. Burgers, C. Tetteroo, J. Pelgrom and M. McGrath (eds) LAC 2014 Proceedings: doi.org/10.5463/lac.2014.44.

Meyer, C., R. Kniess and L. Goossens 2017. Geophysical Prospection in the Ancient City of
Tanagra (Boeotia, Central Greece). Unpublished Report. Berlin: Eastern Atlas GmbH.

Millon, R. 1964. The Teotihuacan Mapping Project. American Antiquity 29: 345-352.

Millon, R. 1973. The Teotihuacán Map. Vol. 1.1: Text. Austin: University of Texas Press.

Millon, R., B. Drewitt and G.L. Cowgill 1973. The Teotihuacán Map. Vol. 1.2: Maps. Austin, University of Texas Press.

Mocci, F., J.M. Palet Martinez, M. Segard, S. Tzortzis and K. Walsh 2005. Peuplement, Pastoralisme et Modes d'Exploitation de la Moyenne et Haute Montagne depuis la Préhistoire dans le Parc National des Écrins, in F. Verdin and A. Bouet (eds) Territoires et Paysages de l'Âge du Fer au Moyen Age. Mélanges Offerts à Philippe Leveau: 197-212. Bordeaux: Presses Universitaires de Bordeaux.

Momigliano, N., A. Greaves, T. Hodos, B. Aksoy, A. Brown, M. Kibaroğlu and T. Carter 2011. Settlement History and Material Culture in Southwest Turkey: Report on the 2008-2010 Survey at Çaltılar Höyük (Northern Lycia). Anatolian Studies 61: 61-121.

Moody, J., L. Nixon, S. Price and O. Rackham 1998. Surveying Poleis and Larger Sites in Sphakia, in W.G. Cavanagh, M. Curtis, N. Coldstream and A. Johnston (eds) Post-Minoan Crete: 87-95. London: British School at Athens.

Muth, S., P. Schneider, M. Schnelle and P. De Staebler (eds) 2016. Ancient Fortifications: A Compendium of Theory and Practice. Oxford: Oxbow Books.

Opitz, R. 2016. Airborne Laser Scanning in Archaeology: Maturing Methods and Democratizing Applications, in M. Forte and S. Campana (eds) Digital Methods and Remote Sensing in Archaeology: Archaeology in the Age of Sensing: 35-50. New York: Springer.

Orengo, H.A. and A. Garcia-Molsosa 2019. A Brave New World for Archaeological Survey: Automated Machine Learning Based Potsherd Detection Using High-Resolution Drone Imagery. Journal of Archaeological Science 112: doi. org/10.1016/j.jas.2019.105013.

Orton, C. 2000. Sampling in Archaeology. Cambridge: Cambridge University Press.

Osborne, R. 1985. Buildings and Residence on the Land in Classical and Hellenistic Greece. Annual of the British School at Athens 80: 119-128.

Palet, J. and H. Orengo 2011. The Roman Centuriated Landscape: Conception, Genesis and Development as Inferred from the Ager Tarraconensis Case. American Journal of Archaeology 115/3: 383-402.

Palmer, C., H. Smith and P. Daly 2007. Ethnoarchaeology, in G. Barker, D. Gilbertson and D. Mattingly (eds) Archaeology and Desertification. 
The Wadi Faynan Landscape Survey, Southern Jordan (Wadi Faynan Series 2): 369-395. Oxford: Oxbow Books.

Papadopoulos, N.G., A. Sarris, W.A. Parkinson, A. Gyucha, R.W. Yerkes, P.R. Duffy and P. Tsourlos 2014. Electrical Resistivity Tomography for the Modelling of Cultural Deposits and Geomorphological Landscapes at Neolithic Sites: a Case Study from Southeastern Hungary. Archaeological Prospection 21/3: 169-183.

Papantoniou, G. and A.K. Vionis 2017. Landscape Archaeology and Sacred Space in the Eastern Mediterranean: a Glimpse from Cyprus. Land 6/2:1-18.

Parini, M.C., L. Sevillano and V. Mayoral forthcoming. Los Espacios Agrarios de la Romanización en el Suroeste de la Península Ibérica. El Caso de La Serena, in J.P. Bellón, I. Grau and V. Mayoral (eds) Arqueología y Sociedad de los Espacios Agrarios. En Busca de la Gente Invisible en la Materialidad del Paisaje.

Pasquinucci, M. 2004. La 'Sententia Minuciorum' e la Valpolcevera: Territorio, Popolamento, 'Terminatio', in R. De Marinis and G. Spadea (eds) I Liguri. Un Antico Popolo Europeo tra Alpi e Mediterraneo: 476-477. Milan: Skira.

Pasquinucci, M. 2013. Centuriation and Roman Land Surveying (Republic through Empire), in C. Smith (ed.) Encyclopedia of Global Archaeology: 1275-1291. New York: Springer Verlag.

Pasquinucci, M. and M.L. Ceccarelli Lemut 1991. Fonti Antiche e Medievali per la Viabilità del Territorio Pisano. Bollettino Storico Pisano 60: 111-138.

Pasquinucci, M. and A. Launaro 2009. Researching 'on the Margins'. Landscape Archaeology in the Polcevera Valley, in I. Holm, E. Svensson and K. Stene (eds) Liminal Landscapes: Beyond the Concepts of 'Marginality' and 'Periphery' (Oslo Archaeological Series 11): 183-201. Oslo: Unipub AS.

Patterson, H. (ed.) 2004. Bridging the Tiber. Approaches to Regional Archaeology in the Middle Tiber Valley (Archaeological Monograph of the British School at Rome 13). London: British School at Rome.

Patterson, H., H. Di Giuseppe and R. Witcher 2020. The Changing Landscapes of the Middle Tiber Valley: The British School at Rome's Tiber Valley Project. Oxford: Archaeopress.

Peacock, D.P.S. 1977. Ceramics in Roman and Medieval Archaeology, in D.P.S. Peacock (ed.) Pottery and Early Commerce. Characterization and Trade in Roman and Later Ceramics: 21-33. London: Academic Press.
Peeters, D. 2012. African Red Slip Ware. Indicator of Economic Activity and Distribution in Boeotia. Unpublished BA Dissertation, Leiden University.

Peeters, D., P. Bes and J. Poblome forthcoming. Making Use of Time and Space- Using African Red Slip Ware as an Indicator of Economic Activity in Mid- and Late Roman Thespiae and Tanagra. Island, Mainland, Coastland and Hinterland: Ceramic Perspectives on Connectivity in the Ancient Mediterranean, in Proceedings of the Conference Held at the University of Amsterdam. 1-3 February 2013, edited by J. Hilditch, A. Kotsonas, C. Beestman-Kruijshaar, M. Revello Lami, S. Rückl and S. Ximeri. Amsterdam: Amsterdam University Press.

Pelgrom, J. 2012. Colonial Landscapes. Demography, Settlement Organization and Impact of Colonies Founded by Rome (4th-2nd Centuries BC). Doctoral Dissertation. Leiden: Leiden University.

Pelgrom, J., M.-L. Marchi, G. Cantoro, A. Casarotto, A. Hamel, L. Lecce, J. García Sánchez and T.D. Stek 2014. New Approaches to the Study of Village Sites in the Territory of Venosa in the Classical and Hellenistic periods. Agri Centuriati 11: 31-58.

Pendlebury, J.D.S. 1939. The Archaeology of Crete. An Introduction. London: Methuen.

Pérez Alvarez, J.A., V. Mayoral Herrera, J.Á. Martínez del Pozo and M.T. de Tena 2013. Multi-Temporal Archaeological Analyses of Alluvial Landscapes Using the Photogrammetric Restitution of Historical Flights: a Case Study of Medellin (Badajoz, Spain). Journal of Archaeological Science 40: 349-364

Perkins, P. and L. Walker 1990. Survey of an Etruscan City at Doganella, in the Albegna Valley. Papers of the British School at Rome 58: 1-143.

Pettegrew, D.K. 2001. Chasing the Family Farmstead: Assessing the Formation and Signature of Rural Settlement in Greek Landscape Archaeology. Journal of Mediterranean Archaeology 14: 189-209.

Pettegrew, D.K. 2007. The Busy Countryside of Late Roman Corinth: Interpreting Ceramic Data Produced by Regional Archaeological Surveys. Hesperia 76: 743-784.

Pettegrew, D.K. 2010. Regional Survey and the Boomand-Bust Countryside. International Journal of Historical Archaeology 14: 215-229.

Philip, G., M. Abdulkarim, P. Newson, A. Beck, D.R. Bridgland, M. Bshesh, A. Shaw, R. Westaway and K. Wilkinson 2005. Settlement and Landscape Development in the Homs Region, Syria. Report on Work Undertaken during 2001-2003. Levant 37: 21-41.

Piccoli, C. 2012. The Recording of Greek Vernacular Architecture. Pharos. Journal of the Netherlands Institute at Athens 17: 50-55. 
Potter, T.W. 1979. The Changing Landscape of South Etruria. London: Elek.

Popovic, S., D. Bulic, et al. (in press). Roman land division in Istria, Croatia:historiography, ALS, structural survey and excavations.

Pournelle, J.R. 2007. From KLM to Corona: A Bird's Eye View of Cultural Ecology and Early Mesopotamian Urbanization, in E.C. Stone (ed.) Settlement and Society: Essays Dedicated to Robert McCormick Adams: 29-62. Los Angeles: Cotsen Institute of Archaeology.

Putzeys, T., T. Thuyne, J. Poblome, I. Uytterhoeven, M. Waelkens and R. Degeest 2004. Analyzing Domestic Contexts at Sagalassos: Developing a Methodology Using Ceramics and MacroBotanical Remains. Journal of Mediterranean Archaeology 17/1: 31-57.

Ratté, C. and P.D. De Staebler (eds) 2012. Aphrodisias V. The Aphrodisias Regional Survey. Mainz: von Zabern.

Redman, C.L. and P.J. Watson 1970. Systematic, Intensive Surface Collection. American Antiquity 35: 279-291.

Renfrew, C. and M. Wagstaff (eds) 1982. An Island Polity. The Archaeology of Exploitation in Melos. Cambridge: Cambridge University Press.

Reynolds, P. 1982. The Ploughzone, in N. Baum and J.P.Zeitler (eds) Festschriftzum 100jährigen Bestehen der Abteilung Vorgeschichte der Naturhistorischen Gesellschaft Nürnberg: 315-340. Nürnberg: Naturhistorischen Gesellschaft Nürnberg.

Rimmington, J.N. 2000. Soil Geochemistry and Artefact Scatters in Boeotia, Greece, in $\mathrm{M}$. Pasquinucci and F. Trement (eds) Non-Destructive Techniques Applied to Landscape Archaeology: 190199. Oxford: Oxbow Books.

Rosen, S.A. 1993a. The Edge of the Empire: The Archaeology of Pastoral Nomads in the Southern Negev Highlands in Late Antiquity. Biblical Archaeologist 56: 189-199.

Rosen, S.A. 1993b. A Roman Period Pastoral Tent Camp in the Negev, Israel. Journal of Field Archaeology 20: 441-451.

Rosen, S.A. 1994. Archaeological Survey of Israel Map of Makhtesh Ramon 204. Jerusalem: Israel Antiquities Authority.

Rosen, S.A. 1997. Lithics After the Stone Age. Walnut Creek, CA: Altamira Press.

Rosen, S.A. 2000. Dissecting the Site: Assays in Decoding Artifact Distribution in a Terminal Pleistocene Campsite in the Negev. Lithic Technology 25: 27-49.

Rosen, S.A. 2017. Basic Instabilities: Climate and Culture in the Negev over the Long Term. Geoarchaeology 32: 6-22.
Runnels, C. 2009. Mesolithic Sites and Surveys in Greece: A Case Study from the Southern Argolid. Journal of Mediterranean Archaeology 22: 57-73.

Runnels, C., E. Panagopoulou, P. Murray, G. Tsartsidou, S. Allen, K. Mullen and E. Tourloukis 2005. A Mesolithic Landscape in Greece: Testing a Site-Location Model in the Argolid at Kandia. Journal of Mediterranean Archaeology 18: 259-285.

Rutter, J.B. 1983. Some Thoughts on the Analysis of Ceramic Data Generated by Site Surveys, in D.R. Keller and D.W. Rupp (eds) Archaeological Survey in the Mediterranean Area (British Archaeological Reports International Series 155): 137-142. Oxford: BAR.

Sapir, Y. and A. Faust 2016. Utilizing Mole-Rat Activity for Archaeological Survey: a Case Study and a Proposal. Advances in Archaeological Practice 4/1: 55-70.

Sarris, A. (ed.) 2015. Best Practices of Geoinformatic Technologies for the Mapping of Archaeolandscapes. Oxford: Oxbow Books.

Schon, R. 2002. Seeding the Landscape: Experimental Contributions to Regional Survey Methodology. Doctoral Dissertation. Bryn Mawr: Bryn Mawr College.

Sevink, J., M. den Haan and P.M. van Leusen 2016. Soils and Soil Landscapes of the Raganello River Catchment (Calabria, Italy) (Raganello Basin Studies 2). Groningen: Barkhuis.

Sevink, J., W. de Neef, M. Di Vito, I. Arienzo, P.A.J. Attema, E.E. van Loon, B. Ullrich, M. den Haan, F. Ippolito and N.P. Noorda 2020. A Multidisciplinary Study of an Exceptional Prehistoric Waste Dump in the Mountainous Inland of Calabria (Italy): Implications for Reconstructions of Prehistoric Land Use and Vegetation in Southern Italy. The Holocene 30/9: 1310-1331.

Sigalos, E. 2004. Housing in Medieval and PostMedieval Greece (British Archaeological Series International Series 1291). Oxford: Archaeopress.

Snodgrass, A.M. 1980. Archaic Greece: The Age of Experiment. London: Dent.

Snodgrass, A.M. 1994. Response: the Archaeological Aspect, in I. Morris (ed.) Classical Greece: Ancient Histories and Modern Archaeologies: 197-200. Cambridge: Cambridge University Press.

Spivey, N. and S. Stoddart 1990. Etruscan Italy. London: Batsford.

Stek, T.D., J. Pelgrom, A. Casarotto, J. García Sánchez, L. Götz, A. Hamel, K. Iannantuono, R. Kalkers, M.K. Termeer and J. Waagen 2016. Santuari, Villaggi, Centri Fortificati e Prima Urbanizzazione tra Sanniti e Romani. ArcheoMolise 27: 26-39.

Stone, D.L., D.J. Mattingly and B. Lazreg (eds) 2011. Leptiminus (Lamta) Report No. 3. The Field Survey (Journal of Roman Archaeology Supplementary 
Series 87). Portsmouth: Journal of Roman Archaeology.

Strasser, T.F., C. Runnels, K. Wegmann, E. Panagopoulou, F. McCoy, C. Digregorio, P. Karkanas and N. Thompson 2011. Dating Palaeolithic Sites in Southwestern Crete, Greece. Journal of Quaternary Science 26: 553-560.

Tetford, P.E., J.R. Desloges and D. Nakassis 2018. The Potential Relationship Between Archaeological Artifact Exposure and Surface Geomorphic Processes: Northeastern Peloponnese, Greece. Journal of Field Archaeology 43: 538-550.

Thomas, D.H. 1975. Non-Site Sampling in Archaeology: up the Creek without a Site, in J.W. Mueller (ed.) Sampling in Archaeology: 61-81. Tucson: University of Arizona Press.

Tol, G.W. 2012. A Fragmented History: A Methodological and Artefactual Approach to the Study of Ancient Settlement in the Territories of Satricum and Antium. Doctoral Dissertation. Groningen: Barkhuis \& Groningen University Library.

Tol, G.W. 2017. From Surface Find to Consumption Trend: a Ceramic Perspective on the Economic History of the Pontine Region (Lazio, Central Italy) in the Roman Period, in T.C.A. de Haas and G.W. Tol (eds) The Economic Integration of Roman Italy. Rural Communities in a Globalizing World: 367387. Leiden: Brill.

Tol, G.W., T.C.A. de Haas, K.L. Armstrong and P.A.J. Attema 2014. Minor Centres in the Pontine Plain. The Cases of Forum Appii and Ad Medias. Papers of the British School in Rome 82: 109-134.

Tourloukis, E. 2011. The Early and Middle Pleistocene Archaeological Record of Greece (Archaeological Studies Leiden University 23). Leiden: Leiden University.

Ur, J.A. 2010. Urbanism and Cultural Landscapes in Northeastern Syria: The Tell Hamoukar Survey, 1999-2001 (Oriental Institute Publications 137). Chicago: The Oriental Institute of the University of Chicago.

Vaccaro, E. 2012. Re-Evaluating a Forgotten Town Using Intra-Site Surveys and the GIS Analysis of Surface Ceramics: Philosophiana-Sofiana (Sicily) in the Longue Durée, in P. Johnson and M. Millett (eds) Archaeological Survey and the City: 107-145. Oxford: Oxbow Books.

Vaccaro, E., M. Ghisleni, A. Arnoldus-Huyzendveld, C. Grey, K. Bowes, M. MacKinnon, A.M. Mercuri, A. Pecci, M.Á.C. Ontiveros, E. Rattigheri and R. Rinaldi 2013. Excavating the Roman Peasant II: Excavations at Case Nuove, Cinigiano (GR). Papers of the British School at Rome 81:129-179.

Vandam, R., E. Kaptijn, P.T. Willett and J. Poblome forthcoming. Highlands and
Lowlands: Different Landscapes, Different Archaeologies? A Diachronic Case-Study from the Taurus Mountains (SW Turkey), in A. Garcia (ed.) Archaeology of Mountain Landscapes. Interdisciplinary Research Strategies of AgroPastoralism in Upland Regions (The Institute for European and Mediterranean Archaeology Distinguished Monograph Series 10). Albany (NY): SUNY Press.

Vandam, R. 2019. Introduction: On the Margins? Thinking through 'Marginal' Landscapes in the Holocene Mediterranean. Journal of Eastern Mediterranean Archaeology \& Heritage Studies 7/4: 407-411.

Vandam, R., E. Kaptijn, et al. 2019. "Marginal" Landscapes: Human Activity, Vulnerability, and Resilience in the Western Taurus Mountains (Southwest Turkey). Journal of Eastern Mediterranean Archaeology and Heritage Studies 7: 432-450.

Van de Velde, P. 2001. An Extensive Alternative to Intensive Survey: Point Sampling in the Riu Mannu Survey Project, Sardinia. Journal of Mediterranean Archaeology 14: 24-52.

Van Gorp, W., J. Sevink and P.M. van Leusen 2020. Post-Depositional Subsidence of the Avellino Tephra Marker Bed in the Pontine Plain (Lazio, Italy): Implications for Early Bronze Age Palaeogeographical, Water Level and Relative Sea Level Reconstruction. Catena 194: doi. org/10.1016/j.catena.2020.104770.

Van Joolen, E. 2003. Archaeological Land Evaluation: A Reconstruction of the Suitability of Ancient Landscapes for Various Land Uses in Italy Focused on the First Millennium BC Groningen. Doctoral Dissertation. Groningen: University of Groningen.

Van Leusen, P.M. 2002. Pattern to Process: Methodological Investigations into the Formation and Interpretation of Spatial Patterns in Archaeological Landscapes. Doctoral Dissertation. Groningen: University of Groningen.

Van Leusen, P.M. 2010. Archaeological Sites Recorded by the GIA Hidden Landscapes Survey Campaigns in the Monti Lepini (Lazio, Italy), 2005-2009 (with contributions by G.W. Tol and C. Anastasia. Palaeohistoria 51/52: 329-424.

Van Leusen, P.M. and H.Feiken 2007.Geo-Archeologie en Landschapsclassificatie in Midden- en ZuidItalië. Tijdschrift voor Mediterrane Archeologie 37: 6-16.

Van Leusen, P.M. and W. de Neef 2018. On the Trail of Pre- and Protohistoric Activities around San Lorenzo Bellizzi. Geo-Archaeological Studies of the University of Groningen, 2010-2015, in: 
C. Colelli and A. Larocca (eds) Il Pollino. Barriera Naturale e Crocevia di Culture. Giornate Internazionali di Archeologia, San Lorenzo Bellizzi, 16-17 Aprile 2016: 39-48. Università della Calabria.

Van Leusen, P.M., W. de Neef and J. Sevink forthcoming. Developing a Systematic approach to the Archaeological Study of Mountain Landscapes: the Raganello Basin Experience, in A. Garcia (ed.) Archaeology of Mountain Landscapes. Interdisciplinary Research Strategies of Agro-Pastoralism in Upland Regions (The Institute for European and Mediterranean Archaeology Distinguished Monograph Series 10). Albany (NY): SUNY Press.

Van Leusen, P.M., G. Pizziolo and L. Sarti (eds) 2011. Hidden Landscapes of Mediterranean Europe (British Archaeological Reports International Series 2320). Oxford: Archaeopress.

Van Leusen, P.M. and N. Ryan 2002. Educating the Digital Fieldwork Assistant, in G. Burenhult (ed.), Archaeological Informatics: Pushing the Envelope. CAA 2001: Computer Applications and Quantitative Methods in Archaeology, Proceedings of the 29th Conference (British Archaeological Reports International Series 1016): 401-412. Oxford: Archaeopress.

Van Leusen, P.M., G.W. Tol and C. Anastasia 2010. Archaeological Sites Recorded by the GIA Hidden Landscapes Survey Campaigns in the Monti Lepini (Lazio, Italy). Palaeohistoria 51/52: 329-424.

Vermeulen, F. 2013. Roman Urban Survey: the Mapping and Monitoring of Complex Settlement Sites with Active Aerial Photography, in C. Corsi, B. Slapšak and F. Vermeulen (eds) Good Practice in Archaeological Diagnostics. Non-Invasive Survey of Complex Archaeological Sites: 69-85. Cham: Springer International Publishing Switzerland.

Vermeulen, F. 2016a. Towards a Holistic Archaeological Survey Approach for Ancient Cityscapes, in M. Forte and S. Campana (eds) Digital Methods and Remote Sensing in Archaeology. Archaeology in the Age of Sensing: 91-112. New York: Springer.

Vermeulen, F. 2016b. Aerial Survey in an Italian Landscape: from Archaeological Site-Detection and Monitoring to Prevention and Management, in F. Boschi (ed.) Looking to the Future, Caring for the Past. Preventive Archaeology in Theory and Practice: 135-146. Bologna: Bononia University Press.

Vermeulen, F., G.L.M. Burgers, S. Keay and C. Corsi (eds) 2012. Urban Landscape Survey in Italy and the Mediterranean. Oxford: Oxbow Books.

Vermeulen, F., D. Van Limbergen, P. Monsieur and D. Taelman 2017. The Potenza Valley Survey (Marche, Italy): Settlement Dynamics and Changing Material
Culture in an Adriatic Valley between Iron Age and Late Antiquity (Studia Archaeologica 1). Rome: Editorial Service System.

Vionis, A.K. 2006. The Archaeology of Ottoman Villages in Central Greece: Ceramics, Housing and Everyday Life in Post-Medieval Rural Boeotia, in A. Erkanal-Öktu, E. Özgen, S. Günel, A.T. Ökse and T. Hall (eds) Studies in Honour of Hayat Erkanal: Cultural Reflections: 784-800. Istanbul: Homer Kitabevi.

Vionis, A.K. 2016. A Boom-Bust Cycle in Ottoman Greece and the Ceramic Legacy of Two Boeotian Villages. Journal of Greek Archaeology 1: 353-383.

Vionis, A.K. 2017a. Settled and Sacred Landscapes of Cyprus: Church and Landscape in the Xeros Valley during the Early Byzantine Period, in M. Horster, D. Nicolaou and S. Rogge (eds) Church Building in Cyprus (Fourth to Seventh Centuries): a Mirror of Intercultural Contacts in the Eastern Mediterranean: 45-69. Münster: Waxmann.

Vionis, A.K. 2017b. Understanding Settlements in Byzantine Greece: New Data and Approaches for Boeotia, Sixth to Thirteenth Centuries. Dumbarton Oaks Papers 71: 127-173.

Vionis, A.K. 2017c. The Byzantine to Early Modern pottery from Thespiai, in J.L. Bintliff and A.M. Snodgrass (eds) Approaching the Ancient City: Urban Survey at Ancient Thespiai, Boeotia, Greece: 351-374. Cambridge: McDonald Institute Monographs.

Vionis, A.K., J. Poblome and M. Waelkens 2009. The Hidden Material Culture of the Dark Ages. Early Medieval Ceramics at Sagalassos (Turkey): New Evidence (ca AD 650-800). Anatolian Studies 59: 147-165.

Vita-Finzi, C. 1969. The Mediterranean Valleys: Geological Changes in Historical Times. Cambridge: Cambridge University Press.

Vroom, J. 1998. Early Modern Archaeology in Central Greece: the Contrasts of Artefact-rich and Sherdless sites. Journal of Mediterranean Archaeology 11: 131-164.

Vroom, J.C. 1999. Medieval and Post-Medieval Pottery From a Site in Boeotia: A Case Study Example of Post-Classical Archaeology in Greece. Annual of the British School at Athens 92: 513-546.

Waagen, J. 2014. Evaluating Background Noise: Assessing Off-Site Data from Field Surveys Around the Italic Sanctuary of S. Giovanni in Galdo, Molise, Italy. Journal of Field Archaeology 39/4: 417-429.

Walsh, K., P.A.J. Attema and T.C.A. de Haas 2014. The Pontine Marshes (Central Italy): a Case Study in Wetland Historical Ecology. Babesch 89: 27-46. 
Ward Perkins, J.B. 1961. Veii. The Historical Topography of the Ancient City. Papers of the British School at Rome 29: 1-123.

Whitelaw, T., M. Bredaki and A. Vasilakis 20062007. The Knossos Urban Landscape Project. Archaeology International 10: 28-31.

Wilkinson, T.J. 1989. Extensive Sherd Scatters and Land-Use Intensity: Some Recent Results. Journal of Field Archaeology 16: 31-46.

Wilkinson, T.J. 2003. Archaeological Landscapes of the Near East. Tucson: University of Arizona Press.

Wilkinson, T.J. 2004. The Disjunction between Mediterranean and Near Eastern Survey: is it Real?, in E.F. Athanassopoulos and W.L.A. Philadelphia (eds) Mediterranean Archaeological Landscapes: Current Issues: 55-67. Philadelphia: University of Pennsylvania Press.

Wilkinson, T.J., G. Philip, J. Bradbury, R. Dunford, D. Donoghue, N. Galiatsatos, D. Lawrence, A. Ricci \& S.L. Smith 2014. Contextualizing Early Urbanization: Settlement Cores, Early States and Agro-pastoral Strategies in the Fertile Crescent During the Fourth and Third Millennia BC. Journal of World Prehistory 27: 43-109.

Winther-Jacobsen, K. 2010. From Pots to People: a Ceramic Approach to the Archaeological Interpretation of Ploughsoil Assemblages in Late Roman Cyprus (Babesch Supplement 17). Leuven: Peeters.

Witcher, R.E. 2006. Broken Pots and Meaningless Dots? Surveying the Rural Landscapes of Roman Italy. Papers of the British School at Rome 74: 39-72. Yekutieli, Y. 2007. Bet al.-Malahi, in B. Saidel and E. Van der Steen (eds) On the Fringe of Society: Archaeological and Ethnoarchaeological Perspectives on Pastoral and Agricultural Societies: 127-138. Oxford: Archaeopress.

Yener, K.A., C. Edens, T.P. Harrison, J. Verstraete and T.J. Wilkinson 2000. The Amuq Valley Regional Project, 1995-1998. American Journal of Archaeology 104: 163-220. 